2009

\title{
Cryptic subtelomeric rearrangements and studies of telomere length
}

Jasen Lee Wise

West Virginia University

Follow this and additional works at: https://researchrepository.wvu.edu/etd

\section{Recommended Citation}

Wise, Jasen Lee, "Cryptic subtelomeric rearrangements and studies of telomere length" (2009). Graduate Theses, Dissertations, and Problem Reports. 2898.

https://researchrepository.wvu.edu/etd/2898 
Cryptic Subtelomeric Rearrangements and Studies of Telomere Length

Jasen Lee Wise

Dissertation submitted to the

Davis College of Agriculture, Natural Resources and Design

at West Virginia University

in partial fulfillment of the requirements

for the degree of

Doctor of Philosophy

In

Genetics and Developmental Biology

Sharon Wenger, Ph.D.

Jed Doelling, Ph.D.

Laura Gibson, Ph.D.

Joginder Nath, Ph.D.

Linda Sargent, Ph.D.

Department of Genetics and Developmental Biology

Morgantown, West Virginia

2009

Keywords: fluorescent in situ hybridization, subtelomere, cryptic rearrangements, chromosomes, cytogenetics, telomere length, chromosome arm size.

Copyright 2009

Jasen Lee Wise 


\title{
ABSTRACT
}

\section{CRYPTIC SUBTELOMERIC REARRANGEMENTS AND STUDIES OF TELOMERE LENGTH}

\author{
Jasen Lee Wise
}

Study One: An estimated five percent of individuals with unexplained mental retardation (MR) have chromosomally unbalanced subtelomere regions. Around half of these individuals inherited the imbalance from a parent with a balanced rearrangement. The frequency of carriers for cryptic balanced translocations is unknown. To determine this frequency, blood samples received from 565 out of 978 phenotypically normal, unrelated individuals were examined using fluorescent in situ hybridization (FISH) probes to analyze all subtelomere regions. No balanced subtelomeric rearrangements were identified. The frequency of balanced cryptic translocations in the general population was estimated to be $1 / 8,000$ from the literature. However, three females out of $379(0.8 \%)$ in this study were determined to be mosaic with regard to the $\mathrm{X}$ chromosome. This is a higher frequency than the 1 in $1000(0.1 \%)$ reported incidence for sex chromosome aneuploidies. Study Two: From a clinically abnormal population, 256 patients with unexplained MR and normal karyotypes were tested for subtelomere rearrangements using FISH probes. Nine were abnormal (3.5\%), in which five were deletions and four were deletion/duplications. Two polymorphisms $(0.7 \%)$ were observed. Parents for five of the abnormal cases were evaluated and all but one was inherited from a parent with a balanced subtelomeric translocation or the same deletion with a similar abnormal phenotype. Study Three: Most human telomere length studies have focused on the overall length of telomeres within a cell. Very few studies have examined telomere length for individual chromosome arms. The relationship between chromosome arm size and the relative length of the associated telomere was studied in cultured lymphocytes from 17 individuals using quantitative FISH (Q-FISH). A statistically significant positive correlation $(\mathrm{p}<0.0001)$ was found between telomere length and the size of the associated chromosome arm. 


\section{DEDICATION}

For Virginia, Lillian, Evelyn, and the late Charles Pascavage Jr. 


\section{ACKNOWLEDGEMENTS}

I would like to make special acknowledgment of the unlimited patience and guidance that Dr. Wenger has provided me for the past seven years. My family has been a tremendous support my whole life and encouraged me. A very special thank you goes to my wife, who sometimes notso-patiently supported me while blessing me with our children. To my committee members, Dr.

Jed Doelling, Dr. Laura Gibson, Dr. Joginder Nath, and Dr. Linda Sargent: much appreciation is due for your consideration and guidance. 


\section{TABLE OF CONTENTS}

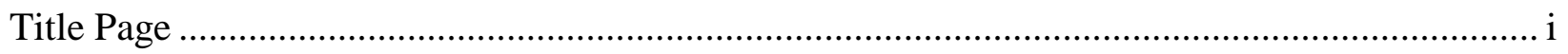

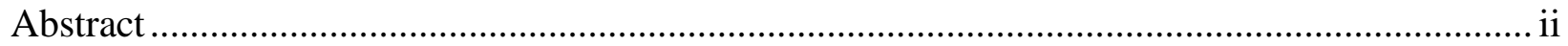

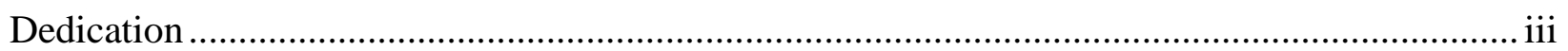

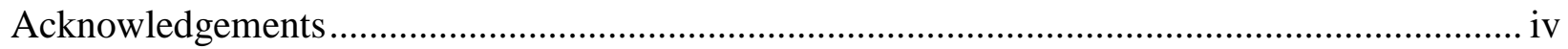

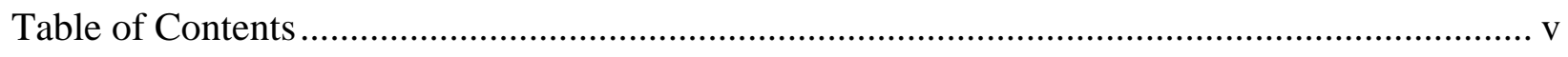

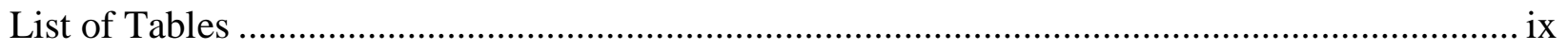

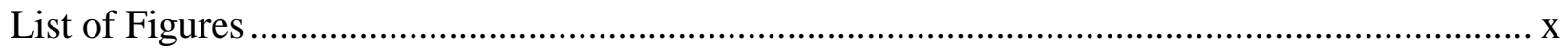

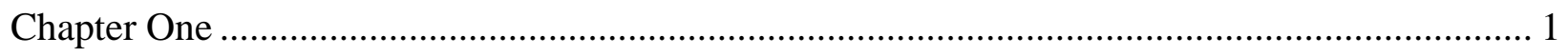

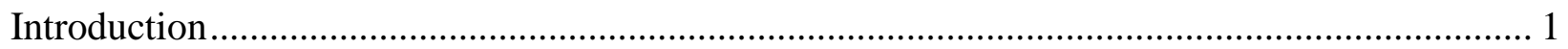

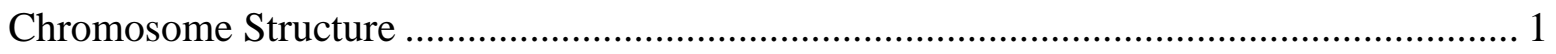

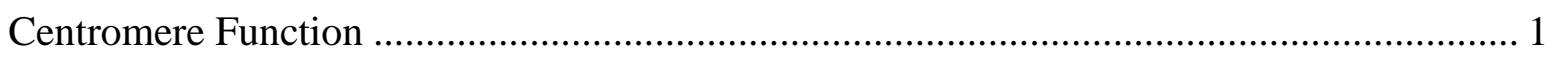

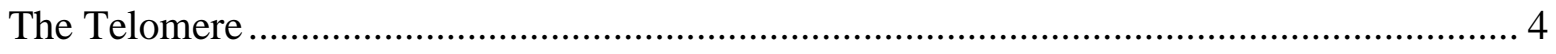

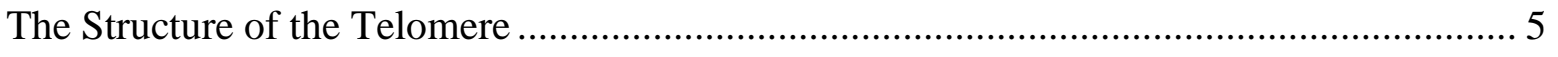

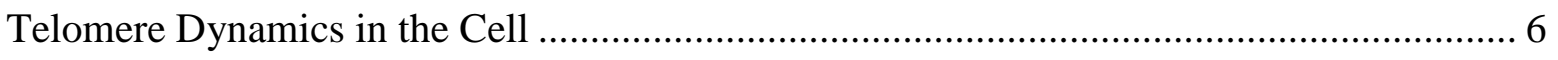

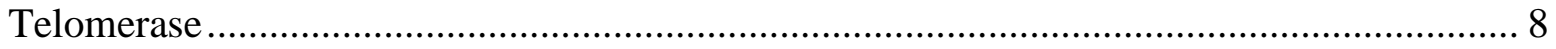

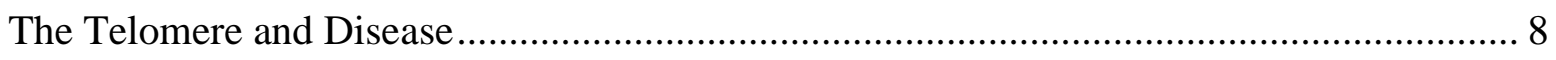

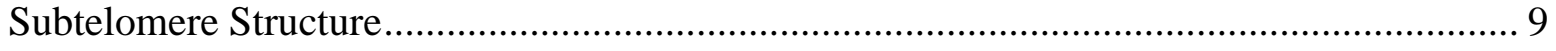

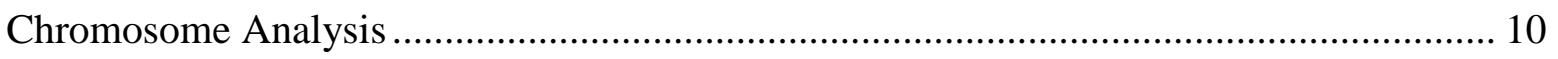

Numerical Chromosome Abnormalities .............................................................. 14

Structural Chromosome Abnormalities ............................................................... 15

Fluorescent In Situ Hybridization (FISH) ........................................................... 16 
Chapter Two.

Balanced Cryptic Subtelomeric Rearrangements and X Chromosome Mosaicism: A Study of 565 Apparently Normal Individuals With Fluorescent In Situ Hybridization ..................................... 20

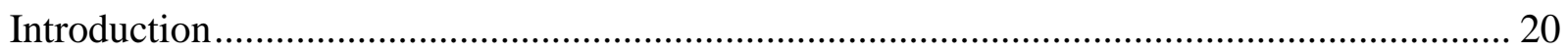

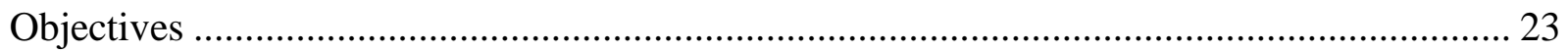

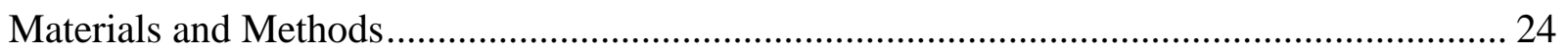

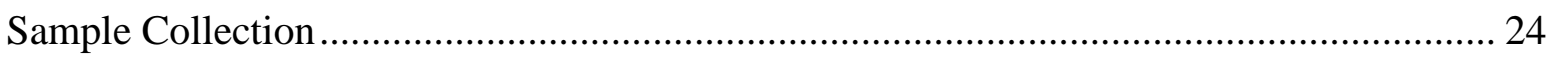

Blood Lymphocyte Culture and Harvest ....................................................................... 24

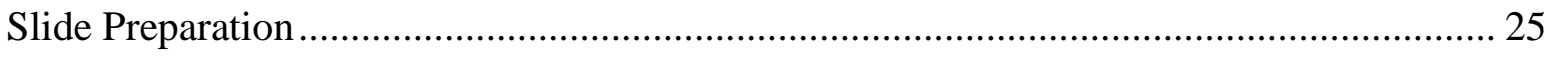

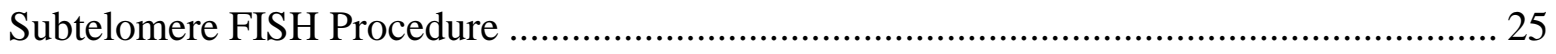

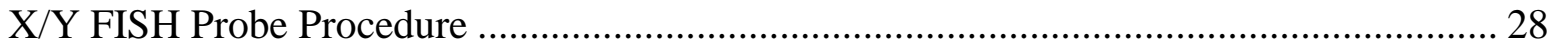

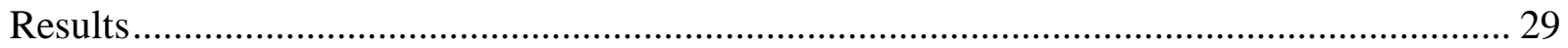

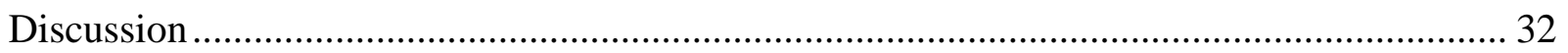

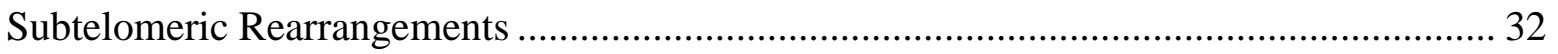

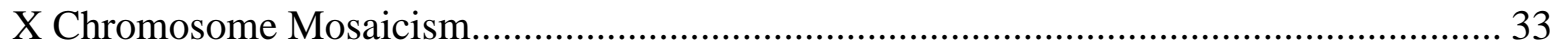

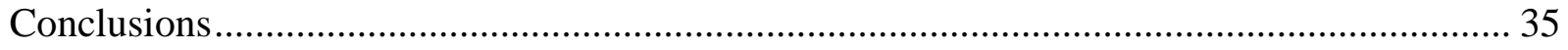

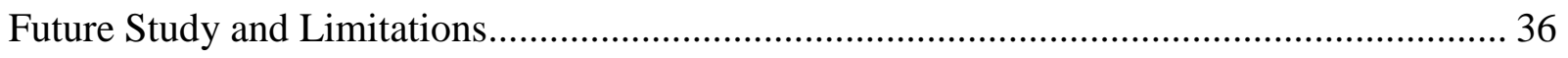

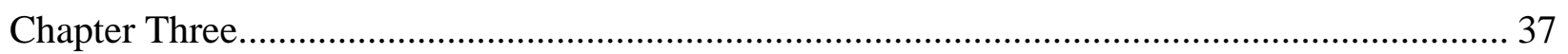

Subtelomeric Deletions: the Importance of Ruling Out Polymorphic Variants or Inherited

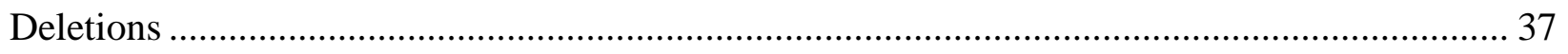

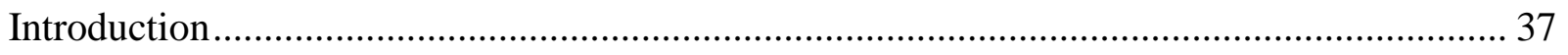




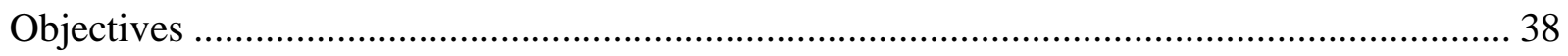

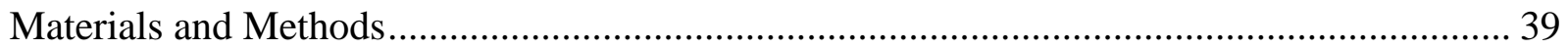

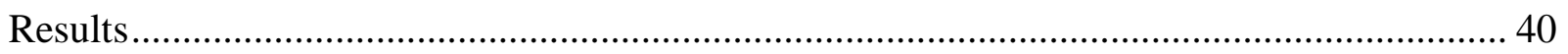

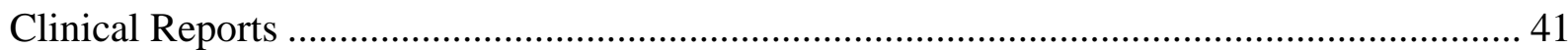

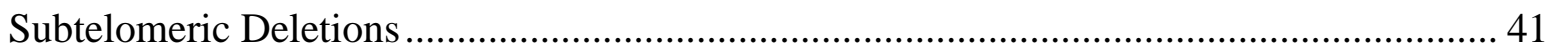

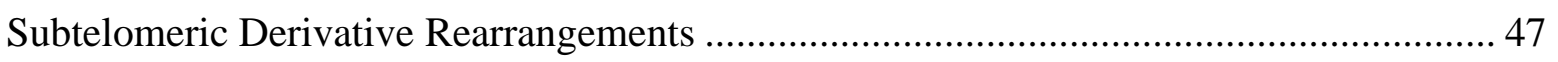

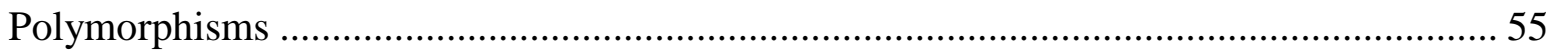

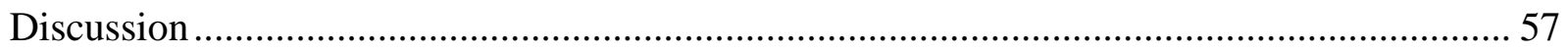

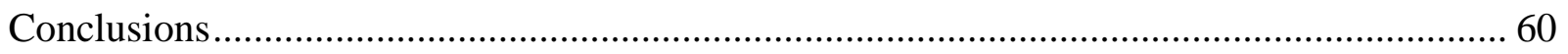

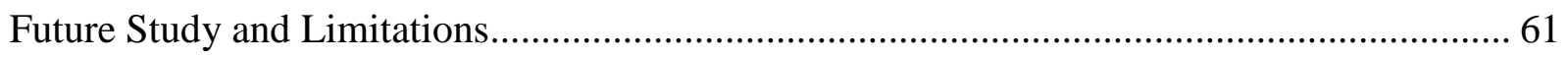

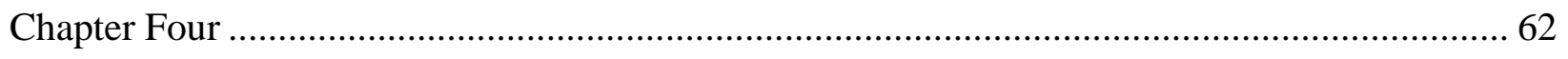

Telomere Length Studies of Individual Human Chromosome Arms .......................................... 62

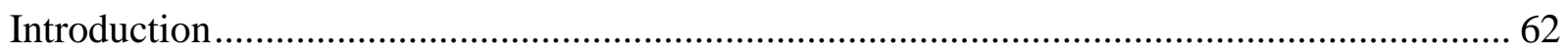

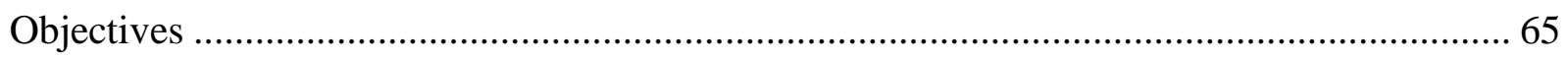

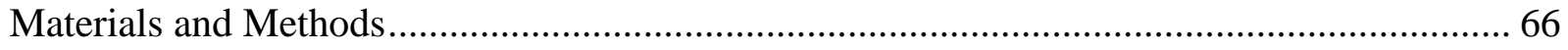

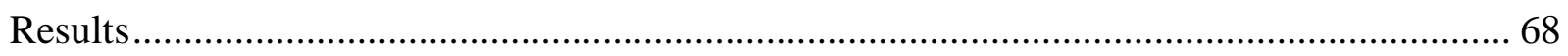

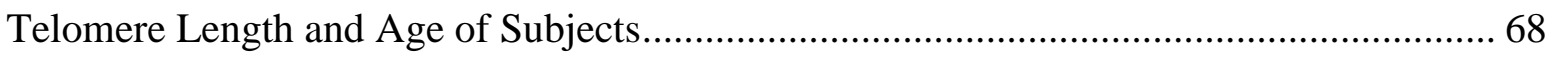

Telomere Length and Chromosome Arm Size ………....................................................... 69

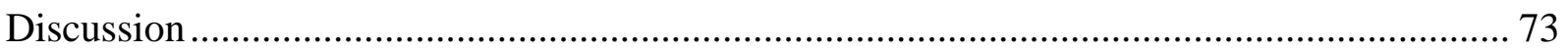

Correcting for Chromosome Variability ……………....................................................... 73

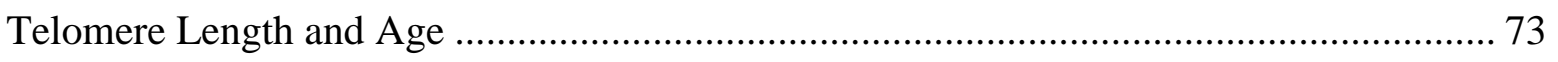




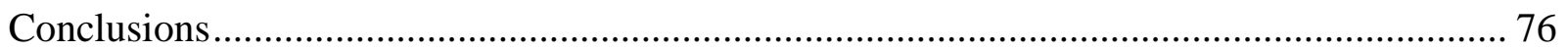

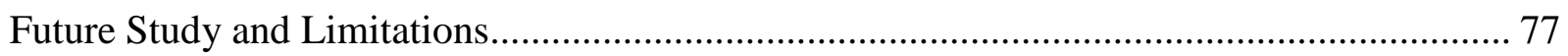

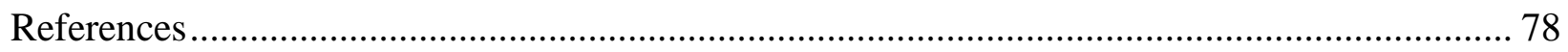

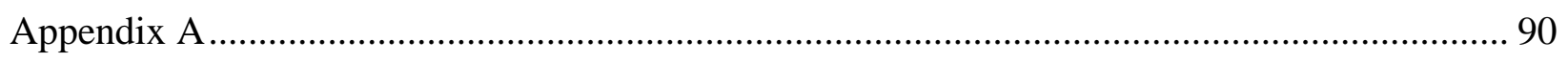

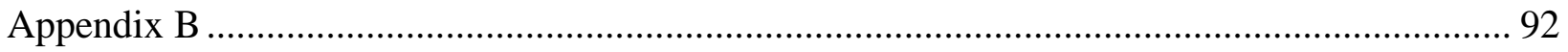

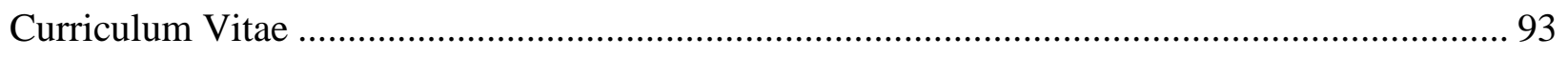

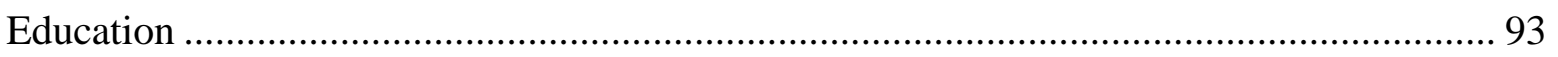

Peer Reviewed Publications............................................................................................ 93

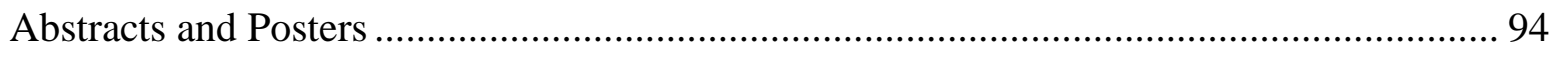




\section{LIST OF TABLES}

Table 1. Examples of ISCN cytogenetic nomenclature ................................................. 14

Table 2. Examples of ISCN FISH nomenclature ................................................................. 18

Table 3. Probe sets included in the ToTelVysion probe panel. ............................................ 26

Table 4. X Chromosome mosaicism in three individuals listed by age ................................. 30

Table 5. Subtelomere rearrangements identified among 256 patients .................................... 40

Table 6. Average telomere length from each individual in the study and associated p values. .. 70

Table 7. Chromosome arm size and telomere length values ............................................. 71

Table 8. Locus and clone ID for each FISH probe used in the ToTelVysion kit. ..................... 92 


\section{LIST OF FIGURES}

Figure 1. Organizational levels of the chromosome ........................................................ 3

Figure 2. Basic structure of a chromosome …............................................................... 4

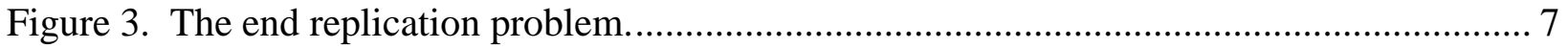

Figure 4. A normal G-banded karyotype at 550 band length. ........................................... 12

Figure 5. Chromosome 16 banding ideogram................................................................... 13

Figure 6. Fluorescent In Situ Hybridization (FISH) . ....................................................... 17

Figure 7. FISH probe for the centromere of the $\mathrm{X}$ chromosome …..................................... 31

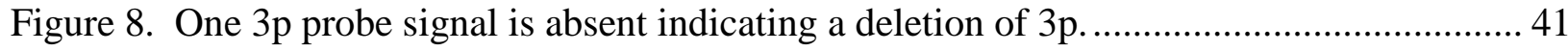

Figure 9. One $4 \mathrm{q}$ probe signal (red) is absent indicating a deletion of $4 \mathrm{q}$............................. 42

Figure 10. One 5p probe signal (green) is absent indicating a deletion of 5p....................... 44

Figure 11. One 5q probe signal (red) is absent indicating a deletion of 5q. ............................ 45

Figure 12. One $15 \mathrm{q}$ probe signal (red) is diminished indicating a deletion of $15 \mathrm{q} 22 \ldots \ldots \ldots \ldots \ldots . . . . . .46$

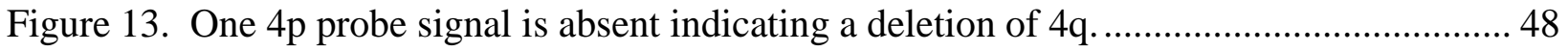

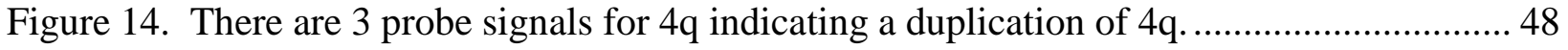

Figure 15. One 9p probe signal is absent indicating a deletion of 9 p.................................. 50

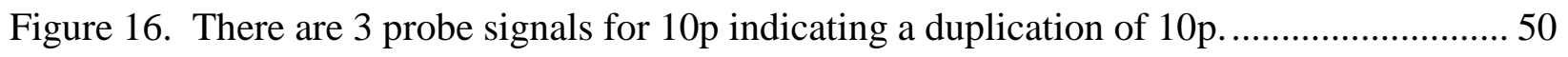

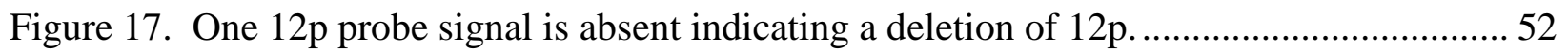

Figure 18. There are 3 probe signals for chromosome $7 q$ indicating a duplication of $7 q$.......... 52

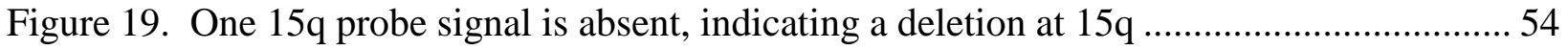

Figure 20. There are 3 probe signals for chromosome 18q indicating duplication of $18 \mathrm{q}$......... 54

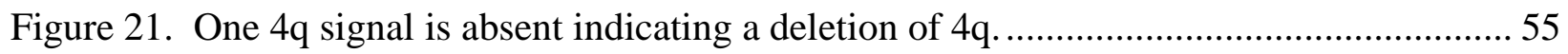

Figure 22. There are three $16 \mathrm{q}$ signals (red) indicating a duplication of $16 \mathrm{q}$.........................5 56

Figure 23. Grayscale image of telomere probes hybridized to a metaphase spread ................. 63

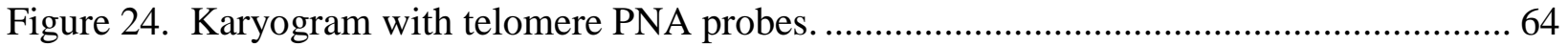

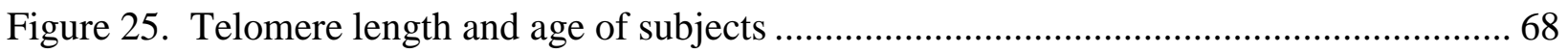




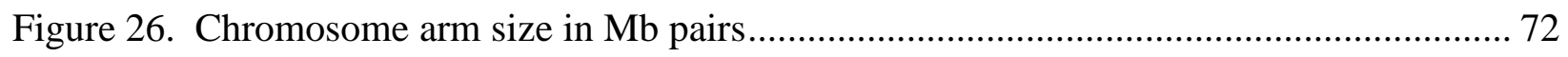




\section{CHAPTER ONE}

\section{INTRODUCTION}

\section{CHROMOSOME STRUCTURE}

"Chromosome" is the title given to the organizational structures of DNA and associated proteins during metaphase when DNA is at the highest level of compaction. The human genome is organized into 22 pairs of autosomes and 1 pair of sex chromosomes (X and Y), totaling 46 chromosomes. Chromosomes are visible during metaphase after DNA replication has occurred and before sister chromatids separate during anaphase.

To form the chromosome structure, double stranded DNA is wrapped around a core of 8 histone proteins, making up the nucleosome, referred to as "beads on a string." The nucleosome then forms the $30 \mathrm{~nm}$ fiber "solenoid" which is the configuration of chromatin in interphase. During mitosis, solenoids coil on themselves multiple times to form supercoils, which attach to scaffold proteins. This is the chromosome that is seen during metaphase, the period in which DNA has the highest level of compaction (Fig. 1). A chromosome is composed of three distinct structural regions; the centromere, the telomere, and the subtelomere (Fig. 2).

\section{CENTROMERE FUNCTION}

Each chromosome has a constriction point called the centromere, which holds sister chromatids together after DNA synthesis and gives the chromosome its characteristic shape. The 
centromere also divides the chromosome into two sections, or "arms." The short arm of the chromosome is labeled the "p arm." The long arm of the chromosome is labeled the "q arm."

The centromere is also where kinetochore formation takes place: proteins bind on the centromeres that form an anchor point for the spindle fibers, which are required for pulling chromosomes toward the centrioles during anaphase of mitosis. Improperly functioning centromeres result in chromosomes that do not align, attach and/or separate chromatids properly, resulting in daughter cells receiving the wrong number of chromosomes, or aneuploidy. 


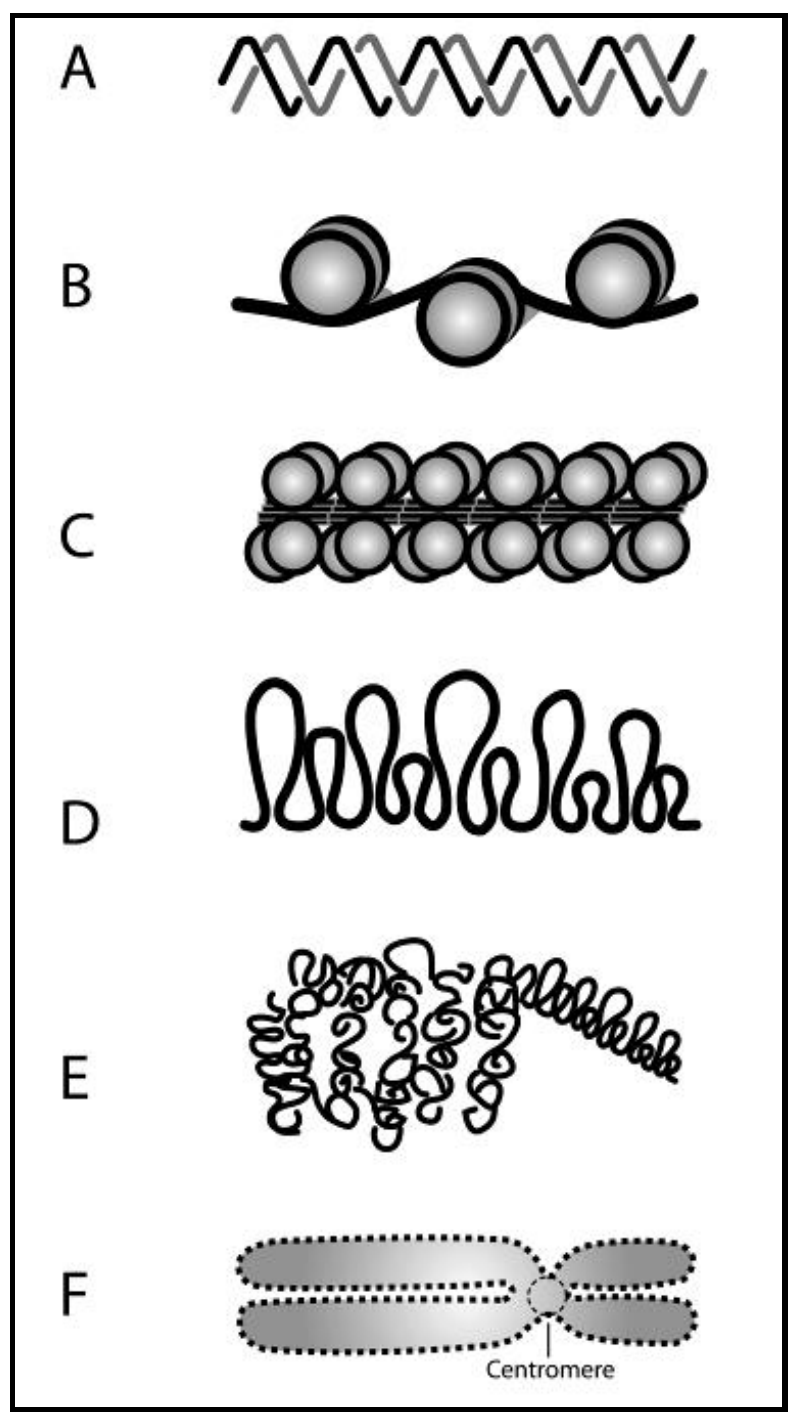

Figure 1. Organizational levels of the chromosome (A) Double stranded DNA (B) DNA organized around histone proteins making the "beads on a string" or nucleosome structure. (C) $30 \mathrm{~nm}$ fiber solenoid (D) supercoiling, (E) supercoiling around protein scaffold (F) macro chromosome structure (Figures courtesy of Deb Lanzendorfer). 


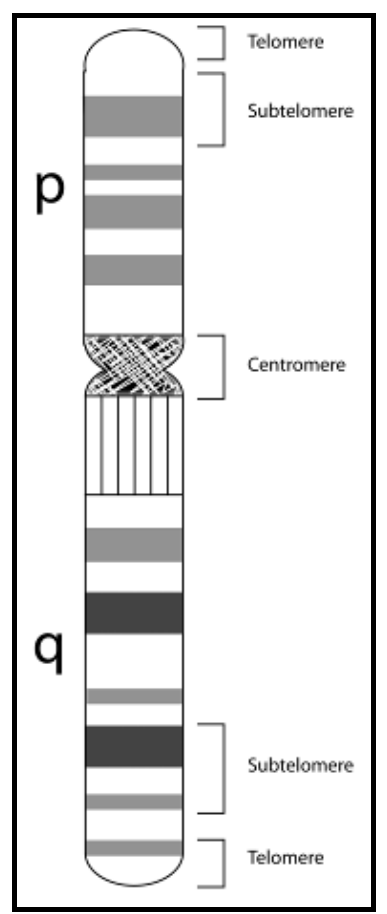

Figure 2. Basic structure of a chromosome (not to scale) showing the p (short) and q (long) arms of the chromosome, the centromere, subtelomere and telomere regions (Figure courtesy of Deb Lanzendorfer based on ISCN 2009).

\section{THE TELOMERE}

The telomere was discovered in 1938 by Muller. After x-irradiating Drosophila chromosomes, he observed interstitial deletions and inversions, but did not see a rearrangement involving the terminal ends of the chromosomes. From these observations he proposed that the terminal ends of chromosomes were structurally different from interstitial regions and coined the term "telomere" from the Greek for "end" (telos) and "part" (meros) (Muller, 1938).

In the 1940's McClintock proposed that the telomere was a protective structure that prevented telomeric fusion. In her studies with maize, she demonstrated that chromosomes without a telomere region formed dicentric chromosomes that resulted in loss, rearrangement, and other aberrations during subsequent cell division (McClintock, 1938, 1939, 1941). Telomeres "cap" the ends of chromosomes and prevent fusion with other chromosomes (De Lange, 2002; Saldanha et al., 2003). Chromosomes that are unprotected at their ends are 
analogous to DNA with broken strands. Without the telomere to protect the end of the chromosome, the chromosome would be prone to aberrations such as translocations and ring formations (Bailey et al., 1999; McEachern et al., 2000; Von Zglinicki et al., 2000). Thus, telomeres play a significant role in stabilizing the genome (Blackburn, 1991; Saldanha et al., 2003; Graakjaer et al., 2004).

\section{THE STRUCTURE OF THE TELOMERE}

Human telomeres are dynamic nucleoprotein structures located at the terminal ends of chromosomes. They are composed of a noncoding, repetitive, G-rich hexanucleotide (TTAGGG) structure measuring 10-15 kilobases in length (Blackburn, 1984). At the very distal end of the telomere is a $300 \mathrm{bp}$ single-stranded segment which forms the T-loop. This loop is analogous to a 'knot' which stabilizes the telomere, preventing the chromosome from being recognized as breakpoints by the DNA repair machinery. Without the T-loop, chromosomal fusion would occur through joining of non-homologous ends. The T-loop is held together by seven known proteins collectively referred to as the shelterin complex (de Lange, 2005).

Three shelterin subunits, TRF1, TRF2, and POT1 directly recognize TTAGGG repeats, which are interconnected by three additional shelterin proteins, TIN2, TPP1, and Rap1. Together they form a complex that allows cells to distinguish telomeres from sites of DNA damage. Without shelterin, telomeres are no longer hidden from the DNA damage surveillance and chromosome ends are inappropriately processed by DNA repair pathways (de Lange, 2005) leading to premature erosion of the telomere. There are several accessory proteins that associate with the shelterin complex, all of which are involved in protecting the telomere from being recognized as double strand breaks (Bailey and Goodwin, 2004; Szilard and Durocher, 2006; Van Overbeek and de Lange, 2006). 
Lansdorp et al., (1996) had examined the telomere length of human chromosomes in cells from different tissues and found that sister chromatid telomere lengths were similar; however, the distribution of telomere lengths between chromosomes was not random. Martens et al., (1998) found that there was a significant difference between the telomere length of individual chromosome arms, with a weak positive correlation between the length of chromosome arms and the corresponding telomeres. Graakjaer et al., (2003; 2006a; 2006b) had found that human telomere length correlated well with total length of the chromosome but did not have as strong a correlation with individual chromosome arm size.

\section{TELOMERE DYNAMICS IN THE CELL}

During each round of DNA replication, the telomere erodes due to two primary mechanisms. The first is a process known as the "end replication problem," which was first proposed independently by James Watson and Alexei Olovnikov in the early 1970s (Olovnikov, 1971; 1973; Watson, 1972). This problem is the result of the inability of DNA polymerase to begin DNA synthesis de novo and the 5' to 3' directionality of DNA synthesis. Therefore DNA synthesis cannot be completed on the lagging strand of DNA (Wang, 1991) (Fig. 3). The second

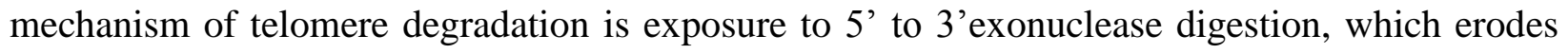
DNA to produce 3' overhangs. 


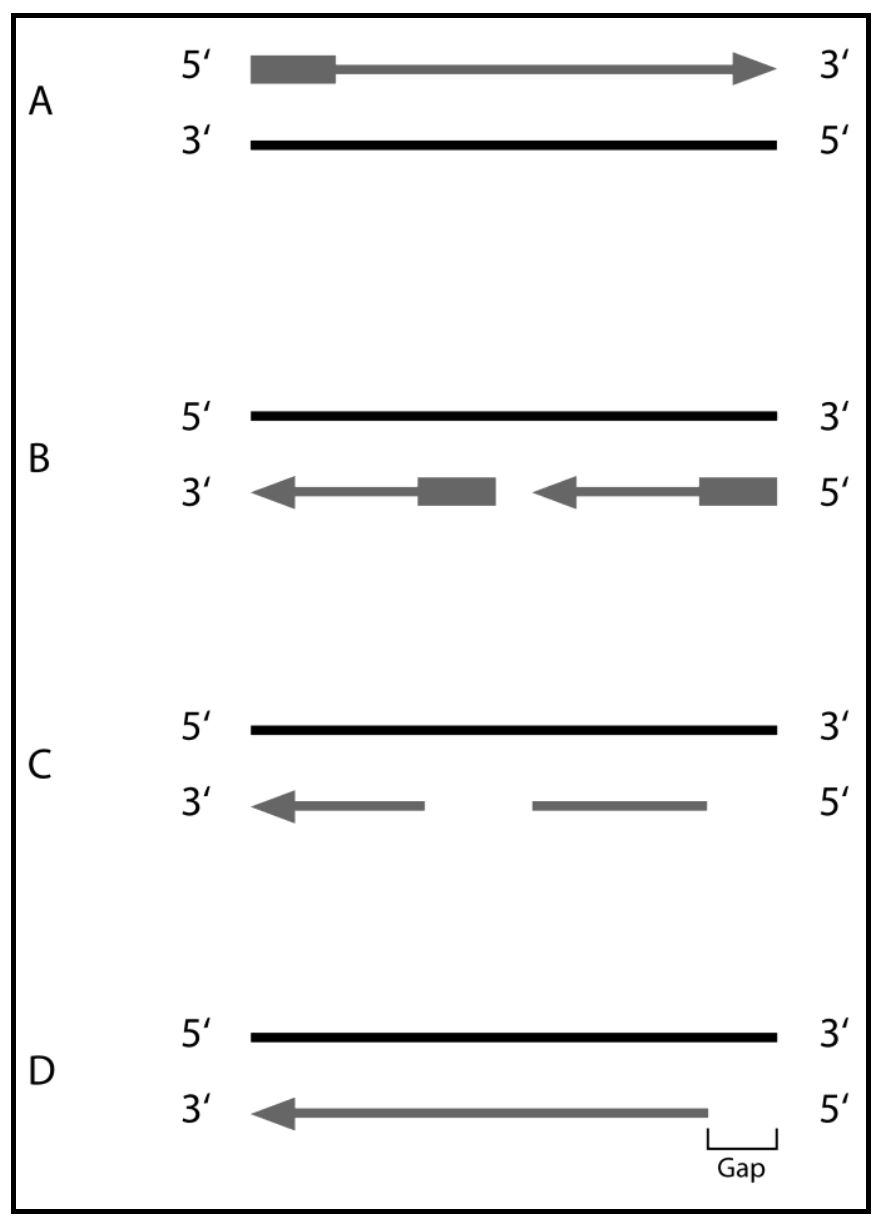

Figure 3. The end replication problem. (A) DNA synthesis can occur without interruption in the 5' to 3' direction. B) DNA replication can only occur in the 5' to 3' direction so lagging strand replication leaves gaps shown in (C). (D) The gaps are filled, but a small section at the end is not filled due to the lack of a 3' OH group for DNA polymerase to bind. Thus the telomere shortens after each round of DNA replication (Figure courtesy of Deb Lanzendorfer).

A cell normally divides a finite number of times (50 to 70$)$ before an end point is reached and the cell undergoes senescence, followed by programmed cell death: this is referred to as the Hayflick limit (Hayflick and Moorhead, 1961). The first connection between telomere length and ageing was made by Cooke and Smith (1986). They noticed that the telomere repeat number in sex chromosomes from sperm were much longer than in adult cells. They proposed that human gametes and stem cells circumvent telomere loss through telomerase activity.

The erosion of telomeres may act as a "clock" to measure the number of cell divisions that have taken place (Harley et al., 1990; Allsopp et al., 1992; Kim et al., 1994). In 2001, 
Hemann and colleagues reported that the shortest telomere, not the average telomere length, determines cell viability and chromosome stability (Hemann et al., 2001). This may indicate that the shortest telomere on any chromosome arm in the cell may trigger cell senescence.

In 1994, Slagboom et al. measured the size of terminal restriction fragments in genomic DNA from 123 monozygotic and dizygotic twins aged 2-95 years. They found the average rate of telomere erosion was 31 base pairs (bp) per year. Frenck et al., (1998) reported that the rate of telomere loss over time is the greatest during early childhood $(1,000-3,000 \mathrm{bp} / \mathrm{yr})$. The rate of telomere erosion then slows (30-60 bp/yr) as age increases. Rufer et al., (1999) confirmed these findings by demonstrating that telomere length decreases in lymphocytes as a function of age.

\section{TELOMERASE}

Telomerase was first discovered in Tetrahymena, a ciliated protozoan, by Blackburn in 1984 (Blackburn, 1984). Telomerase is a reverse transcriptase that carries its own RNA template. It is composed of 2 subunits TERC and TERT. The presence of the RNA template in telomerase allows for the extension of the telomere repeat. Telomerase is inactive In normal somatic cells. Therefore, during normal somatic cell division there is an overall reduction in telomere length. In rapidly reproducing cells such as germline and cancer cells, telomerase is active and the cell lines are immortalized (Chiu and Harley 1997; Dhaene et al., 1998; 2000; Lauzon et al., 2000).

\section{THE TELOMERE AND DiSEASE}

Most cancer cells up regulate telomerase activity, thereby maintaining telomere length and maintaining cell proliferation. This does not mean that telomerase activity causes malignancy. Additional cell cycle checkpoints are involved in cell cycle regulation. Therefore, 
malignancy occurs only when a combination of these check points are circumvented (Shay and Wright, 2001). However, telomerase activity is associated with $>80 \%$ of malignancies (Bekaert et al., 2002; Saldanha et al., 2003; Shay and Wright, 2007), suggesting that tumor proliferation may be related to maintenance of telomere length.

Short telomeres have been correlated to a multitude of diseases and environmental factors including diabetes (Allsopp et al., 1992; Demissie et al., 2006; Sampson et al., 2006), cardiovascular disease (Samani et al., 2001; Brouilette et al., 2003; 2007; Obana et al., 2003; Benetos et al., 2004; Fuster and Andres 2006; Kurz et al., 2006; Bekaert et al., 2007; Fitzpatrick et al., 2007), smoking (Satoh et al., 1996; Valdes et al., 2005; Morla et al., 2006), cognitive ageing (Harris et al., 2006; Martin-Ruiz et al., 2006), life stress (Epel et al., 2004; Lansdorp, 2006), mood disorders (Simon et al., 2006), lack of exercise (Cherkas et al., 2008), mortality, (Martin-Ruiz et al., 2006) and obesity (Valdes et al., 2005; Zannolli et al., 2008). Each of the previous factors all have a common connection in physiological stress which may lead to greater numbers of cell division. It is important to note that although the correlations exist, short telomeres may not be the causative factor, but a result of the disease.

\section{SUBTELOMERE STRUCTURE}

Subtelomere regions on each chromosome arm are located between chromosome-specific sequences and the arrays of telomeric repeats that cap the chromosome. Subtelomeres are the most distal sequences of non-repetitive unique-sequence DNA on the chromosome, have the highest density of genes in the human genome and are prone to recombination (HeliasRodzewicz et al., 2002). Subtelomere regions consist of mosaic blocks of duplicated sequences with unique chromosome-specific sequences interspersed throughout. This transition from the 
terminal telomeric end to the specific sequences is gradual and on some chromosomes can be as large as $300 \mathrm{~kb}$ (Riethman et al., 2005).

The composition of human subtelomeres is evident from fluorescent in situ hybridization (FISH) analyses of cloned segments of subtelomeric regions. Some subtelomeres, such as 7q, have a simple structure and little homology to other ends. Other subtelomeres consist of duplicated genomic segments, or "duplicons", that produce patterns of homology. For example, it has been shown that the human $3 \mathrm{q}$ subtelomere is related to at least 35 other chromosome ends (Brown, et al., 1990; Cross et al., 1990; de Lange, et al., 1990; Wilkie et al., 1991)

Some subtelomeric sequences are repeated near centromeres and other interstitial locations. This indicates past transfers of material among these sites. For example, Ijdo et al. (1992) concluded that the presence of sequences at $2 q 13$ is common to the ends of several chromosomes; two ancestral chromosomes fused end to end at this site to form human chromosome 2.

Crossover frequency increases with distance from the centromere and degree of sequence homology. Due to the large amount of sequence homology and subterminal location, subtelomere regions are prone to recombination (Riethman et al., 2005). Rearrangements of the subtelomeres, resulting in deletions and/or duplications, have been shown to be a cause of mental retardation (MR) (Flint et al., 1995).

\section{CHROMOSOME ANALYSIS}

Human chromosomes have been studied since the early 1900s when the movement and behavior of the "dark staining bodies" from which chromosomes took their name was of great interest (Gartler, 2006). In 1921, Theophilus S. Painter published his first paper on human chromosomes, showing the presence of a $\mathrm{Y}$ chromosome in male testicular preparations with a 
total count of 48 chromosomes (Painter, 1921). In 1956, Joe Hin Tjio and Albert Levan reported that the correct number of human chromosomes was 46 . Their finding was due to advancements in cell culture techniques such as treatment with hypotonic solution which allowed better spreading of metaphase preparations (Tijo and Levan, 1956).

The most common preparation of human chromosomes for constitutional analysis uses lymphocytes from peripheral blood. The cells are cultured in nutrient-rich media with phytohemagglutinin (which stimulates cell division) for 3 days and are harvested using colcemid, which prevents the formation of spindle fibers and arrests the cell at metaphase when chromosomes are condensed and visible. To promote a good view of the chromosomes, the cells are treated with a hypotonic solution which forces the cells to swell. The cells are then fixed with an acidic acid/methanol solution which preserves the preparation. Cells are dropped onto slides, rupturing cells and allowing spreading of chromosomes to minimize overlapping. The chromosomes are then stained for visibility with Giemsa.

Human chromosome analysis by karyotyping began in the early 1960s. An image of a metaphase spread was taken and the chromosomes were cut from a photograph and arranged by size and position of the centromere. Currently, this is done digitally on a computer rather than by photographic methods.

Giemsa-banding or G-banding is obtained by staining with Giemsa following digestion of proteins associated with chromosomes using trypsin. This process yields a series of light and dark stained bands. The heterochromatic dark regions are late-DNA replicating and AT rich while the euchromatic light regions are early-DNA replicating and GC rich. Cells that have 450 or more bands in a normal human haploid genome are used for karyotypic analysis (Fig. 4). 


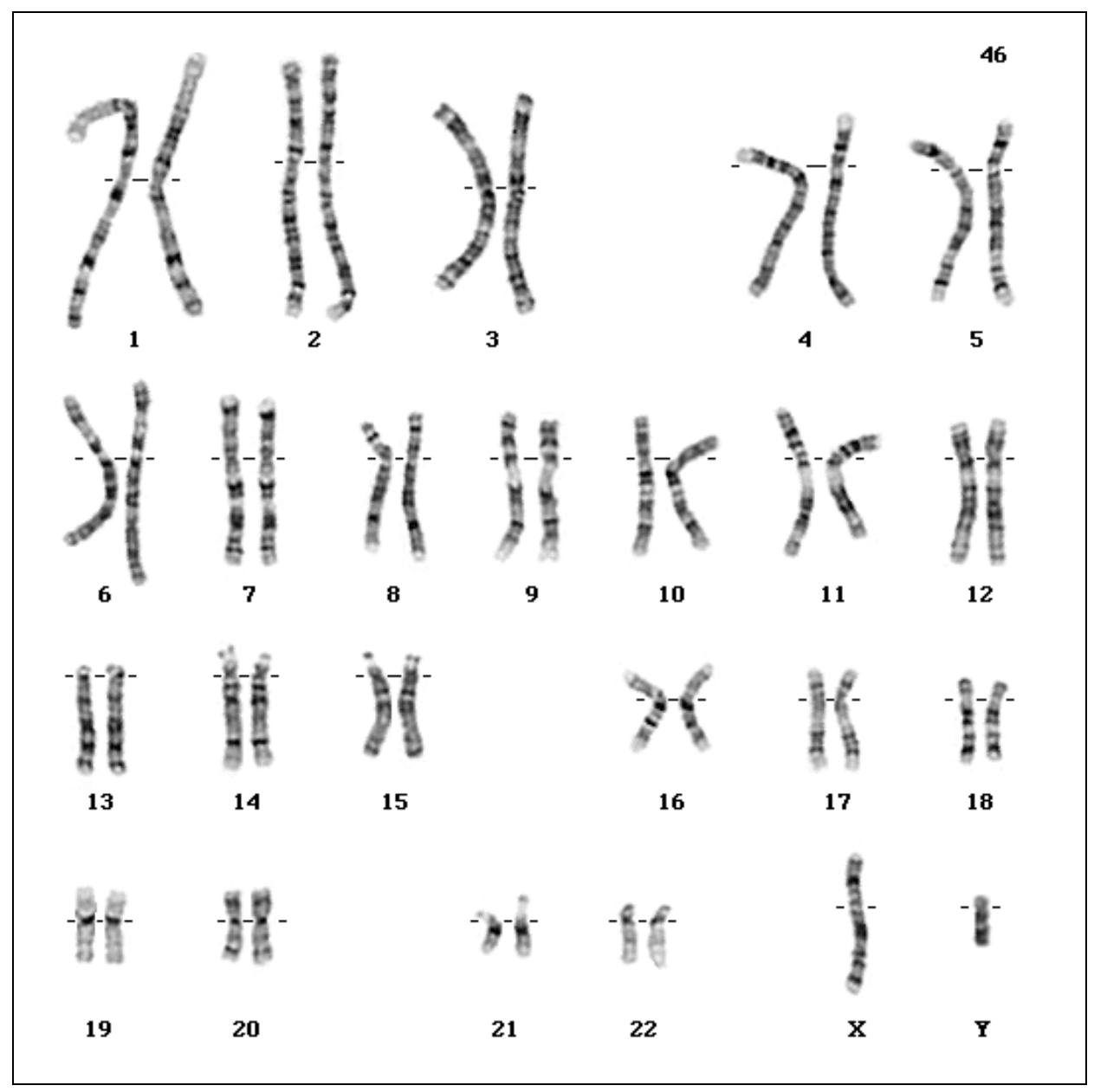

Figure 4. A normal G-banded karyotype at 550 band length. Chromosomes are arranged by size and centromere position. The sex chromosomes are arranged in the lower right hand corner (Figure courtesy of Dr. Sharon Wenger.)

An international committee has met once every 5 to 10 years (since 1975) to standardize the nomenclature for human cytogenetic karyotyping. The nomenclature is updated in a publication entitled the International System for Human Cytogenetic Nomenclature (ISCN), most recently published in 2009 ("International Standing Committee on Cytogenetic Nomenclature", 2009).

Currently, the karyotype is written in a standard format using the following order: Number of chromosomes, sex chromosome composition, numerical and structural abnormalities in numerical order, with breakpoints in parentheses. The band numbers have been standardized 
beginning at the centromere and increasing as the bands progress towards the terminal ends of the chromosome. For example, the nomenclature 16q22.1 indicates the long arm of chromosome 16 at band 22.1 (Fig. 5). A few examples of the nomenclature relevant to the studies within this work are located in Table 1.

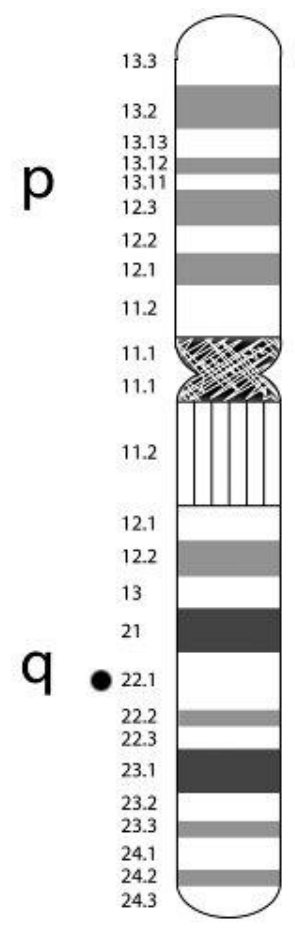

Figure 5. Chromosome 16 banding ideogram. In a karyogram the $\mathrm{p}$ arm is the shorter arm and oriented to the top. The numbers indicate a banding "landmark."(Figure based on ISCN 2009 and is courtesy of Deb Lanzendorfer.) 
Table 1. Examples of ISCN cytogenetic nomenclature

\begin{tabular}{|c|c|}
\hline Karyotype & Interpretation \\
\hline $46, X Y$ & A normal male karyotype \\
\hline $46, X X$ & A normal female karyotype \\
\hline $47, \mathrm{XX},+21$ & $\begin{array}{l}\text { An abnormal female karyotype with an additional } \\
\text { chromosome } 21\end{array}$ \\
\hline $47, \mathrm{XY},+18$ & $\begin{array}{l}\text { An abnormal male karyotype with an additional chromosome } \\
18\end{array}$ \\
\hline $45, \mathrm{X}$ & An abnormal female karyotype with only $1 \mathrm{X}$ chromosome \\
\hline $47, \mathrm{XYY}$ & $\begin{array}{l}\text { An abnormal male karyotype with an additional Y } \\
\text { chromosome }\end{array}$ \\
\hline $47, \mathrm{XXX}[89] / 46, \mathrm{XX}[11]$ & $\begin{array}{l}\text { A mosaic female karyotype, the cell lines are separated by a / } \\
\text { and percentages are located within brackets }\end{array}$ \\
\hline $46, X X, \operatorname{del}(5)(\mathrm{p} 15.3)$ & $\begin{array}{l}\text { A female karyotype with a terminal deletion located on the } \mathrm{p} \\
\text { arm of chromosome } 5 \text { at band } 15.3\end{array}$ \\
\hline $46, X Y, \operatorname{der}(4) t(4 ; 8)(\mathrm{p} 16 ; \mathrm{p} 23)$ & $\begin{array}{l}\text { A male karyotype with a derivative chromosome composed } \\
\text { of a terminal deletion of chromosome } 4 p \text { at band } 16 \text { and a } \\
\text { duplication of chromosome } 8 \text { at band } 23 \text { to the telomere }\end{array}$ \\
\hline
\end{tabular}

\section{NUMERICAL CHROMOSOME ABNORMALITIES}

Chromosome abnormalities can be numerical, with extra or missing chromosomes as a result of nondisjunction or anaphase lag. Numerical abnormalities usually arise during meiosis and gamete formation. In 1959, the earliest reports identified numerical chromosome abnormalities for autosomes in Down syndrome or trisomy 21 (Lejeune et al., 1959), and sex chromosomes including Turner syndrome or monosomy X (Ford et al., 1959), Klinefelter syndrome or 47,XXY (Jacobs and Strong, 1959), XXX females (Jacobs et al., 1959) and XYY males (Sandburg et al., 1961). The development of amniocentesis as an important clinical 
application in the 1960s permitted the further development of the cytogenetics field for prenatal diagnosis (Steele and Breg, 1966)

Nondisjunction or anaphase lag occurring during mitosis will give rise to an individual who is mosaic for both normal and abnormal cells. If this aneuploidy occurs early during fetal development, higher percentages of mosaicism may occur. Low percentages will be present if the error occurs at a later time during fetal development or after birth. In addition, mosaicism may be limited to an area of the body or a specific tissue.

\section{STRUCTURAL CHROMOSOME ABNORMALITIES}

Structural chromosome abnormalities include isochromosomes, translocations, inversions, deletions, or duplications. Structural abnormalities often arise from crossing-over errors during recombination of homologous or non-homologous chromosomes. Structural chromosomal abnormalities are balanced if there is no net gain or loss of chromosomal material, and unbalanced if there is net gain and/or loss. In general, balanced rearrangements (inversions, reciprocal translocations) have no effect on the phenotype. There are exceptions to this, however, such as when a break during the formation of the inversion or balanced translocation disrupts a gene.

A carrier of a balanced reciprocal translocation can produce gametes that after fertilization give rise to an entirely normal child, a phenotypically normal balanced carrier, or various unbalanced karyotypes with a combination of monosomy for part of one of the chromosomes and trisomy for part of the other. 


\section{FLUORESCENT IN SITU HYBRIDIZATION (FISH)}

A G-banded karyotype can readily detect deletions or duplications that are 5 megabases $(\mathrm{Mb})$ or larger in size. However, any duplication or deletion smaller than $5 \mathrm{Mb}$ may be undetectable due to the resolution limits of the light microscope (Shaw-Smith et al., 2004).

Molecular techniques have been developed to address the resolution limits of the Gbanded karyotype. Fluorescent in situ hybridization (FISH) has provided a means to visually detect microdeletions and duplications in an interphase cell or a metaphase spread. First, a probe is constructed that is large enough to hybridize specifically with its target but not so large as to impede the hybridization process. The DNA probe is directly labeled with a fluorophore. Tagging can be done in various ways, such as nick translation or Polymerase Chain Reaction (PCR) using nucleotides labeled with a fluorophore (Pinkel et al., 1986).

The hybridization is accomplished by layering a DNA probe onto a slide containing the fixed cells of interest. The probe and the nuclear DNA are codenatured by heat and then allowed to reanneal, such that specific binding will occur between homologous regions (Fig. 6). Repetitive DNA sequences must be blocked by adding short fragments of DNA to the sample. Excess probe is removed and the presence or absence of the probe target can be visualized with a fluorescent microscope and quantified on a cell by cell basis. FISH probes can identify chromosome aberrations at a much higher resolution $(<5 \mathrm{Mb})$ than classical cytogenetics, regardless of the stage of cell cycle. The resolution of a FISH probe is determined by its design, please see appendix B for examples. 


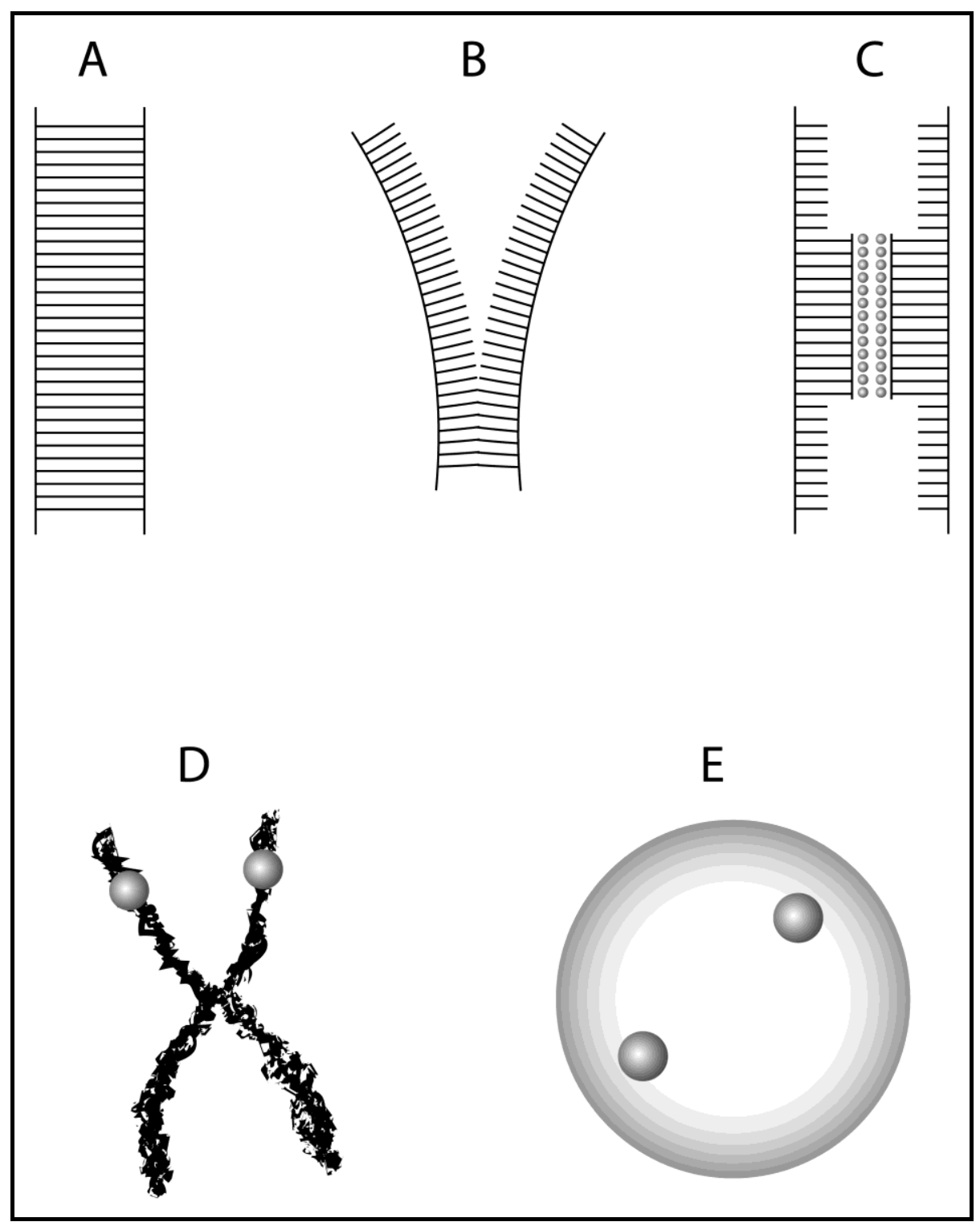

Figure 6. FISH. (A) Double stranded DNA (B) Cellular DNA is denatured into single strands by heat (C) A probe tagged with fluorochrome hybridized to complementary sequences of the DNA strand. (D) Metaphase chromosome where sister chromatids each contain a signal (E) During interphase two signals are observed representing a binding site on each chromosome. (Image courtesy of Deb Lanzendorfer.)

Using ISCN nomenclature for FISH performed on a karyotyped metaphase spread, the total number of chromosomes and sex chromosomes is followed by ".ish" and a description of the FISH findings (Table 2). For interphase cell analysis, the karyotype is written starting with 
nuc ish, followed by the probe locus used in parenthesis with " $\mathrm{x}$ \#", with \# indicating the number of signals seen. For a deletion, the probe locus is followed by "“_“.

Table 2. Examples of ISCN FISH nomenclature

\begin{tabular}{|l|l|}
\hline $\begin{array}{l}\text { 46,XY.ish del(4)(4q35) } \\
(\mathrm{D} 4 \mathrm{~S} 2930-) \text { mat }\end{array}$ & $\begin{array}{l}\text { A normal male karyotype, however FISH reveals a } \\
\text { microdeletion of the probe region D4S2930 that was } \\
\text { maternally inherited. }\end{array}$ \\
\hline $\begin{array}{l}\text { 46,XY.ish der(9)t(9;10) } \\
(\mathrm{p} 24 ; \mathrm{p} 15)(305 \mathrm{~J} 7-, \mathrm{Z} 96139+) \text { pat }\end{array}$ & $\begin{array}{l}\text { A normal male karyotype, however FISH reveals a derivative } \\
\text { chromosome 9 composed of a deletion of the probe region on } \\
\text { chromosome 9 and a copy number gain of the probe region of } \\
\text { chromosome 10. This was paternally inherited. }\end{array}$ \\
\hline $\begin{array}{l}\text { 46,XY.ish 22q11.2(D22S75x2) } \\
\text { nuc ish(DXZ1x3) }\end{array}$ & $\begin{array}{l}\text { A normal male karyotype was obtained. Additionally, a } \\
\text { was demonstrates } 2 \text { copy numbers of the D22S75 locus }\end{array}$ \\
\hline $\begin{array}{l}\text { wiSH was performed on interphase cells. Three signals for } \\
\text { nuc ish(D21Z1x3)[100/400]/ }\end{array}$ & $\begin{array}{l}\text { FISH was performed on interphase cells. 100 cells out of } \\
\text { to0 had 3 signals for the centromere of chromosome 21. }\end{array}$ \\
\hline
\end{tabular}

Microdeletions are responsible for many identifiable syndromes including WolfHirschhorn (4p16.3), Williams (7q11.23), Prader-Willi (15q11.2 paternal), Angelman (15q11.2 maternal), and DiGeorge (22q11.2) syndromes. However, the deletion is not always detected on a G-banded karyotype. In 1967, McGavin et al., described a case of Cri-du-chat (5p15.3) syndrome with an apparently normal karyotype (McGavin et al., 1967). Later in 1969, Hoehn and Engel suggested that minute deletions may be responsible for these patients' syndromes (Hoehn and Engel, 1969). 
In 1989, a family with multiple children affected with Cri-du-chat syndrome did not show a deletion on chromosome $5 \mathrm{p}$ by a G-banded karyotype. Restriction fragment length polymorphism (RFLP) analysis of the affected individuals showed monosomy of 5p15.1-pter region. It was then discovered by FISH that one of the parents was a balanced translocation carrier (Overhauser et al., 1989).

In 1991, Altherr et al. reported a similar case involving a patient with Wolf-Hirschhorn syndrome. All initial karyotypes were reported as normal, but because the patient's phenotype was that of Wolf-Hirschhorn syndrome, RFLP and FISH analyses were performed. The molecular testing identified a $4 \mathrm{p}$ terminal deletion that was inherited from a parent with a balanced cryptic translocation (Altherr et al., 1991). Since well characterized clinical presentations were found to be the result of cryptic imbalances inherited from a parent, it was hypothesized that other less-defined or uncharacterized phenotypes may be the result of cryptic rearrangements (Altherr et al., 1991).

It was suggested by Ledbetter in 1992, that cryptic chromosome abnormalities could clinically be screened by FISH. He further suggested that cryptic telomere imbalances may occur in children with unexplained MR, and that multicolor FISH probes could be used as an effective diagnostic tool (Ledbetter, 1992). 


\section{CHAPTER TWO}

\section{BALANCED CRYPTIC SUBTELOMERIC REARRANGEMENTS AND X CHROMOSOME MOSAICISM: A STUDY OF 565 APPARENTLY NORMAL INDIVIDUALS WITH FLUORESCENT IN SITU HYBRIDIZATION}

\section{INTRODUCTION}

The classification of mental retardation (MR) is typically divided into four categories: mild (IQ of 50-70), moderate (IQ of 35-50), severe (IQ of 20-35) and profound (IQ of less than 20). Mild MR is ten times more frequent than the moderate, severe, and profound categories combined (Anderlid et al., 2002). The incidence of MR in the general population has been estimated to be in the range of $1 \%$ to $3 \%$ (Baker et al., 2002; Harada et al., 2004; Shaffer, 2005; Palomares et al., 2006). About 10 percent of all MR is the result of chromosome abnormalities (Flint and Wilkie, 1996). An estimated $40 \%$ of severe MR and 10\% of mild MR is the result of detectable chromosome abnormalities (Van Karnebeek et al., 2002). The cause of MR can only be identified in $50 \%$ of affected individuals. However, in cases of mild to moderate MR the cause is diagnosed in only $25 \%$ of these individuals.

Unbalanced cryptic rearrangements of the subtelomere regions have been shown to be a cause of idiopathic MR (IMR). In 1995, Flint et al. was the first to report subtelomeric chromosomal rearrangements associated with mental retardation with unknown etiology. By using variable nucleotide tandem repeat (VNTR) polymorphism analysis, the researchers were able to show that $6 \%$ of individuals with idiopathic MR in their study had small subtelomeric abnormalities (Flint et al., 1995). 
The first study using subtelomere FISH probes was reported in 1999, when Knight and colleagues screened 284 children with unexplained moderate to severe retardation and 182 children with unexplained mild retardation. Their data showed that small (undetectable by karyotype) chromosomal abnormalities occurred with a frequency of $7.4 \%$ in the children with moderate to severe mental retardation, and of $0.5 \%$ in the children with mild retardation. They estimated that the population incidence of these unbalanced rearrangements to be as high as 2.1 in 10,000 . Therefore, the researchers suggested that standard medical practice for individuals with unexplained MR and a normal G-banded karyotype should include testing for subtelomeric rearrangements using DNA FISH probes (Knight et al., 1999).

In 2002, van Karnebeek et al., screened 184 children (under the age of 18) with an IQ of less than 85 for subtelomeric rearrangements by using FISH. Only one subtelomeric deletion $(0.5 \%)$ was detected by FISH (de novo deletion $12 \mathrm{q} 24.33$-qter). The authors concluded that this low frequency was likely explained by the lack of clinical selection bias for individuals who were at higher risk for such rearrangements.

In 2004, Bocian et al. examined 84 families with history of IMR and normal G-banded karyotypes. They identified nine (10.7\%) subtelomeric rearrangements, of which six were of parental origin. However, when retrospectively examined it was determined that most of the rearrangements could have been detected or suspected with high resolution G-banding with resolutions as low as the 550 band level.

In 2005, Adeyinka et al. retrospectively examined 2,170 clinical records of individuals with MR, a normal G-banded karyotype, and subtelomere FISH results. One hundred thirty nine, (5.6\%), had abnormalities of the subtelomere region. Seventy-one patients had deletions, 53 had 
derivative chromosomes, and 15 had balanced rearrangements. The abnormality was inherited in $51.8 \%$ of patients. (Adeyinka et al., 2005).

The largest study of subtelomeric rearrangements to date was a retrospective study with broad selection criteria including MR, developmental delay (DD), behavioral disorders, autism, and growth delay. Of the 11,688 patients who had a normal karyotype, 357 (2.5\%) were found to have subtelomeric rearrangements by FISH. The most common abnormalities reported in this study were deletions of 1p, 22q, 4p, 9q, 8p, 2q and 20p in that order. (Ravnan et al., 2006).

In summary, the incidence of subtelomere abnormalities varies greatly, and depends on the stringency of the criteria involved in patient selection and sample size (Ravnan et al., 2006). For example, numerous studies have shown subtelomeric defects to be found in the range of 0.5$10.7 \%$ of individuals with IMR and a normal karyotype (Knight et al., 1997, 1999; Anderlid et al., 2002; Bocian et al., 2004; Li and Zhao, 2004). Higher percentages (20\%) were from studies using highly selective criteria, where selection of individuals was limited to those who had a phenotype suggestive of a chromosome disorder such as a family history of MR, growth retardation and multiple congenital abnormalities (MCA) (de Vries et al., 2001; Walter et al., 2004). 


\section{OBJECTIVES}

Cytogenetically visible balanced translocations have an incidence of 1 in 600 in the general population (Estop et al., 1997). Parents who are carriers of balanced translocations with a normal phenotype can have children with unbalanced chromosomes. Like visible rearrangements, cryptic balanced rearrangements (undetectable by a G-banded karyotype) can also result in children with an unbalanced rearrangement. Several studies have reported that half of all patients with an unbalanced cryptic rearrangement have inherited it from a parent with a cryptic balanced translocation, however the frequency of individuals who carry a balanced cryptic translocation is unknown. In this study, a population of 565 unrelated, phenotypically normal individuals was screened with subtelomere FISH probes to determine the incidence of balanced cryptic translocation carriers. 


\section{MATERIALS AND METHODS}

\section{SAMPLE COLLECTION}

Subjects for this study were from the Center for Oral Health Research in Appalachia (COHRA) (Polk et al., 2008), as an ongoing cross-sectional oral health etiology study. COHRA enrolls families from two central West Virginia counties and two western Pennsylvania counties and performs a detailed assessment protocol after an informed consent process approved by the Institutional Review Boards (IRB) of the University of Pittsburgh and West Virginia University (WVU). A total of 978 COHRA subjects were included in this study. Due to delay in shipping of blood samples, approximately one fourth of samples did not yield metaphase cells in culture and therefore could not be included in this study. A total of 484 (164 males and 320 females) blood samples were screened by FISH. In addition, IRB approval was obtained to use discarded samples from the WVU cytogenetics clinical laboratory. An additional 81 (22 males and 59 females) samples were selected on the basis of a normal karyotype at the 550 band level and a diagnosis excluding mental retardation, which were then de-identified prior to analysis.

\section{BLOOD LyMPHOCYTE CULTURE AND HARVEST}

One $\mathrm{ml}$ of blood was added to $7 \mathrm{ml}$ of culture media (Appendix A) in a $15 \mathrm{ml}$ sterile conical centrifuge tube and mixed by inversion. The culture was incubated for 72 hours at $37^{\circ} \mathrm{C}$. Ninety $\mu$ l of colcemid (Gibco Cat \#757575) was added to each culture for 30 minutes. The cultures were then centrifuged at $1200 \mathrm{rpm}$ for 10 minutes. Supernatant was removed by aspiration and $9 \mathrm{ml}$ of hypotonic solution $(0.075 \mathrm{M} \mathrm{KCl})$ was added, mixed by inversion, and incubated at $37^{\circ} \mathrm{C}$ for 10 minutes. Following incubation, $3 \mathrm{ml}$ of fixative $(1: 3$ glacial acidic acid to absolute methanol) was added to each culture, mixed by inversion and centrifuged at 1200 
rpm for 10 minutes. Supernatant was removed by aspiration and the cell pellet was resuspended in $10 \mathrm{ml}$ of fixative, mixed by inversion and centrifuged at $1200 \mathrm{rpm}$ for 10 minutes. The cell pellet was washed with fixative until the cell pellet was clean and white. The cultures were then stored at $4^{\circ} \mathrm{C}$.

\section{SLIDE PREPARATION}

The cell pellet was removed from a $4^{\circ} \mathrm{C}$ refrigerator and brought to room temperature (RT). After centrifugation, supernatant was removed and the cell pellet was re-suspended to an appropriate volume of fixative to obtain 5 or more metaphase cells per 10X field of view. Microscope slides were propped up at a $45^{\circ}$ angle over a $73^{\circ} \mathrm{C}$ steaming water bath. Cells in suspension were dropped onto the top of the slide and allowed to run to the bottom. The slide was then placed horizontally until all fixative had evaporated and a grainy sheen was visible on the slide. The slide was removed from the water bath and allowed to air dry at room temperature in a slide rack.

\section{SUBTELOMERE FISH PROCEDURE}

The commercially available subtelomere FISH probe set ToTelVysion (cat\# 33-270000, Abbott Molecular, Il) has been used in many recent studies (Li and Zhao, 2004; Iqbal et al., 2005; Ravnan et al., 2006) and is currently used in the WVU cytogenetics laboratory. The 41 subtelomere probes are specific to the $\mathrm{p}$ and $\mathrm{q}$ subtelomeres of chromosomes 1-12, and 16-20, the $\mathrm{q}$ subtelomeres of the acrocentric chromosomes $(13,14,15,21$, and 22), and the $\mathrm{Xp} / \mathrm{Yp}$ and $\mathrm{Xq} / \mathrm{Yq}$ pseudo-autosomal region subtelomeres. The set consists of a mixture of CEP (Centromere Enumeration Probe) and LSI (Locus Specific) probes. Each of the 41 ToTelVysion probes hybridizes within $300 \mathrm{~kb}$ of the proximal end of the telomere, allowing for greater 
sensitivity for detection of specific subtelomeric regions, and also minimizes cross hybridization with other subtelomeric regions with sequence homology. The probes range in size from $70 \mathrm{~kb}$ (17p) to as large as $191 \mathrm{~kb}(5 \mathrm{p})$. The probes are arranged in 15 sets that recognize 2-3 subtelomeres per set (Table 3) Each probe and its clone ID are listed in Appendix B.

Table 3. Probe sets included in the ToTelVysion probe panel.

\begin{tabular}{|c|l|}
\hline Set & \multicolumn{1}{|c|}{ Subtelomere Locus and Fluorochrome } \\
\hline 1 & 1p Green, 1q Orange, Xp/Yp Yellow, CEP X Aqua \\
\hline 2 & 2p Green, 2q Orange, Xq/Yq Yellow, CEP X Aqua \\
\hline 3 & 3p Green, 3q Orange, 22q Yellow, LSI bcr (22q11) Aqua \\
\hline 4 & 4p Green, 4q Orange, 21q Yellow, LSI AML (21q22) Aqua \\
\hline 5 & $5 p$ Green, 5q Orange \\
\hline 6 & 6p Green, 6q Orange, 13q Yellow, LSI 13 (13q14) Aqua \\
\hline 7 & 7p Green, 7q Orange, 14q Yellow \\
\hline 8 & 8p Green, 8q Orange, 17p Yellow, CEP 17 Aqua \\
\hline 9 & 9p Green, 9q Orange, 17q Yellow, CEP 17 Aqua \\
\hline 10 & $10 p$ Green, 10q Orange, 15q Yellow, LSI PML (15q22) Aqua \\
\hline 11 & $11 p$ Green, 11q Orange, 18p Yellow, CEP 18 Aqua \\
\hline 12 & $12 p$ Green, 12q Orange, 18q Yellow, CEP 18 Aqua \\
\hline 13 & $16 p$ Green, 16q Orange \\
\hline 14 & 19p Green, 19q Orange \\
\hline $10 p$ Green, 20q Orange \\
\hline 12
\end{tabular}

The prepared metaphase spread slides were washed in a series of $2 \mathrm{X}$ Saline Sodium Citrate (SSC) for 10 minutes at $37^{\circ} \mathrm{C}, 1 \%$ formaldehyde for 15 minutes at room temperature (RT), 1X Phosphate Buffered Saline (PBS) for 5 minutes at RT, pepsin solution (Appendix A) for 13 minutes at $37^{\circ} \mathrm{C}, 1 \mathrm{X}$ PBS for 5 minutes at $\mathrm{RT}$ and then air dried. The slides were then put 
through a series of ethanol washes of $70 \%, 85 \%$, and $100 \%$ for 1 minute each and allowed to air dry at room temperature.

Probe working solutions were prepared by adding $3 \mu$ of ToTelVysion probe solution to $30 \mu \mathrm{l}$ of cDenHyb (InSitus, cat \#D002) centrifuged briefly and vortexed in a microfuge tube. Three $\mu$ of each working solution was placed in the middle of one of 5 respective circled areas on a slide. A $12 \mathrm{~mm}$ circular coverslip was placed on top and all air bubbles were driven out. When 5 spots per slide were completed, autoclave tape was placed across the entire slide and pressed firmly around the coverslips for a tight seal. Slides were placed on a hotplate for 3 minutes at $90^{\circ} \mathrm{C}$, transferred to a light-tight box, and incubated overnight in a $37^{\circ} \mathrm{C}$ water bath.

The next day, in a minimal light room, the slides were removed from the water bath and de-coverslipped. The slides were then washed in $0.4 \mathrm{X}$ SSC $/ 0.3 \% \mathrm{NP}-40$ at $73^{\circ} \mathrm{C}$ for two minutes and then for 30 seconds in $2 \mathrm{X} \mathrm{SSC} / 0.1 \% \mathrm{NP}-40$ at RT. The slides were completely air dried in the dark. Twenty $\mu \mathrm{l}$ of $1 \mathrm{X}$ 4',6-diamidino-2-phenylindole (DAPI) counterstain was applied to the dried slides and coverslipped (20 mm X $50 \mathrm{~mm})$. The slides were maintained in a light-tight box for transport to the microscope and storage for up to a week at $4{ }^{\circ} \mathrm{C}$.

A Leica epi-fluorescent microscope equipped with a DAPI single bandpass, aqua single bandpass, and a red/green dual bandpass filter was used for signal enumeration. Yellow signals were read using the red/green filter. Five metaphase and 5 interphase cells were scored for each probe set. 


\section{X/Y FISH PROBE PROCEDURE}

To confirm abnormal subtelomere FISH results regarding $\mathrm{X}$ chromosomes, slides were prepared as described above and co-hybridized with $\mathrm{X}$ and $\mathrm{Y}$ centromere probes. One hundred interphase cells were analyzed for the number of $\mathrm{X}$ and $\mathrm{Y}$ centromere signals. 


\section{RESULTS}

Blood samples from a total of 565 phenotypically normal unrelated individuals were evaluated for cryptic rearrangements using subtelomeric FISH probes. No balanced cryptic rearrangements were observed by FISH; all samples showed a normal location of signals. Since the frequency for a balanced cryptic rearrangement could not be based on observation, an estimate for the frequency of carriers for balanced subtelomere rearrangements (X) was calculated based on information from the literature using the following equation: $(A)(B)(C)(D)(E)=X$ where $A$ is the $2 \%$ of the population with MR (Baker et al., 2002), B is the 50\% of MR patients with unknown etiology (Flint and Wilkie, 1996), C is the estimated 5\% incidence of subtelomeric abnormalities in MR patients with unknown etiology (Walter et al., 2004), D is the $50 \%$ percent risk of an unbalanced rearrangement being inherited from a parent with a balanced subtelomeric translocation (Knight et al., 1999), and $\mathrm{E}$ is the $50 \%$ chance that a carrier would have a child with an unbalanced rearrangement (due to segregation during meiosis). Using the above equation, the incidence of cryptic balanced subtelomeric rearrangement carriers in the general population who have affected children was estimated to be approximately 1 in 8000 .

Among the specimens that were analyzed with subtelomeric FISH probe sets containing $\mathrm{Xp} / \mathrm{Yp}$ and $\mathrm{Xq} / \mathrm{Yq}$, mosaicism for $\mathrm{X}$ chromosome aneuploidy was identified in 3 of 379 women (0.8\%). Using a separate $\mathrm{X} / \mathrm{Y}$ centromeric probe set (specific for this probe), the FISH results were confirmed in interphase cells for these individuals: $89 \%$ triple $\mathrm{X}$ in a 36 year old, 5\% triple $\mathrm{X}$ chromosome in a 52 year old, and multiple cell lines including $11 \%$ single $\mathrm{X}, 6 \% \mathrm{XXX}$ and 2\% XXXX in a 54 year old (Fig. 7) (Table 4). 
Table 4. $X$ chromosome mosaicism in three individuals listed by age. The $X$ columns show the percentage of cells analyzed that had monosomy $\mathrm{X}$, a normal number of $\mathrm{X}$ chromosomes, trisomy $\mathrm{X}$ and tetrasomy $\mathrm{X}$.

\begin{tabular}{|c|c|c|c|c|c|}
\hline \multirow{2}{*}{$\begin{array}{c}\text { Patient } \\
\text { Number }\end{array}$} & \multirow{2}{*}{ Age } & \multicolumn{4}{|c|}{ Mosaic Percentage of X chromosomes } \\
\cline { 3 - 6 } & & $1 \mathrm{X}$ & $2 \mathrm{X}$ & $3 \mathrm{X}$ & $4 \mathrm{X}$ \\
\hline 1 & 36 & - & $11 \%$ & $89 \%$ & - \\
\hline 2 & 52 & - & $95 \%$ & $5 \%$ & - \\
\hline 3 & 54 & $11 \%$ & $81 \%$ & $6 \%$ & $2 \%$ \\
\hline
\end{tabular}




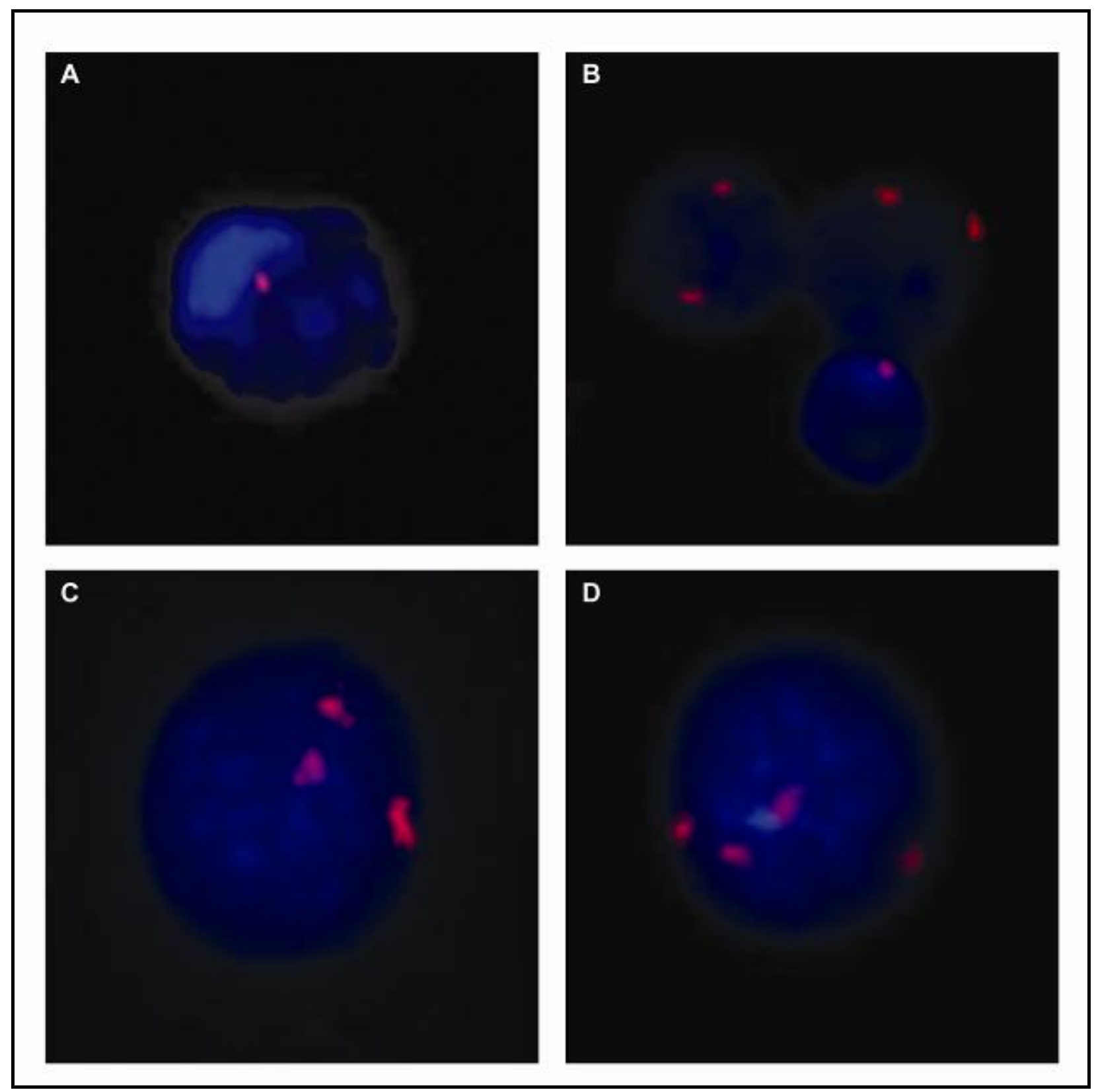

Figure 7. FISH probe for the centromere of the $\mathrm{X}$ chromosome hybridized to interphase cells (A) A cell with one signal for the centromere of the $X$ chromosome, or monosomy $X$. (B) Two normal cells showing two signals for the X chromosome, and one cell with monosomy X. (C) A cell showing trisomy X. (D) A cell with tetrasomy X. 


\section{DISCUSSION}

\section{SUBTELOMERIC REARRANGEMENTS}

No balanced cryptic translocations were found in the 565 subjects who were screened by subtelomere FISH probes. From this sample size, it was not possible to determine the frequency of balanced subtelomeric translocation carriers. Sample size was limited due to the number of individuals enrolled in the study who donated blood, culture failures and the cost of FISH probes.

The calculated incidence of cryptic balanced subtelomeric rearrangement carriers in the general population is estimated to be approximately 1 in 8000 . Therefore, it was not surprising that cryptic balanced translocations were not identified among the 565 subjects in the study.

The reported incidence of individuals with unbalanced subtelomeric rearrangements in the general population has been estimated to be 2.1 in $10,000(\sim 1$ in 4762$)$ by Knight et al., (1999). Since half of these individuals inherited the rearrangement from a parent (Knight et al., 1999; Adeyinka et al., 2005), the frequency of parents who are balanced translocation carriers would be half as frequent, or around 1 in 9524. The difference between the calculated estimate of 1/8,000 and the estimate of Knight et al., 1999 is most likely due to the variation in the reported percentages and criteria for evaluation of MR. Regardless, the incidence of balanced subtelomeric rearrangements is at least 10 times less prevalent than carriers of visible reciprocal translocations (1/600). 


\section{CHromosome Mosaicism}

Individuals who are mosaic have two or more populations of somatic cells that are genetically different. Aneuploidy of the $\mathrm{X}$ chromosome can arise by mitotic nondisjunction or anaphase lag. There are several factors to consider when observing low level mosaicism: are the results due to genuine mosaicism, technical artifact or age related?

In tissue culture artifacts the gain of the $\mathrm{X}$ chromosome has been shown to occur in less than 1 in 2500 cells (Wenger et al., 1984). For this study tissue culture artifact has also been ruled out because previous FISH studies have shown that cultured lymphocytes reflect in vivo aneuploidy rates and that there is no significant difference between cultured lymphocyte and uncultured lymphocyte stability (Guttenbach et al., 1995 and Catalán et al., 2000).

Age related $\mathrm{X}$ chromosome aneuploidy has been attributed to premature centromere division in older women. Several studies have demonstrated that peripheral blood metaphase cells from women generally 50 years of age and older could have an average of $4-5 \% \mathrm{X}$ chromosome loss and less than $1 \% \mathrm{X}$ chromosome gain attributed to mitotic error (Jacobs et al., 1961; Fitzgerald, 1975; Ford and Russell, 1985; Abruzzo et al., 1985, Russell et al., 2007). This finding has been substantiated in interphase cells using FISH probes, demonstrating that women older than 60 years of age had an average X chromosome loss of 3.4\% (as high as 9\%) and gain of less than 1\% (Guttenbach et al., 1995; Mukherjee, et al., 1996).

All 3 of the individuals identified with mosaicism in this study had gains of $\mathrm{X}$ chromosomes. Although two of the three women were over the ages of 50, all of these women had a cell line with $5 \%$ or greater for an extra X chromosome. Because age related aneuploidy in 
females usually involves loss of the $\mathrm{X}$ chromosome in lymphocytes, this would suggest that the cells with a gain of an $\mathrm{X}$ chromosome are not related to age or tissue culture artifact.

The incidence of sex chromosome mosaicism in the general population is from studies in the literature from the late 1970s. These reports used newborn or prenatal populations, with limited number of analyzed metaphases. A representative study reported $0.1 \%$ aneuploidy for sex chromosomes in newborn studies based on analysis of 3-5 cells (Hook and Hamerton 1977). By screening the general population with FISH, many more cells could be screened by FISH than with karyotypes.

The finding of mosaicism in $0.8 \%$ of women suggests that numerical abnormalities of the $\mathrm{X}$ chromosome may be more common in females than previously reported. This underreporting is most likely due to lack of an abnormal phenotype. Individuals who have low level mosaicism for the $\mathrm{X}$ chromosome are less likely to have a clinically relevant phenotype and therefore would go undiagnosed in the general population. 


\section{CONCLUSIONS}

Based on a review of the literature, the incidence of cryptic translocation carriers is estimated to be approximately $1 / 8,000$, which is 10 times less prevalent than the frequency of visible reciprocal translocations. While no balanced subtelomeric rearrangements were identified, three females in this study were determined to be mosaic for the $\mathrm{X}$ chromosome. Mosaicism for XXX cell lines were observed in the lymphocyte cultures of 3 in 379 women $(0.8 \%)$, which is a higher frequency than the 1 in $1000(0.1 \%)$ reported for sex chromosome aneuploidies. These findings suggest that numerical abnormalities of the $\mathrm{X}$ chromosome are more common in females than previously reported. 


\section{FUTURE STUDY AND LIMITATIONS}

Sample size of the project was reduced due to a large number of blood samples with no growth. This was most likely due to long shipping delays. The blood collection took place in multiple locations off site and samples were frequently held several days for batch shipping. More than 150 of the samples were received up to two weeks after collection of the sample. Reduced mitotic indices occur after four days due to death of lymphocytes.

Sample size was also limited to those who chose to donate blood. Many individuals with a family history of MR or other factors that may be indicative of a chromosomal imbalance such as multiple miscarriages, did not choose to have themselves or their children donate blood. This is assumed to be for reasons of preventing undue stress from an invasive procedure.

This study could have been improved by minimizing delay in shipping specimens from the study sites and by encouraging individuals to donate blood. If rearrangements were detected, it would have been interesting to use array CGH (discussed in detail in chapter three) to detect the size of the deletion and/or duplication. 


\section{CHAPTER THREE}

\section{SUBTELOMERIC DELETIONS: THE IMPORTANCE OF RULING OUT POLYMORPHIC VARIANTS OR INHERITED DELETIONS

\author{
INTRODUCTION
}

Numerous studies have reported cryptic subtelomere chromosome imbalances in patients with unexplained MR or DD identified by FISH. Incidence reports of subtelomere imbalances vary greatly, depending on sample size and the stringency of the criteria for patient selection. In general, subtelomeric imbalances have been identified in 3-10\% of individuals with idiopathic mental retardation (IMR) and a normal karyotype (Knight et al., 1999; Anderlid et al., 2002; Bocian et al., 2004). Several checklists have been developed that provide common guidelines for patient selection (de Vries et al., 2001; Walter et al., 2004), which gives a higher sensitivity for detection.

However, not all subtelomeric imbalances are necessarily disease causing. Benign subtelomeric polymorphisms have been reported since 1991 (Wilkie et al., 1991). For example, there is a common polymorphism on chromosome $2 \mathrm{q}$ where alleles had a $55 \mathrm{~kb}$ difference in length (Macina et al., 1994). Additional common polymorphisms have been identified at the 4q and 10q subtelomere regions (Wong et al., 2005). In a large study of patients with IMR (Ravnan et al., 2006), $0.5 \%$ of all of imbalances observed by FISH were found to be polymorphic variants. The most common variants were deletion or duplication of 10q, deletion of $4 \mathrm{q}$, deletion of Yq, deletion of 2q, and duplication of Xp/Yp onto Xq. 


\section{OBJECTIVES}

Many studies have reported the incidence of individuals with MR and a normal karyotype who have a FISH-identified cryptic rearrangement that range from 2.5 to $10 \%$, depending on criteria used for selection. The objective of this study was to retrospectively determine the frequency of individuals in a clinical population who had abnormal results by subtelomere FISH. In this study log books from the West Virginia University cytogenetics laboratory were reviewed for individuals with IMR and a normal karyotype, to determine the frequency of these individuals who had abnormal subtelomere results by FISH. Additionally, records were searched to determine if the parents were tested for the same abnormality, and if one of the parents had the same abnormality as the child, parental medical records were checked for incidence of an abnormal phenotype. This study will determine the importance of parental testing in confirmation of subtelomeric abnormalities and polymorphisms. 


\section{MATERIALS AND METHODS}

Institutional Review Board (IRB) approval was obtained to review cytogenetics laboratory records from December 2001 to December 2007 for subtelomere FISH performed on patients with MR/DD and a normal G-banded karyotype. A total of 256 patients were found to fit these criteria. Medical records were examined for those with abnormal FISH results. Laboratory and medical records were also checked for parents of children with abnormal FISH results. 


\section{RESULTS}

Blood samples from two hundred and fifty six pediatric patients were evaluated for subtelomere rearrangements using FISH probes. These patients had MR or DD as well as diagnoses including seizures, autism, short stature and microcephaly. Nine, or 3.5\%, of these patients had abnormal results: 5 with deletions and 4 with deletion/duplications. Of the five terminal deletions identified in this study, two were inherited. Although requested, parental blood was not received for the other submicroscopic deletions for $3 p, 5 q$ and $15 q 22$, which have previously been reported with an abnormal phenotype (de Vries et al., 2003; Ravnan et al., 2006). Four derivative rearrangements were detected of which two were known to be inherited by a parent and one was de novo. Two polymorphisms $(0.78 \%)$ were detected. One of the polymorphisms was a $4 \mathrm{q}$ deletion, while the other was an additional $16 \mathrm{q}$ subtelomere signal on $18 \mathrm{p}$ shown to have a normal signal pattern using Cytocell probe for $16 \mathrm{q}$.

Table 5. Subtelomere rearrangements identified among 256 patients

\begin{tabular}{|c|}
\hline Deletions \\
\hline $46, \mathrm{XY}, \operatorname{del}(3)(\mathrm{p} 25)$ \\
$46, \mathrm{XY}, \operatorname{del}(4)(\mathrm{q} 35) \mathrm{mat}$ \\
$46, \mathrm{XX}, \operatorname{del}(5)(\mathrm{p} 15.3) \mathrm{pat}$ \\
$46, \mathrm{XY}, \operatorname{del}(5)(\mathrm{q} 35)$ \\
$46, \mathrm{XY}, \operatorname{del}(15)(\mathrm{q} 22)$ \\
\hline Derivative Rearrangements \\
\hline $46, \mathrm{XX}, \operatorname{der}(4) \mathrm{t}(4 ; 8)(\mathrm{p} 16 ; \mathrm{p} 23) \mathrm{dn}$ \\
$46, \mathrm{XY}, \operatorname{der}(9) \mathrm{t}(9 ; 10)(\mathrm{p} 24 ; \mathrm{p} 15) \mathrm{pat}$ \\
$46, \mathrm{XY}, \operatorname{der}(12) \mathrm{t}(7 ; 12)(\mathrm{q} 36 ; \mathrm{p} 13)$ \\
$46, \mathrm{XY}, \operatorname{der}(15) \mathrm{t}(15 ; 18)(\mathrm{q} 26 ; \mathrm{q} 23) \mathrm{mat}$ \\
\hline
\end{tabular}




\section{CLINICAL REPORTS}

\section{SUBTELOMERIC DELETIONS}

Patient 1 - 46,XY.ish del(3)(p25)(D3S4559-)

Patient 1 was born at 41 weeks gestation with a birth weight of 7 pounds 6 ounces. He did not walk until age 2 and had delayed speech. He was in the 25th percentile for height and weight and the 10th percentile for head circumference. He was referred for genetic evaluation at age 4 for his developmental delays. He presented with bilateral ptosis and a right nasolacrimal duct obstruction. Subtelomere FISH revealed a terminal deletion of the short arm of chromosome 3 (Fig. 8). His family history included an aunt who had multiple miscarriages. Both parents had declined to be karyotyped.

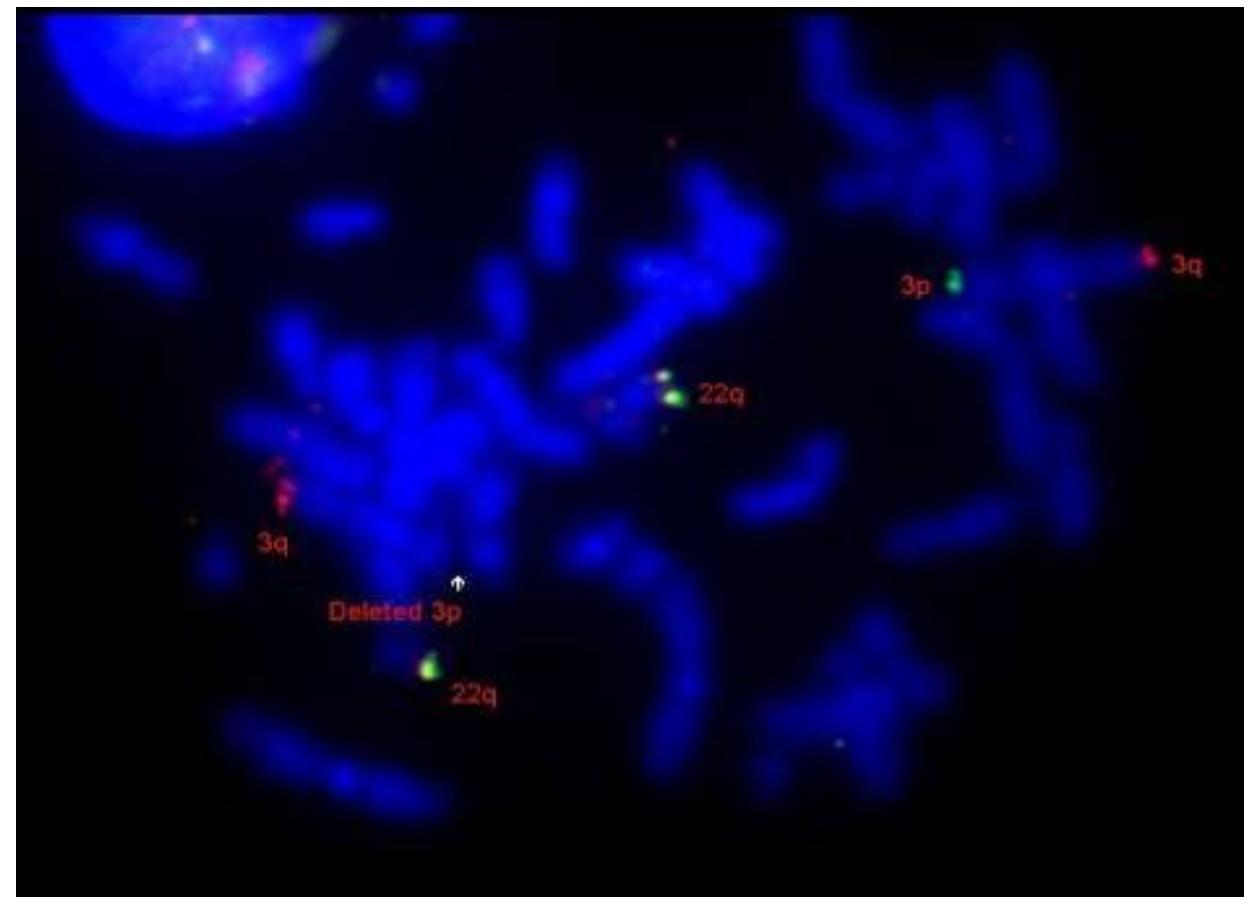

Figure 8. One $3 p$ probe signal is absent indicating a deletion of $3 p$. 


\section{Patient 2 - 46,XY.ish del(4)(4q35)(D4S2930-)mat}

Patient 2 was born at 38 weeks gestation, weighed 6 pounds and was 18 1/4 inches long. He was hospitalized twice before 3 months of age due to cyanotic episodes. An atrio-ventrical (AV) defect was identified prenatally by ultrasound, and was repaired at 3 months of age. At 2.5 years of age he was 33.75 inches long (5th percentile), weighed 23 pounds, 4 ounces $(<1 / 3$ percentile), and his head circumference was $47.2 \mathrm{~cm}$ (10th percentile). He had a high forehead, posterior displaced hair whorl, small palpebral fissures, and a café au lait spot. His muscle tone was lower than average. Subtelomere FISH revealed a terminal deletion of the long arm of chromosome 4 that was found to be inherited from his mother (Fig. 9). His mother, father and paternal grandfather all were diagnosed with Ehlers-Danlos syndrome, however, he did not exhibit any symptoms. His mother had hearing loss due to multiple ear infections, mitral valve prolapse, and had attended special education. His maternal uncle was in special education.

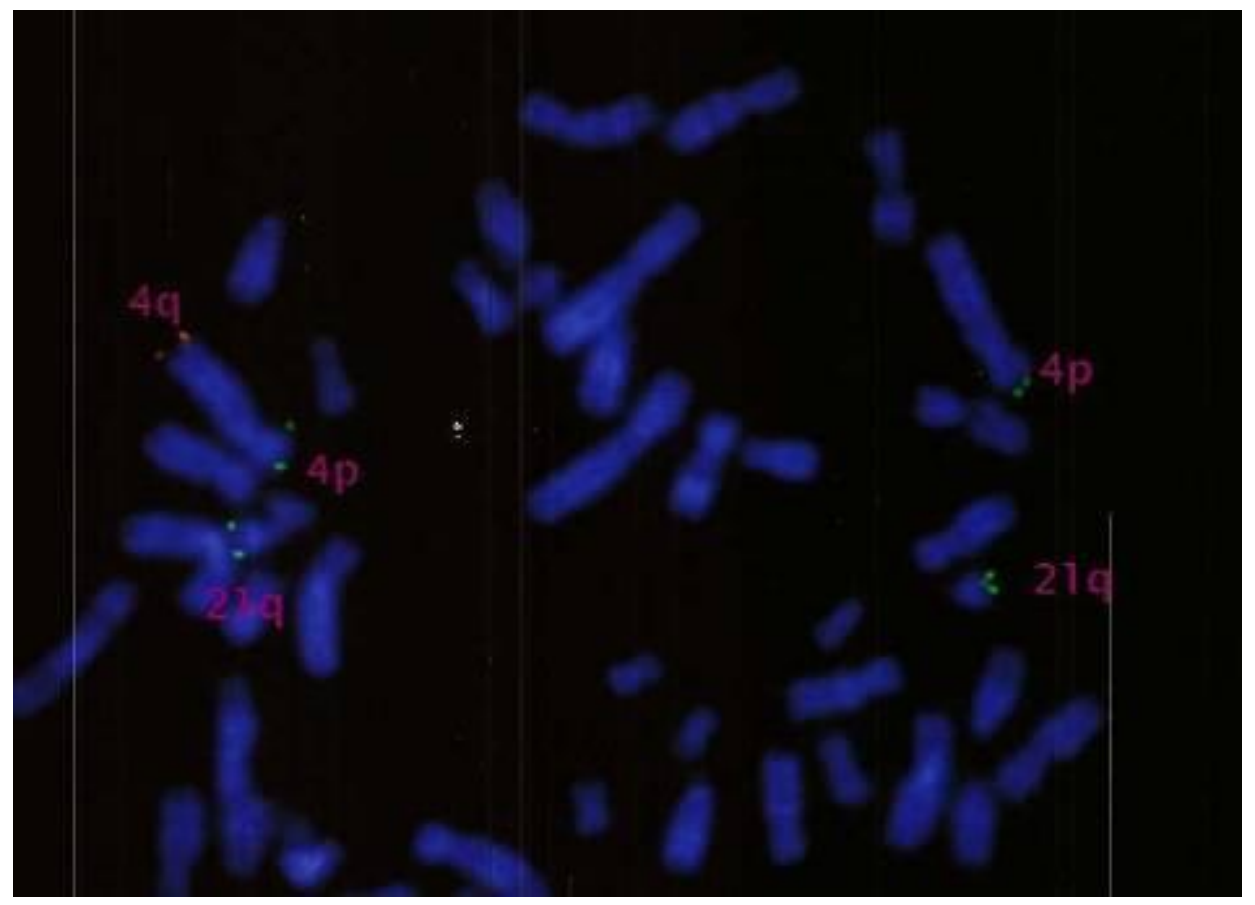

Figure 9. One $4 \mathrm{q}$ probe signal (red) is absent indicating a deletion of $4 \mathrm{q}$. 


\section{Patient 3 - 46,XX.ish del(5)(p15.3)(C84C11-)pat}

Patient 3 was born 10 days late by C-section secondary to poor progression and decreased heart rate. She weighed 8 pounds 3 ounces at birth. She was a poor eater who choked easily. Her language was delayed and she was late-developing in every area. She did not maintain eye contact and did not tolerate loud noises. She was referred for genetic evaluation after an initial diagnosis of autism. At 33 months she communicated on a level of less than a 12 month old. Her social and emotional skills were determined to be at less than 12 months. Her gross motor skills were at 24 to 36 months and her fine motor skills were at 12 to 18 months. Subtelomere FISH revealed a terminal deletion of the short arm of chromosome 5 (Fig. 10) that was inherited from her father. Some members of her mother's family had required special education and another was diagnosed with bipolar disorder. The father was slow, had been enrolled in special education, had scoliosis, microcephaly and a heart murmur. The paternal grandmother reported that the father cried like a cat in infancy. The paternal aunt and grandfather had learning disabilities. 


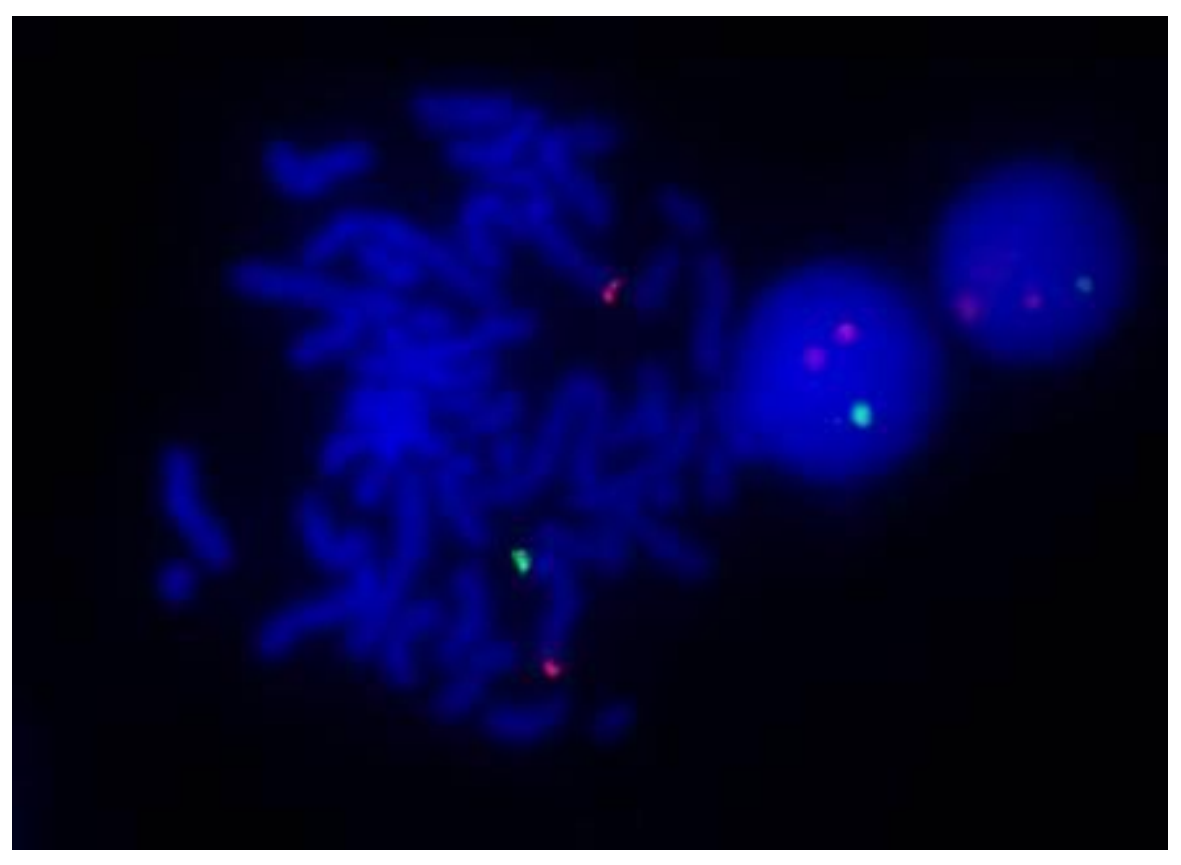

Figure 10. One 5p probe signal (green) is absent indicating a deletion of $5 p$.

\section{Patient 4 - del(5)(q35)(GS3508/T,5QTEL703-)}

Patient 4 was adopted at 6 months of age, sat at 9 months, walked at 14 mo, and was toilet trained at $2.5 \mathrm{yr}$ of age. At $3.5 \mathrm{yrs}$ he weighed $32.7 \mathrm{lb}$ (50th percentile), his height was 40.5" (50th percentile) and head circumference was $50 \mathrm{~cm}$. He had a phenotype and developmental problems of fetal alcohol syndrome. He was knock-kneed and had trigonocephaly. He had behavior problems and was hyperactive. Subtelomere FISH revealed a deletion of 5q35 (Fig. 11). Family history was not available. 


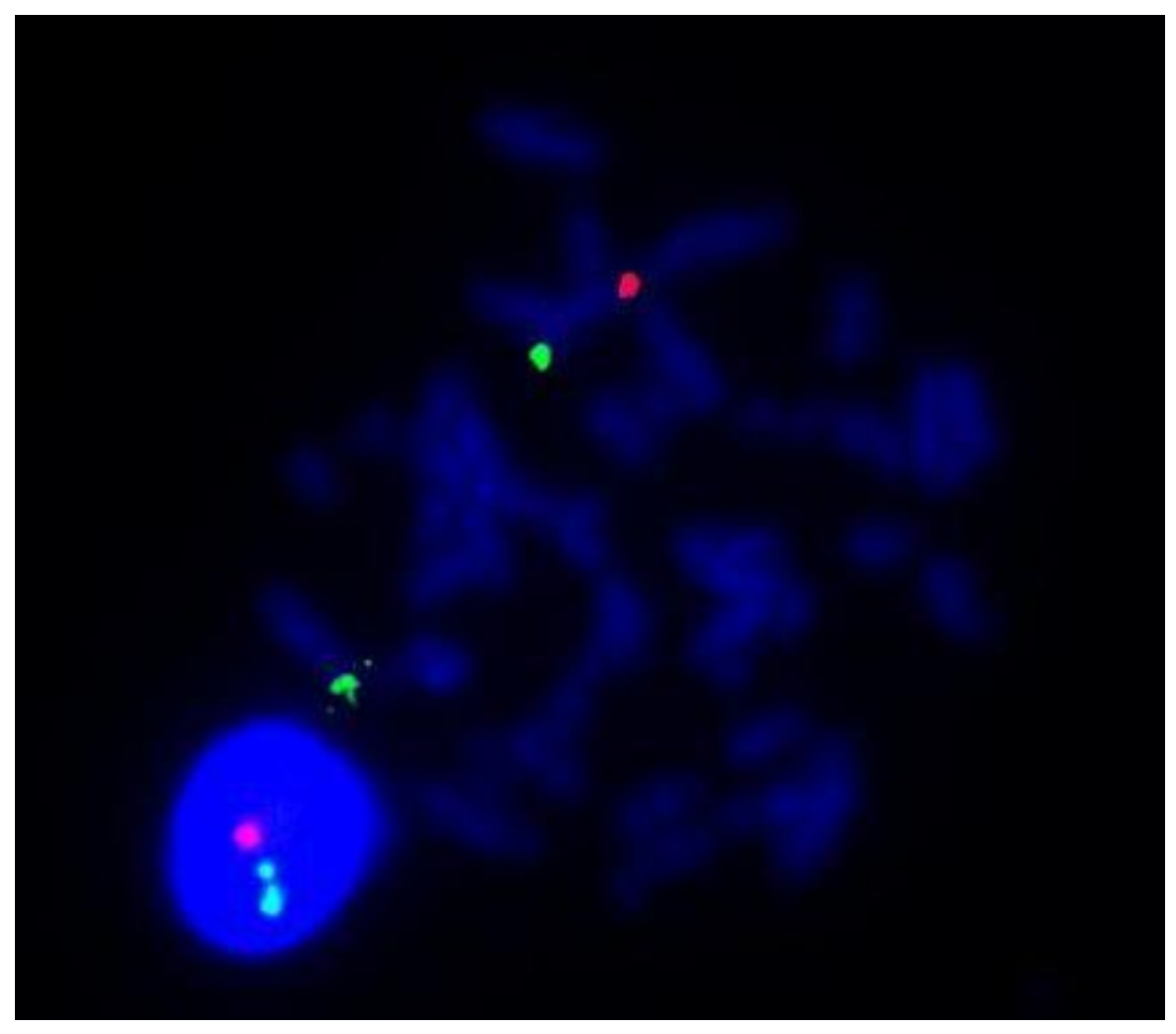

Figure 11. One 5q probe signal (red) is absent indicating a deletion of 5q.

\section{Patient 5 - del(15)(q22)(PML dim)}

Patient 5 was delivered by C-section with a birthweight of $9 \mathrm{lb} 1 \mathrm{oz}$, and length of 21 inches. He had a repair of cleft lip/palate at $1 \mathrm{yr}$ of age. He also had recurrent ear infections and the mother did not think he was significantly delayed until kindergarten. In the 5th grade he was achieving at 3rd grade level. IQ testing showed mild MR. At 12 1/5 years of age his weight was 90th percentile, height 75 th percentile, head circumference 95 th percentile. He has synophrys with a heavy brow, mild ptosis, broad nasal bridge and slightly tapered fingers. Subtelomere FISH revealed a diminished signal of $15 \mathrm{q} 22$ indicating a deletion (Fig. 12). Family history includes mother's second child died at $11 \mathrm{hrs}$ of life from probable heart defect. Father has 
siblings with significant intellectual impairment and a nephew with cleft lip and palate. The mother had normal size signals, but the father was not tested.

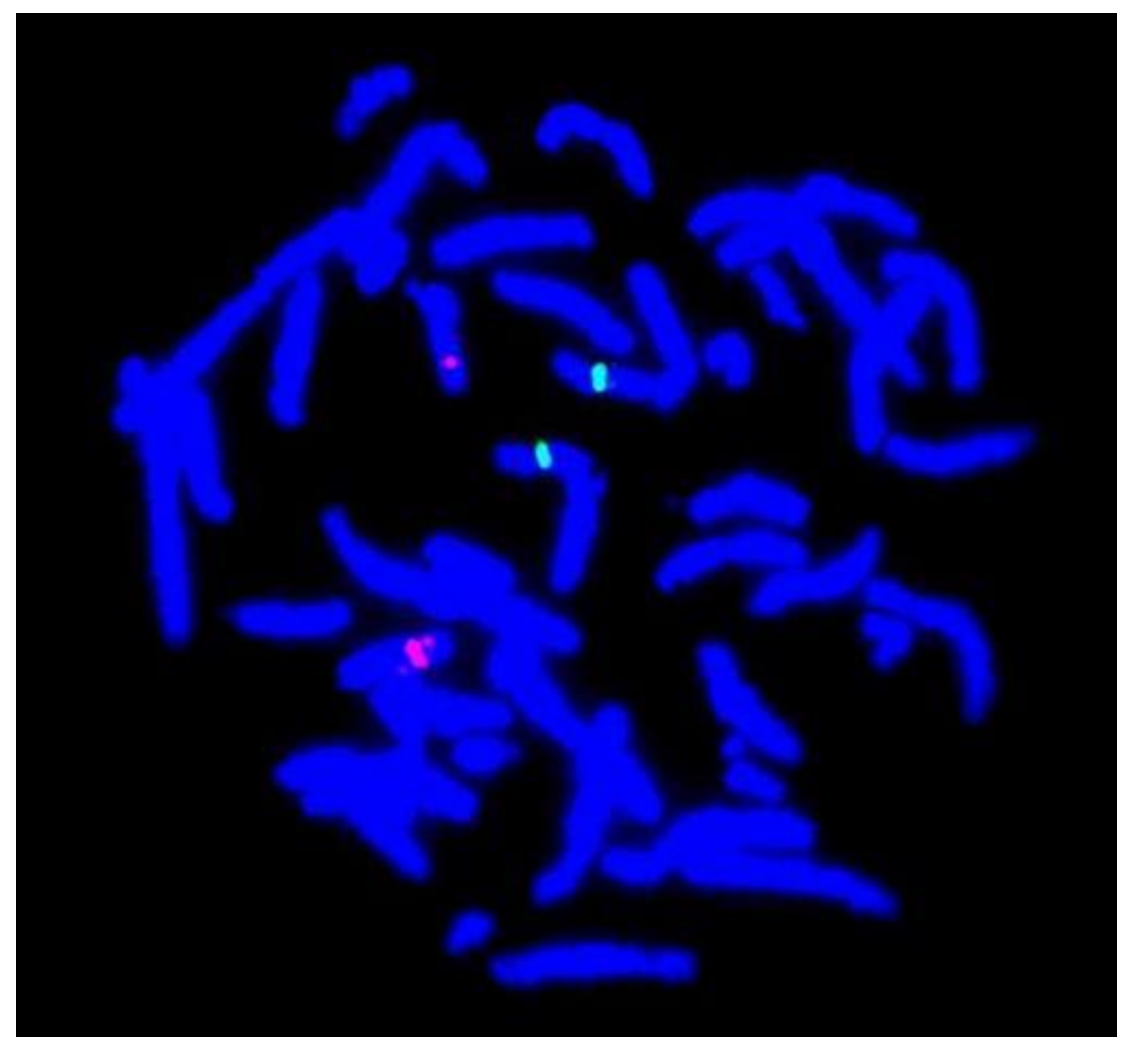

Figure 12. One 15q probe signal (red) is diminished indicating a deletion of $5 \mathrm{q} 22$. 


\section{SUBTELOMERIC DERIVATIVE REARRANGEMENTS}

Patient 6 - 46,XX.ish der(4)t(4;8)(p16;p23)(GS10K2-,D8S504+)dn

Patient 4 was born full term with a weight of 4 pounds, a length of 16.25 inches, and a head circumference of 29 inches. At 2 weeks of age, all of her measurements were below the 5 th percentile. She was diagnosed with intrauterine growth retardation, cleft lip, cleft palate, a dysplastic iris, a flat nasal bridge, simple ears, heart defects, and a depressed chin. She had bilateral clinodactyly and was hypertonic. Subtelomere FISH revealed a de novo rearrangement between $4 p$ and $8 p$, resulting in loss of $4 p$ subtelomeric region and duplication of $8 p$ subtelomeric region (Fig. 13 and Fig. 14). No family history was available. 


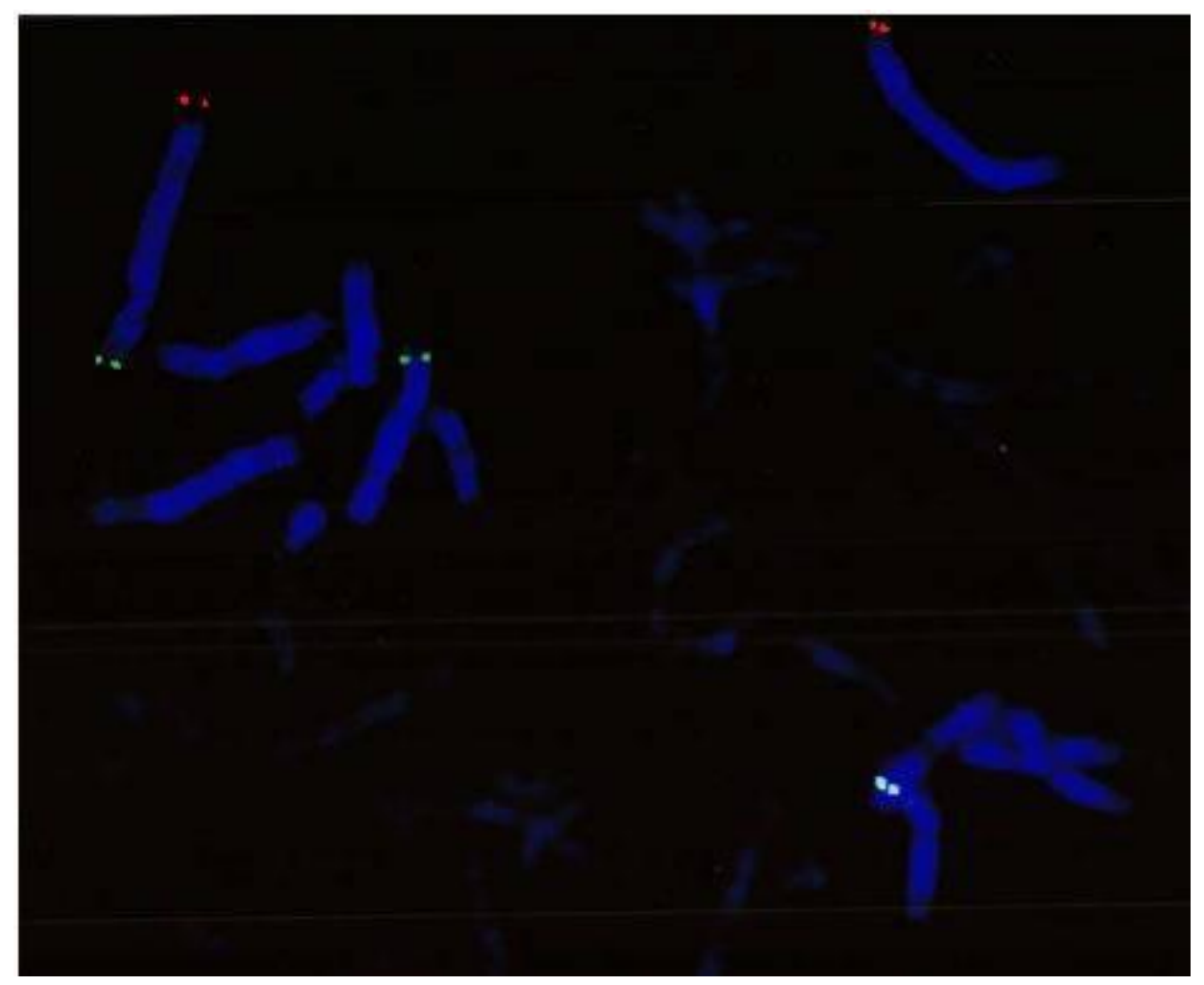

Figure 13. One $4 p$ probe signal is absent indicating a deletion of $4 \mathrm{q}$.

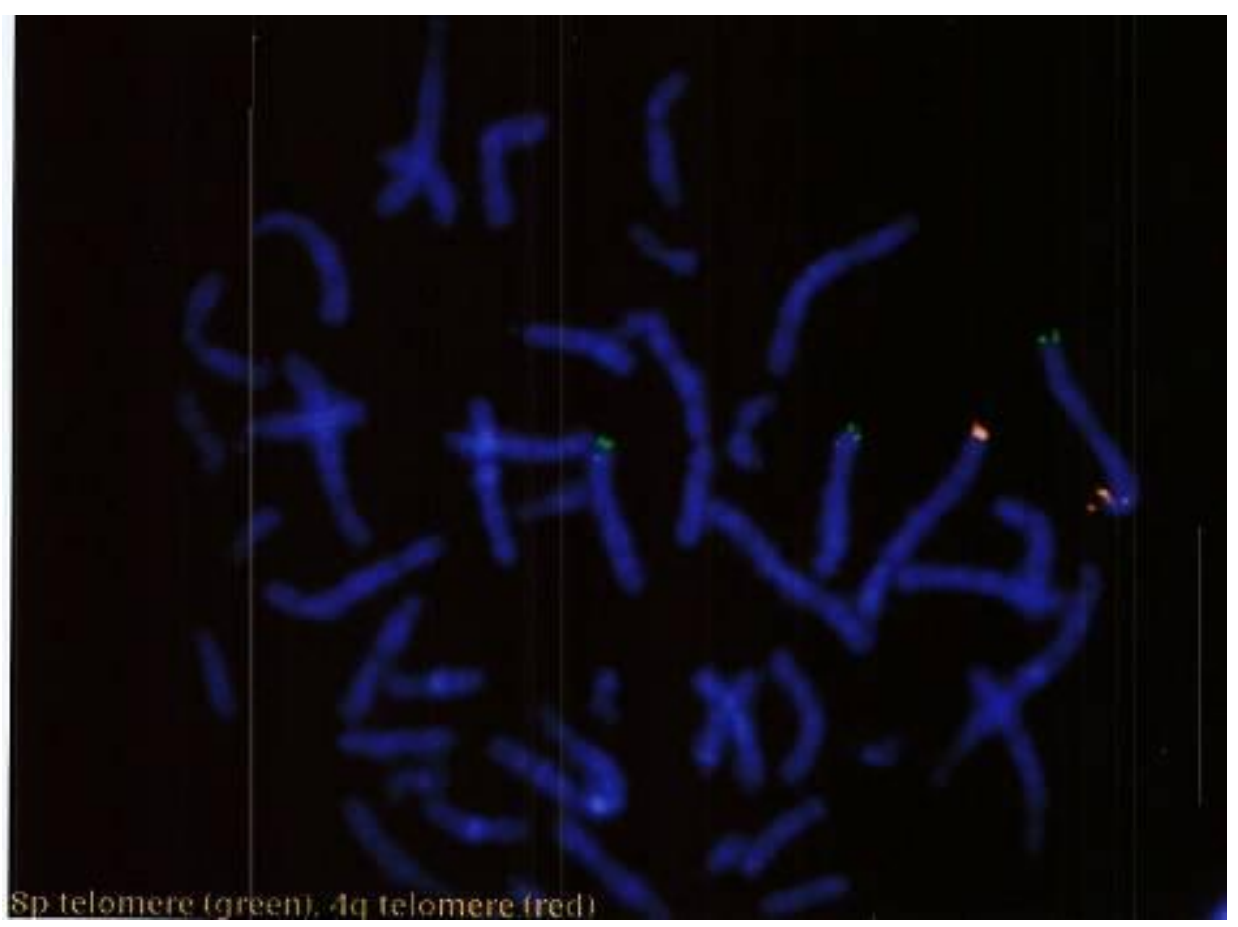

Figure 14. There are 3 probe signals for $4 q$ indicating a duplication of $4 q$. 
Patient 7 - 46,XY.ish der(9)t(9;10)(p24;p15)(305J7-,Z96139+)pat

Patient 5 was a 1-year-old male presenting with seizures, developmental delays, decreased reflexes, and hypotonia. He was unable to walk or crawl. He was below the 3rd percentile for length and was slow to gain weight. He had a heart murmur and abnormal eye movements with his left eye deviating inward. Subtelomere FISH showed a derivative chromosome 9 that was inherited from his father who was found to have balanced translocation, resulting in deletion of $9 \mathrm{p}$ subtelomeric region and duplication of $10 \mathrm{p}$ subtelomeric region (Fig. 15 and Fig. 16). The patient had a brother in good health. 


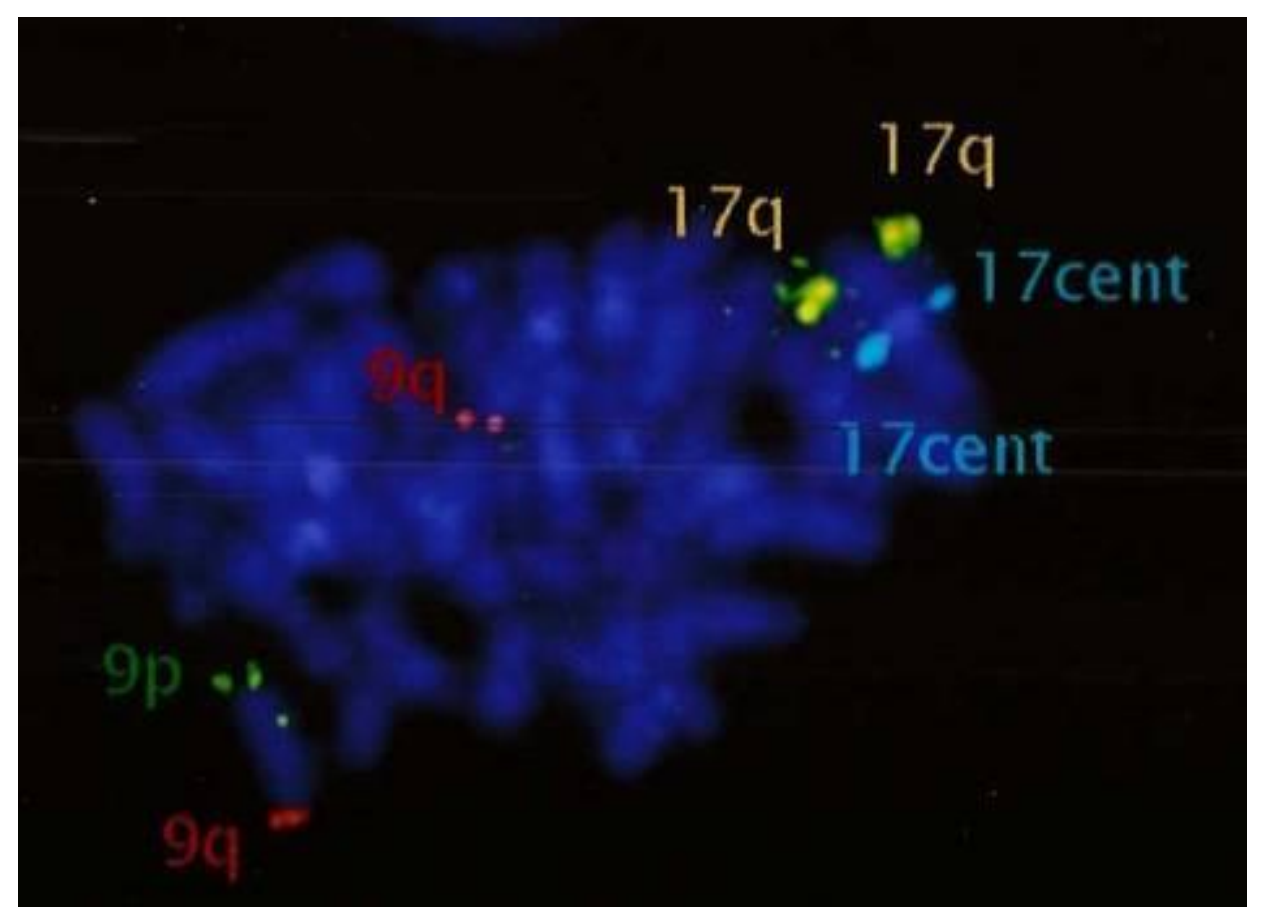

Figure 15. One $9 p$ probe signal is absent indicating a deletion of $9 p$.

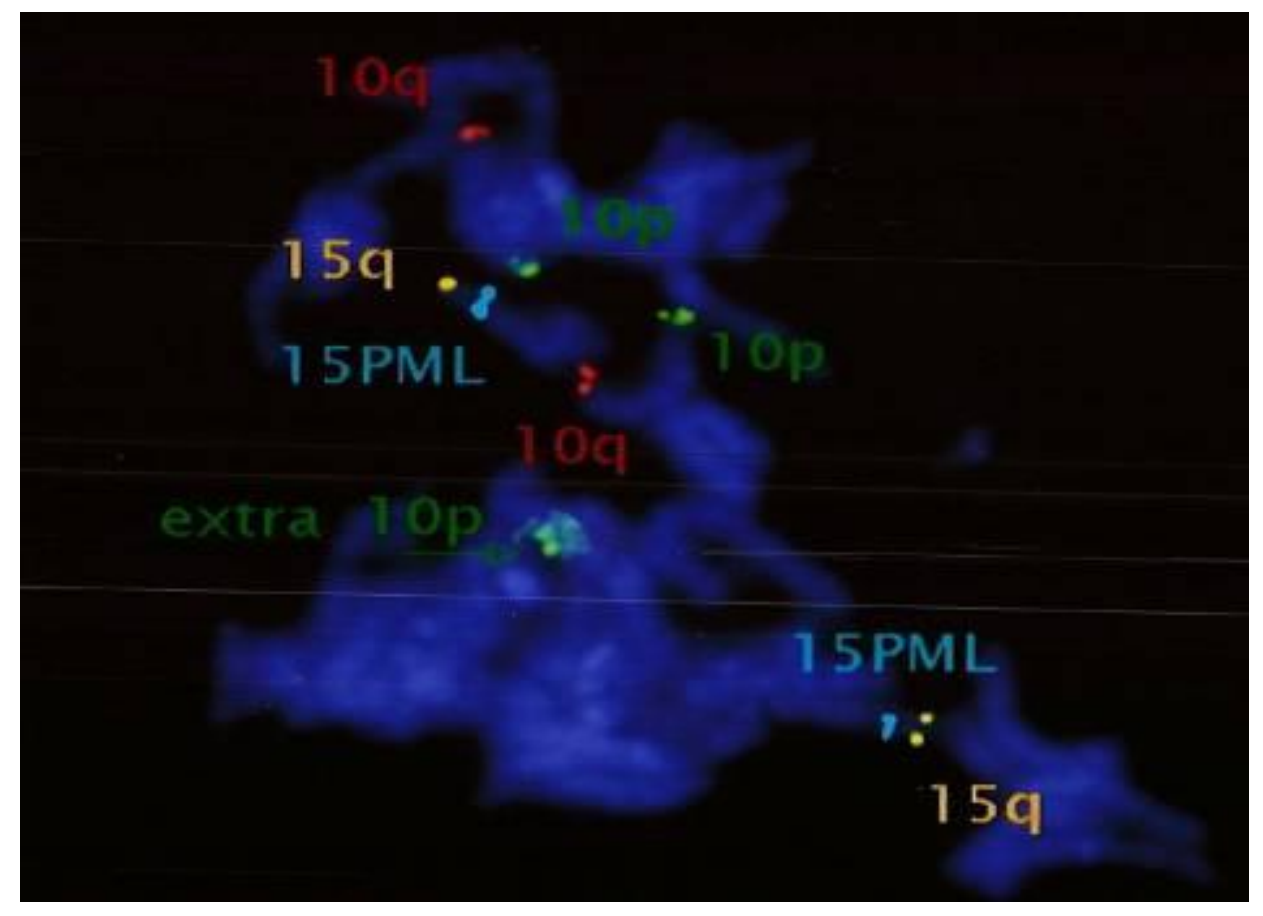

Figure 16. There are 3 probe signals for 10p indicating a duplication of 10p. 
Patient 8 - 46,XY.ish der(12)t(7;12)(q36;p13)(7QTEL203-,8M16+)

Patient 6 was born at full term with a birth weight of 7 pounds 8 ounces. He had delayed speech and did not walk until 2.5 years. He was toilet trained at 5 years of age. At 6 years of age he was autistic, had a mild Dandy-Walker variant malformation of the brain, and was microcephalic. All of his measurements were below the 5th percentile. He was hirsute and his speech was echolalic. He had a sebaceous adenoma of the left parietal area, a low anterior and posterior hairline, and slightly low set ears. He had difficulty with fine motor skills. He was polite and liked to help when he could. He engaged in self stimulating behaviors, did not make eye contact, and disliked loud sounds. He was seen by a speech language pathologist, but did not respond well. He was delayed socially and emotionally. Telomere FISH revealed a derivative 12 chromosome with deletion of $12 p$ subtelomeric region and duplication of $7 q$ subtelomeric region (Fig. 17 and Fig. 18). His mother has social anxiety problems, obsessive-compulsive disorder, and sociopathic tendencies. The father has several nieces with unknown mental impairments. His parents declined karyotyping. 


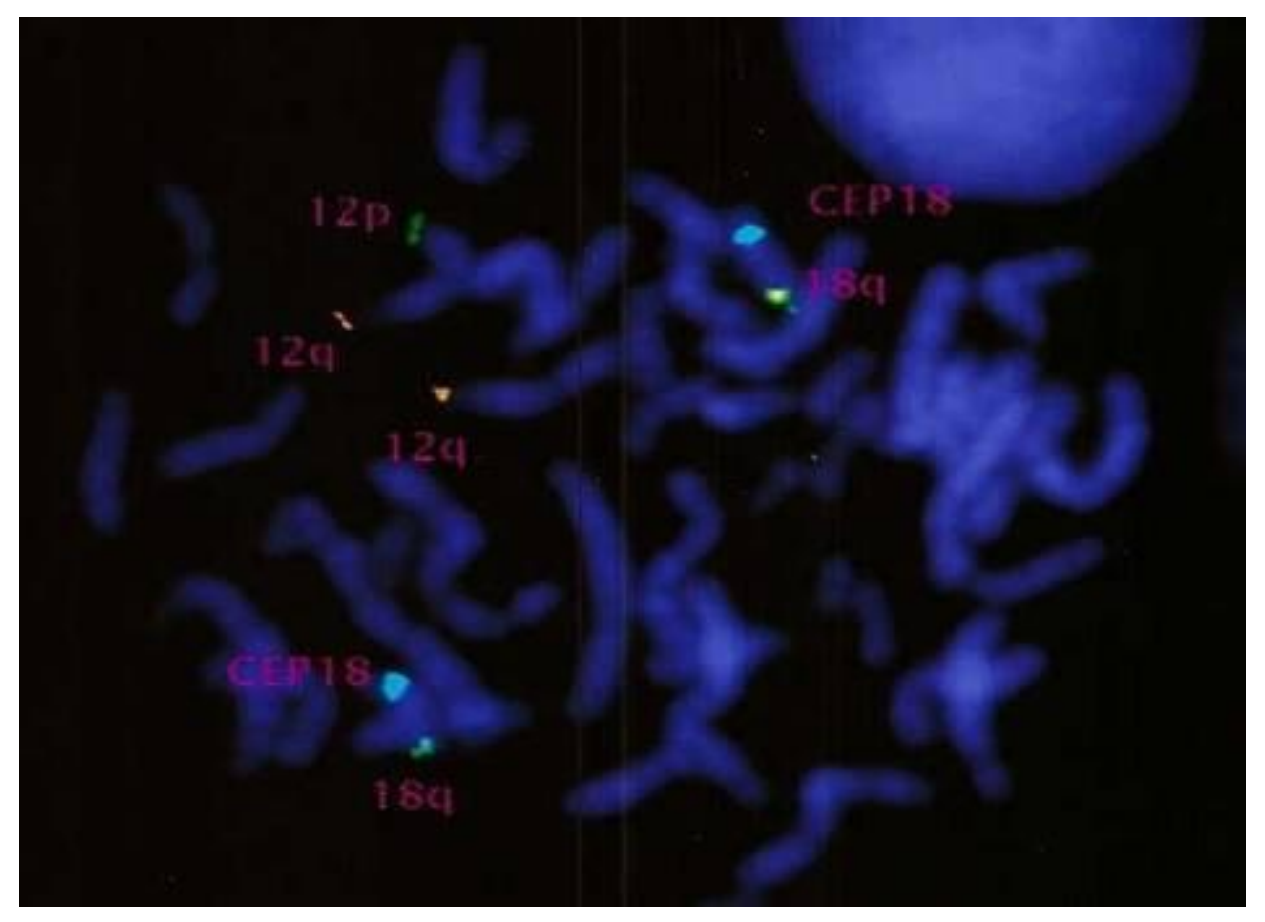

Figure 17. One $12 \mathrm{p}$ probe signal is absent indicating a deletion of $12 \mathrm{p}$.

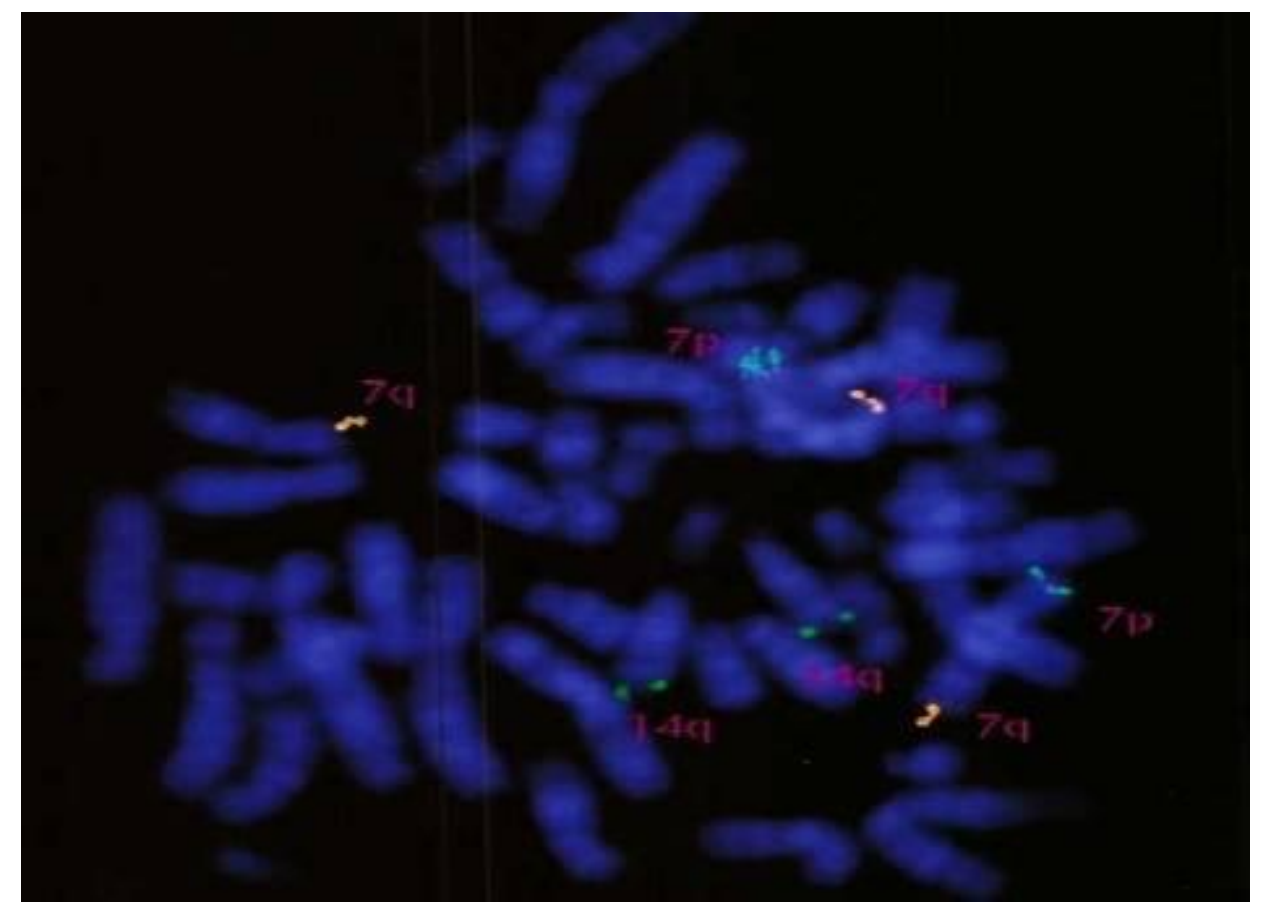

Figure 18. There are 3 probe signals for chromosome $7 q$ indicating a duplication of $7 q$. 
Patient 9 - 46,XY.ish der(15)t(15;18)(q26;q23)(D15S936-,D18S1390+)mat

Patient 7 was born after 38 weeks gestation from an uncomplicated pregnancy. At birth, his weight was 4 pounds and 10 ounces and his length was 17 1/2 inches. He first crawled and spoke at 1 year of age, but quit speaking soon thereafter. He was referred for genetics evaluation at 13 months of age for a receding chin, short stature, bicuspid valve problems, hypertonia, single palmar creases, and $5^{\text {th }}$ digit camptodactyly. His mother had a history of miscarriages. He had one half-sibling who had an 18q deletion. FISH results showed a derivative chromosome 15 with deletion of $15 q$ subtelomeric region and duplication of $18 \mathrm{q}$ subtelomeric region (Fig. 19 and Fig. 20). The derivative 15 was inherited from his mother, who had a balanced translocation. 
PML

-

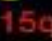

$10 p$

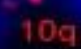

Figure 19. One $15 q$ probe signal is absent, indicating a deletion at $15 q$

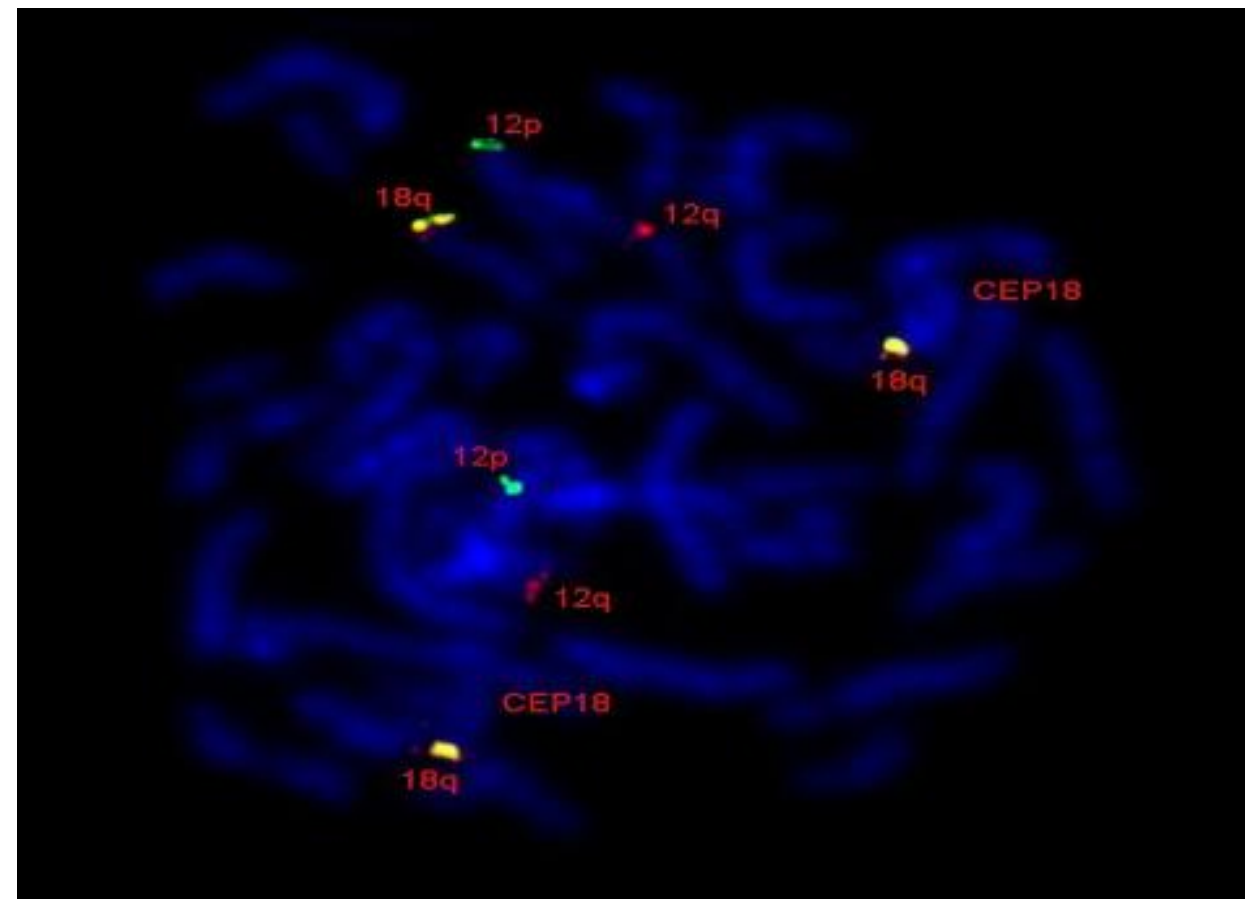

Figure 20. There are 3 probe signals for chromosome $18 \mathrm{q}$ indicating duplication of $18 \mathrm{q}$. 


\section{POLYMORPHISMS}

Polymorphisms are ruled out by testing the same sample with another FISH probe which has a different sequence arrangement and binding specificities. A rearrangement/deletion can be ruled a polymorphism if one probe identifies it as abnormal and it is not confirmed abnormal with a second probe, or a parent with a normal phenotype has the same abnormality identified by FISH.

Two polymorphisms were detected. One of the polymorphisms was a 4q deletion (Fig. 21), which has previously been reported (Ravnan et al., 2006), while the other was an additional 16q subtelomere signal on 18p (Fig. 22), shown to have a normal signal pattern using Cytocell probe for $16 \mathrm{q}$.

Figure 21. One $4 q$ signal is absent indicating a deletion of $4 q$. Upon testing with a second probe this was found to be a polymorphism. 


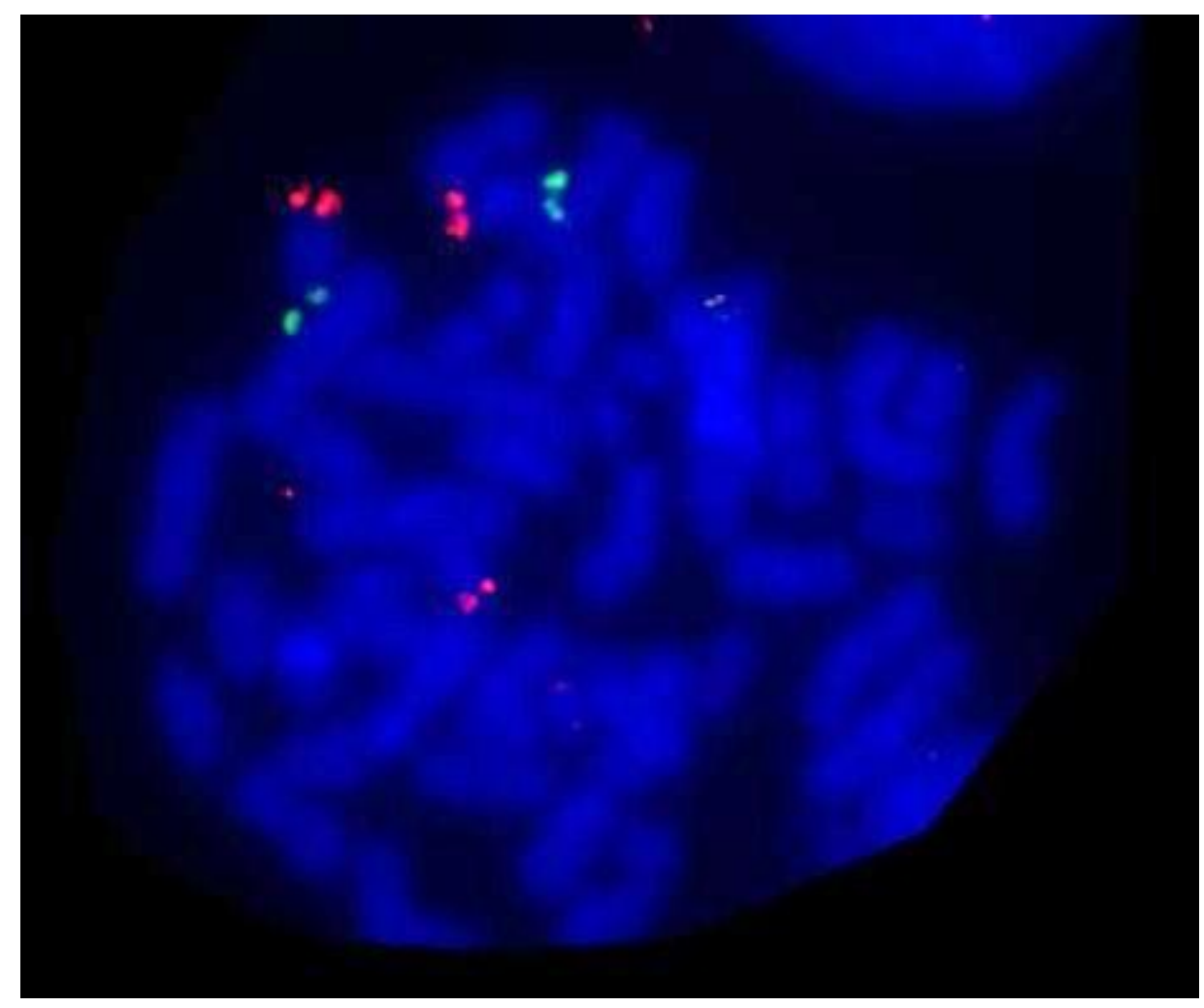

Figure 22. There are three 16q signals (red) indicating a duplication of $16 \mathrm{q}$ on to chromosome 18. Upon testing with a second probe this was found to be a polymorphism. 


\section{DISCUSSION}

In 2005 the American College of Medical Genetics published guidelines for the cytogenetic evaluation of individuals with DD or MR. They recommended that if no chromosome abnormality is found at the 550 band level, subtelomere FISH was appropriate (Shaffer, 2005). Following identification of deletion and/or duplication, standard procedure is to confirm deletions or duplications with an alternative probe from another manufacturer and request parental blood to rule out inheritance of a polymorphism. The detection rate of abnormalities associated with polymorphisms in this study population was $0.78 \%$, which is similar to the $0.5 \%$ for all types of polymorphic variants identified in a large study (Ravnan et al., 2006).

Previous reports in the literature have shown that $3-10 \%$ of individuals with idiopathic MR and a normal karyotype had subtelomere rearrangements (Knight et al., 1999; Anderlid et al., 2002; Bocian et al., 2004). In the largest published study, deletion or deletion/duplication was identified in $2.5 \%$ of the evaluated population. These results fall on the lower end of the reported range, suggesting that the criteria for choosing patients were not strict (Ravnan et al., 2006).

For this population, results showed more than half of subtelomere deletions and rearrangements were transmitted by a parent ( 4 out of 5 with parental testing), which is consistent with what has been reported in the literature (Knight et al., 1999; Adeyinka et al., 2005; Ravnan et al., 2006).

Inheritance of subtelomere deletions may be more common than previously recognized. Few reports have indicated deletions inherited by an affected parent. Adeyinka et al, identified 
reported that among 28 patients with deletions, 9 (32\%) had an inherited deletion, whereas 19 (68\%) were de novo. Recently, three more instances of inherited subtelomere deletions have been reported, involving 5p and 6q (Samanich et al., 2008; Dalton et al., 2008, Fang et al., 2008). This further emphasizes the importance of testing parents and knowing their phenotype to rule out polymorphisms or to provide counseling for recurrence risk.

In this study, two of the terminal deletions were inherited from parents who had an abnormal phenotype. The use of FISH to identify cryptic chromosome rearrangements and deletions has been very successful. However, like all assays, FISH has its limitations (KaiserRogers et al., 2000). FISH requires an initial knowledge of what genetic disorder is suspected. For example, if a patient presents with the classic phenotype of Angelman syndrome, a probe for $15 q 11.2$ can be used to confirm the diagnosis. However, a large number of individuals do not fit within a categorically recognizable phenotype. To detect the possible genetic cause of an unrecognized phenotype resulting from a chromosome disorder, a better screening tool is required.

Based on its recent successes, aCGH (array comparative genomic hybridization) will likely replace FISH for screening in prenatal and pediatric genetic diagnostics. Subtelomere FISH is currently rarely requested. For example, aCGH has been successful in detection of disorders in as little as one $\mathrm{ml}$ of amniotic fluid and does not need cultured cells (Rickman et al., 2006). Numerous studies have used aCGH to identify microdeletions for targeted areas of the genome (Harada et al., 2004; Tyson et al., 2004; 2005; Iqbal et al., 2005; Ballif et al., 2006; BarShira et al., 2006; Kitsiou-Tzeli et al., 2007) or whole genome screening (Veltman et al., 2002; de Vries et al., 2005; Bauters et al., 2005; Le Caignec et al., 2005; Schoumans et al., 2005; Lugtenberg et al., 2006; Rosenberg et al., 2006). Many others have shown that interstitial 
deletions and expanded subtelomere resolution are clinically diagnostic (Kirchoff et al., 2004; Friedman et al., 2006; (Krepischi-Santos et al., 2006; Ballif et al., 2007). Recent American College of Medical Genetics guidelines (Manning and Hudgins, 2007) suggest that aCGH be used as an adjunct for screening patients who have MR or multiple congenital abnormalities. 


\section{CONCLUSIONS}

In conclusion, nine out of 256 (3.5\%) patients had abnormal subtelomere FISH studies, in which five were deletions and four were deletion/duplications. In addition, two polymorphisms $(0.78 \%)$ were identified. Parents for two of the five patients with deletions were tested and found to have the same deletion as their child (patients 2 and 3), and a similar abnormal phenotype. Two of four individuals inherited their derivative rearrangement/deletion from a parent who was a balanced carrier (patients 7 and 9). These results emphasize the importance of parental testing as well as contact with the clinician in order to interpret the deletion as a polymorphism or inherited through an affected parent, the latter which may be more common than previously thought. 


\section{FUTURE STUDY AND LIMITATIONS}

It would have been beneficial to have more family history and FISH results from the parents of patients $1,4,5$ and 8 , none of which had complete immediate family information. This would have given better data for the inheritance of rearrangements. Performing aCGH on individuals, including immediate family members would have the potential to reveal additional information about the size of the deletions and duplications detected. 


\section{CHAPTER FOUR}

\section{TELOMERE LENGTH STUDIES OF INDIVIDUAL HUMAN CHROMOSOME ARMS}

\section{INTRODUCTION}

The human telomere is a highly repetitive GC rich protective structure located at the terminal regions of the chromosomes. The telomere "caps" the ends of chromosomes to prevent end-to-end fusions, which could result in whole chromosome and segmental aneuploidy. The inverse relationship between overall telomere length and its role in ageing and premature ageing diseases has been well documented (Shay and Wright, 2001; 2007). However, only a few studies have examined the length of telomeres for individual chromosome arms in humans.

Lansdorp and colleagues (Lansdorp et al., 1996) had found that the telomere length for sister chromatids was similar in cells from different tissues; however, the distribution of telomere length between chromosomes was not random. Martens and colleagues (Martens et al., 1998) found that there was a significant difference between the telomere length of individual chromosome arms, with a weak positive correlation between the length of chromosome arms and the corresponding telomeres. Graakjaer and colleagues (Graakjaer et al., 2003; 2004; 2006a; 2006b) had found that human telomere length correlated well with chromosome length but did not have as strong a correlation with individual chromosome arm size.

Telomere length has been quantified by several methods including direct sequencing, Southern blot based methods, flow cytometry, three-dimensional confocal microscopy, and 
Quantitative FISH (Q-FISH) (Figs. 23 and 24) (Hultdin et al., 1998; Uhlmann et al., 2000; Slijepcevic, 2001; Baerlocher et al., 2002; Perner et al., 2003). Q-FISH uses Peptide Nucleic Acid (PNA) probes to bind to the telomere repeat. A PNA probe consists of a peptide sequence that can bind to specific DNA sequences much like a DNA binding domain within a DNA binding protein.

The advantages of a PNA probe are having a shorter hybridization time due to absence of a charge and being less prone to nonspecific binding. The PNA probe is coupled with a fluorescent dye and works much the same way as a DNA FISH assay. Theoretically, PNA FISH has a resolution of $300 \mathrm{bp}$ (Aubert and Lansdorp, 2008). However, like most assays the accuracy of the measurements depends on quality of the chromosome preparation and the condition of the instrumentation collecting the images.

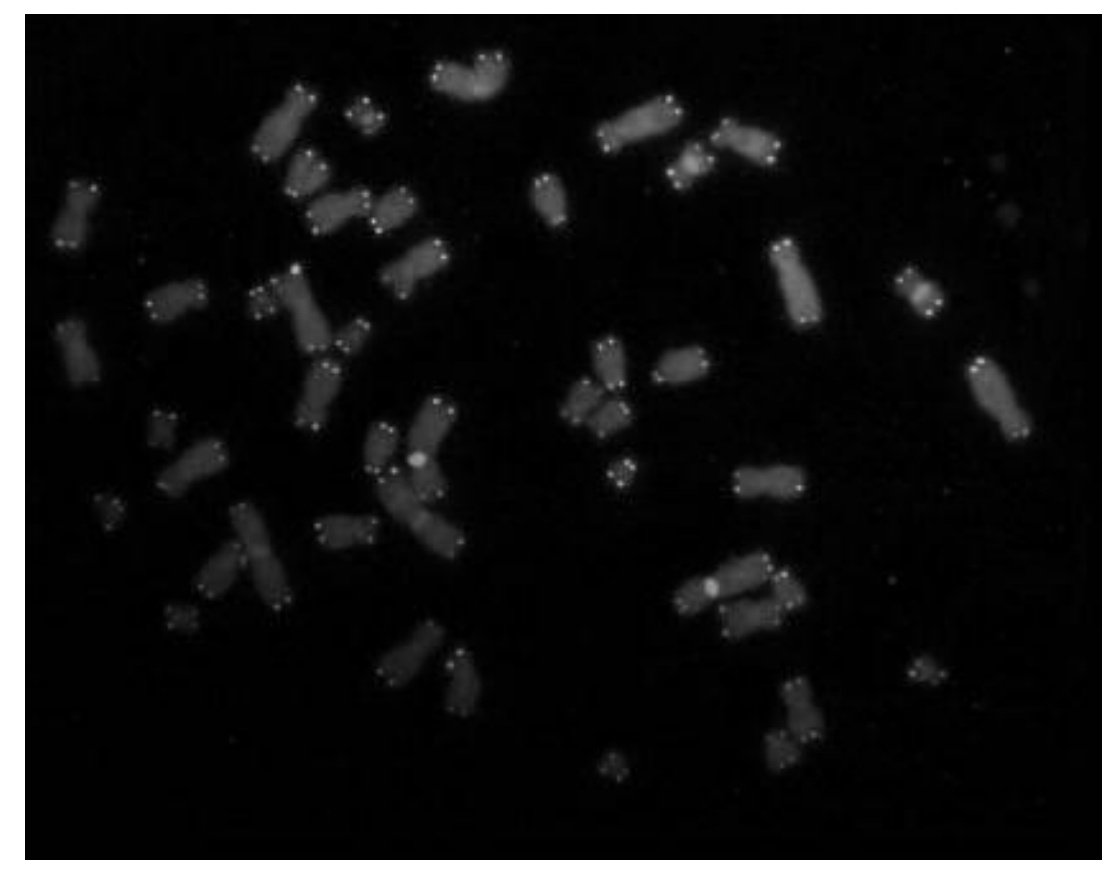

Figure 23. Grayscale image of a hybridized metaphase spread showing Q-FISH probe fluorescence at each telomere and the centromere reference probe on chromosome 2. 

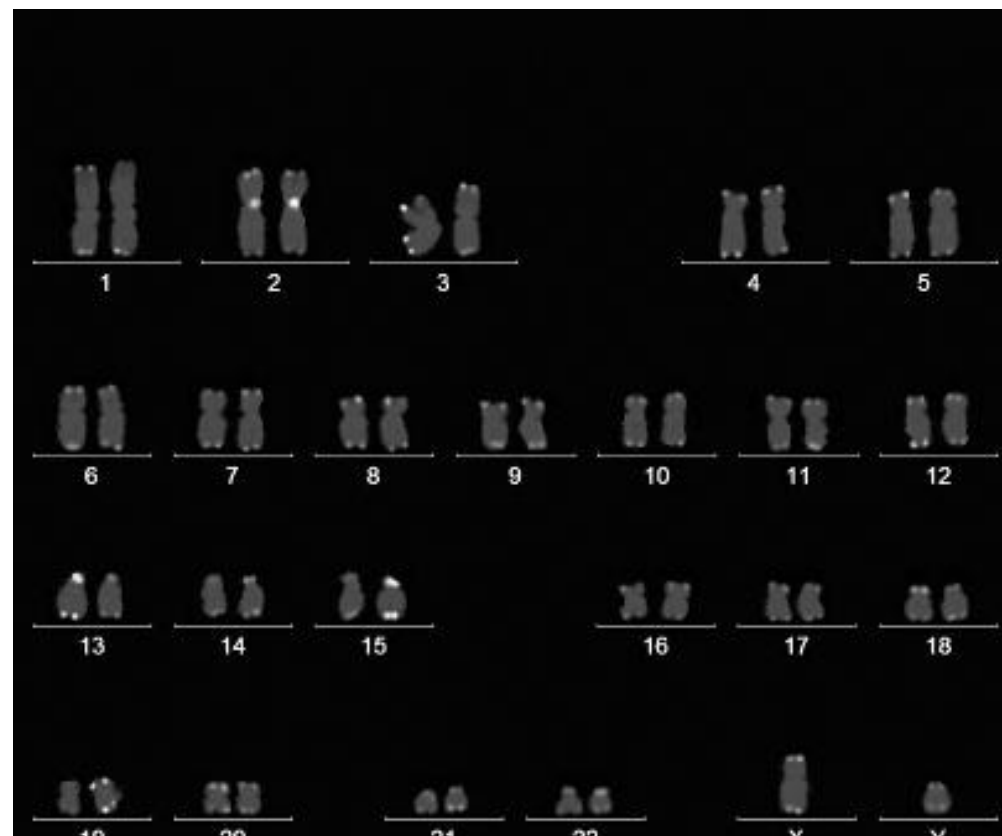

$$
\frac{\mathrm{a}}{21} \frac{\mathrm{A0}}{22}
$$
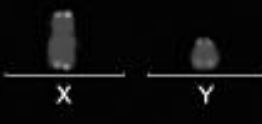

Figure 24. Karyogram of telomere PNA probe hybridized image with signals at each telomere and the reference probe for centromere 2 . 


\section{OBJECTIVES}

The purpose of this study was to examine telomere length of individual chromosome arms in metaphase cells from cultured lymphocytes of 17 individuals using quantitative fluorescent in situ hybridization (Q-FISH) and to make comparisons to the physical length of the chromosome arm. Previous studies have shown correlations to chromosome arm size, however none have fully investigated these relationships in any great detail. Q-FISH for telomere length was performed using peptide nucleic acid (PNA) probes which are highly specific and provide a high resolution (Slijepcevic, 2001) allowing for quantitative measurement of telomeres by digitally measuring the intensity of probe signals on metaphase chromosomes against a reference

probe. Rather than relying on the photographic size by measurement of each chromosome arm in photographs, the length of each chromosome arm in $\mathrm{Mb}$ was obtained from the National Center for Biotechnology Information (NCBI) map viewer website. 


\section{MATERIALS AND METHODS}

Subjects for this study were drawn from the Center for Oral Health Research in Appalachia (COHRA; Polk et al., 2008), an ongoing cross-sectional oral health etiology study. COHRA ascertains families from two central West Virginia counties and two western Pennsylvania counties and performs a detailed assessment protocol after an informed consent process approved by the IRBs of the University of Pittsburgh and West Virginia University.

Seventeen COHRA subjects were included in the study: 8 male and 9 female, with ages ranging from 2 to 45 years of age, average age 18.9 years (median 15 years). Telomere lengths were measured in a total of 76 metaphase cells from 17 individuals giving a total of 152 individual measurements for each chromosome arm (with the exception of the $\mathrm{X}(\mathrm{n}=120)$ and $\mathrm{Y}$ $(\mathrm{n}=32)$ chromosomes). No consideration was given for relationship.

Peripheral blood lymphocytes were processed using standard cytogenetic techniques (described in Chapter 1). Cells were dropped onto slides, which were then immersed for: 2 min. in Tris Buffered Saline (TBS), 2 min. in 3.7\% formaldehyde in 1X TBS, 10 min. in TBS, 10 min. in Pre-Treatment solution (DAKO, Glostrup, Denmark) and 10 min. in TBS. The slides were immersed through a series of ethanol washes of $70 \%, 85 \%$, and $100 \%$ for 1 min. each and then allowed to air dry at room temperature.

Hybridization protocol was followed as provided by the manufacturer (DAKO). Ten $\mu$ of FITC PNA telomere probe mix (DAKO) and FITC PNA chromosome 2 centromere probe (courtesy of DAKO) was added to prepared slides, coverslipped and sealed with tape. The probe and chromosome preparation were codenatured for $5 \mathrm{~min}$. at $80^{\circ} \mathrm{C}$ and placed in the dark at room temperature for $30 \mathrm{~min}$. Slides were immersed in the supplied rinse solution (DAKO) for 1 
min. to remove coverslips. The slides were washed in the supplied wash solution for $5 \mathrm{~min}$. at $65^{\circ} \mathrm{C}$. The slides were then dehydrated by immersion through a series of ethanol washes of $70 \%$, $85 \%$, and $100 \%$ for $1 \mathrm{~min}$. each and allowed to air dry at room temperature. Twenty $\mu 1$ of $1 \mathrm{X}$ DAPI counterstain (In Situs, Albuquerque, NM) was applied to the dried slides and coverslipped (20 mm X $50 \mathrm{~mm})$.

Metaphases were photographed using ISIS (MetaSystems, Altlussheim, Germany) software on a Leica epi-fluorescent microscope equipped with a DAPI single bandpass, and a FITC single bandpass filter. The images were then background corrected, and the color channels were placed in inverted grayscale mode, approximating a G-banding pattern to allow for easier karyotyping.

The telomere measurement software package from MetaSystems was used to quantify telomere length on the $\mathrm{p}$ and $\mathrm{q}$ arms of each chromosome relative to the reference signal on chromosome 2. Measurements were reported as arbitrary units of Relative Telomere Length Units (RTLU), which is the ratio of telomere signal intensity to the centromere 2 reference signal. The size of each chromosome arm (measured in $\mathrm{Mb}$ ) was estimated from data provided online from the National Center for Biotechnology Information (NCBI) Map Viewer (NCBI, 2008).

Relative telomere length measurements were plotted against the size of the corresponding chromosome arm. Regression analysis was performed and correlation coefficients were calculated. P values were obtained from the regression analysis. 


\section{RESULTS}

\section{TELOMERE LENGTH AND AgE OF SuBJECTS}

The total telomere length from 17 individuals was measured and averaged. Fig 25 shows average telomere length plotted against the age of the individual in years. The regression line shows a trend in reduction of average telomere length with age, however these results were not statistically significant.

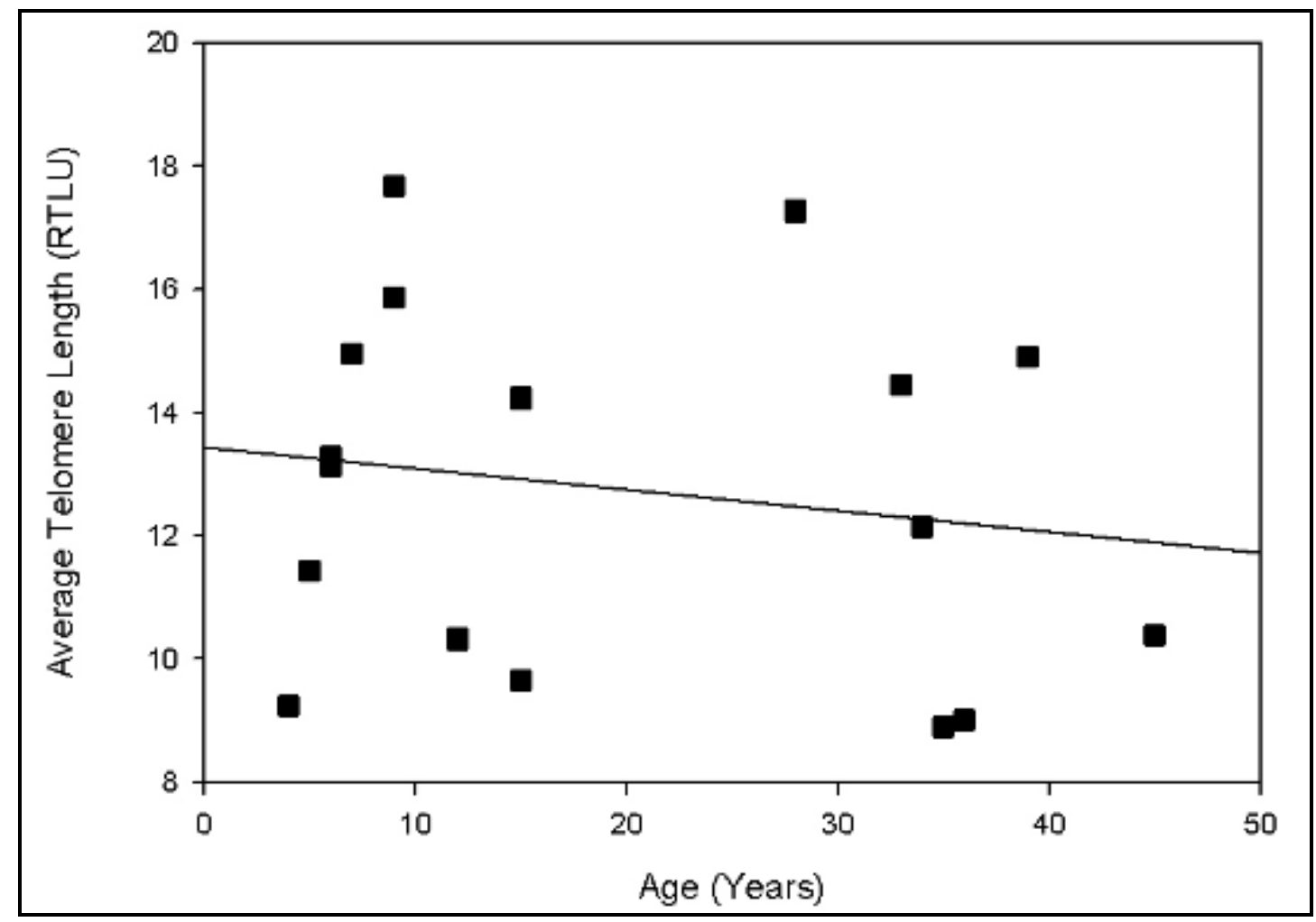

Figure 25. Telomere length and age. Overall telomere length is plotted against age showing the trendline of age and telomere length. 


\section{TElomere LengTH AND CHROMOSOME ARM SIZE}

Chromosome arm length in $\mathrm{Mb}$ was compared to telomere length (RTLU) for each chromosome arm for each individual in this study to see if a consistent pattern was observed from individual to individual (Table 6). Direct correlation was found for all individuals; statistically significant correlations were seen in 11 of $17(65 \%)$. Three of the remaining 6 were close to the 0.05 cutoff for significance.

Due to consistency of the relationship between lengths for telomeres and chromosome arm lengths among individuals, the data were pooled for each chromosome arm to determine the mean value for each corresponding telomere ratio to the centromere signal, RTLU. After pooling of data, average telomere length (RTLU) was compared to chromosome arm size (in Mb) using bivariate analysis. The result was a highly significant $(\mathrm{p}<0.0001)$ correlation (Fig. 26). The overall data had a positive correlation coefficient (r) of 0.60 (Table 7). 
Table 6. Average telomere length for each individual in the study with associated $\mathrm{p}$ values. A bivariate fit of average telomere length by chromosome size (in $\mathrm{Mb}$ ) was performed to correlate the relationship between physical chromosome size and relative telomere length, and had a highly significant $(\mathrm{p}<0.0001)$ positive correlation. $\mathrm{n}$ is equal to the number of measurements per chromosome.

\begin{tabular}{|c|c|c|c|c|c|}
\hline Individual & sex & age & $\mathrm{n}$ & $\begin{array}{c}\text { Average } \\
\text { Telomere } \\
\text { Length } \\
\text { (RTLU) }\end{array}$ & $\mathrm{p}=$ \\
\hline 1 & Female & 7 & 6 & 14.96 & $0.0107 *$ \\
\hline 2 & Female & 15 & 8 & 14.24 & $0.006^{*}$ \\
\hline 3 & Female & 9 & 16 & 15.88 & 0.4061 \\
\hline 4 & Female & 9 & 6 & 17.67 & 0.0575 \\
\hline 5 & Female & 5 & 20 & 11.44 & $0.0008 *$ \\
\hline 6 & Female & 6 & 6 & 13.12 & 0.0686 \\
\hline 7 & Male & 45 & 8 & 10.39 & $0.0338^{*}$ \\
\hline 8 & Male & 39 & 4 & 14.91 & 0.3145 \\
\hline 9 & Male & 34 & 6 & 12.14 & $0.019 *$ \\
\hline 10 & Male & 35 & 10 & 8.91 & 0.1919 \\
\hline 11 & Female & 36 & 16 & 9.02 & $0.0094 *$ \\
\hline 12 & Female & 28 & 4 & 17.28 & $<0.0001^{*}$ \\
\hline 13 & Female & 33 & 6 & 14.46 & $0.0252^{*}$ \\
\hline 14 & Male & 12 & 12 & 10.33 & $0.0086^{*}$ \\
\hline 15 & Male & 6 & 8 & 13.29 & 0.0506 \\
\hline 16 & Male & 15 & 8 & 9.65 & $0.0161 *$ \\
\hline 17 & Male & 4 & 8 & 9.25 & $0.0259 *$ \\
\hline \multirow[t]{2}{*}{ Overall } & & & 152 & & $<0.0001^{*}$ \\
\hline & & & & & $* p<0.05$ \\
\hline
\end{tabular}


Table 7. Chromosome arms arranged by size in $\mathrm{Mb}$ and the corresponding mean telomere length value (RTLU) pooled from all 17 subjects.

\begin{tabular}{|c|c|c|c|}
\hline $\begin{array}{c}\text { Chromosome } \\
\text { Arm }\end{array}$ & $\begin{array}{c}\text { Chromosome } \\
\text { Arm Size (M bp) }\end{array}$ & RTLU & $\begin{array}{c}\text { Standard } \\
\text { Deviation }\end{array}$ \\
\hline $2 q$ & 149.7 & 10.55 & 3.53 \\
\hline $4 q$ & 140.2 & 14.02 & 4.24 \\
\hline $5 q$ & 133.3 & 13.13 & 3.84 \\
\hline $1 \mathrm{p}$ & 124.3 & 14.38 & 3.42 \\
\hline $1 \mathrm{q}$ & 122.7 & 13.24 & 4.33 \\
\hline $6 q$ & 110.5 & 13.53 & 3.42 \\
\hline $3 q$ & 108.3 & 13.00 & 3.12 \\
\hline $8 \mathrm{q}$ & 100.8 & 13.55 & 3.80 \\
\hline $7 q$ & 99.9 & 14.00 & 4.91 \\
\hline $13 q$ & 98.0 & 13.82 & 3.72 \\
\hline $12 q$ & 96.6 & 13.14 & 3.98 \\
\hline $\mathrm{Xq}$ & 95.5 & 12.64 & 4.51 \\
\hline $10 \mathrm{q}$ & 94.7 & 14.04 & 5.20 \\
\hline $2 p$ & 93.3 & 12.74 & 3.99 \\
\hline $3 p$ & 91.7 & 14.46 & 3.96 \\
\hline $14 q$ & 90.4 & 13.29 & 4.81 \\
\hline $9 q$ & 88.2 & 11.83 & 3.31 \\
\hline $15 q$ & 83.0 & 12.52 & 3.00 \\
\hline $11 q$ & 81.1 & 14.23 & 4.20 \\
\hline $6 p$ & 60.5 & 11.53 & 4.24 \\
\hline $18 \mathrm{q}$ & 59.9 & 12.24 & 3.28 \\
\hline$X p$ & 59.5 & 13.92 & 4.70 \\
\hline $7 p$ & 59.1 & 12.57 & 3.93 \\
\hline $17 q$ & 56.8 & 10.82 & 4.39 \\
\hline $11 p$ & 52.9 & 12.22 & 5.11 \\
\hline $9 p$ & 51.8 & 11.62 & 3.97 \\
\hline $16 q$ & 50.8 & 11.78 & 4.23 \\
\hline $4 p$ & 50.8 & 13.32 & 3.20 \\
\hline $5 p$ & 47.7 & 12.74 & 3.65 \\
\hline $\mathrm{Yq}$ & 46.7 & 6.75 & 2.29 \\
\hline $8 p$ & 45.2 & 12.87 & 3.78 \\
\hline $10 p$ & 40.3 & 11.45 & 2.53 \\
\hline $16 \mathrm{p}$ & 38.2 & 11.28 & 3.23 \\
\hline $22 q$ & 38.2 & 11.19 & 3.79 \\
\hline $19 q$ & 35.5 & 10.38 & 3.47 \\
\hline $12 p$ & 35.4 & 10.62 & 3.92 \\
\hline $20 q$ & 34.9 & 10.18 & 3.61 \\
\hline $21 q$ & 34.7 & 10.87 & 3.33 \\
\hline $19 p$ & 28.5 & 9.82 & 3.18 \\
\hline $20 p$ & 27.1 & 12.76 & 3.26 \\
\hline $17 p$ & 22.2 & 10.69 & 3.72 \\
\hline $15 p$ & 17.0 & 11.57 & 3.52 \\
\hline $18 p$ & 16.1 & 11.57 & 3.63 \\
\hline $13 p$ & 16.0 & 11.46 & 4.53 \\
\hline $14 p$ & 15.6 & 11.24 & 3.05 \\
\hline $21 \mathrm{p}$ & 12.3 & 10.60 & 3.63 \\
\hline $22 p$ & 11.8 & 10.24 & 4.39 \\
\hline$Y p$ & 11.3 & 10.06 & 2.07 \\
\hline
\end{tabular}




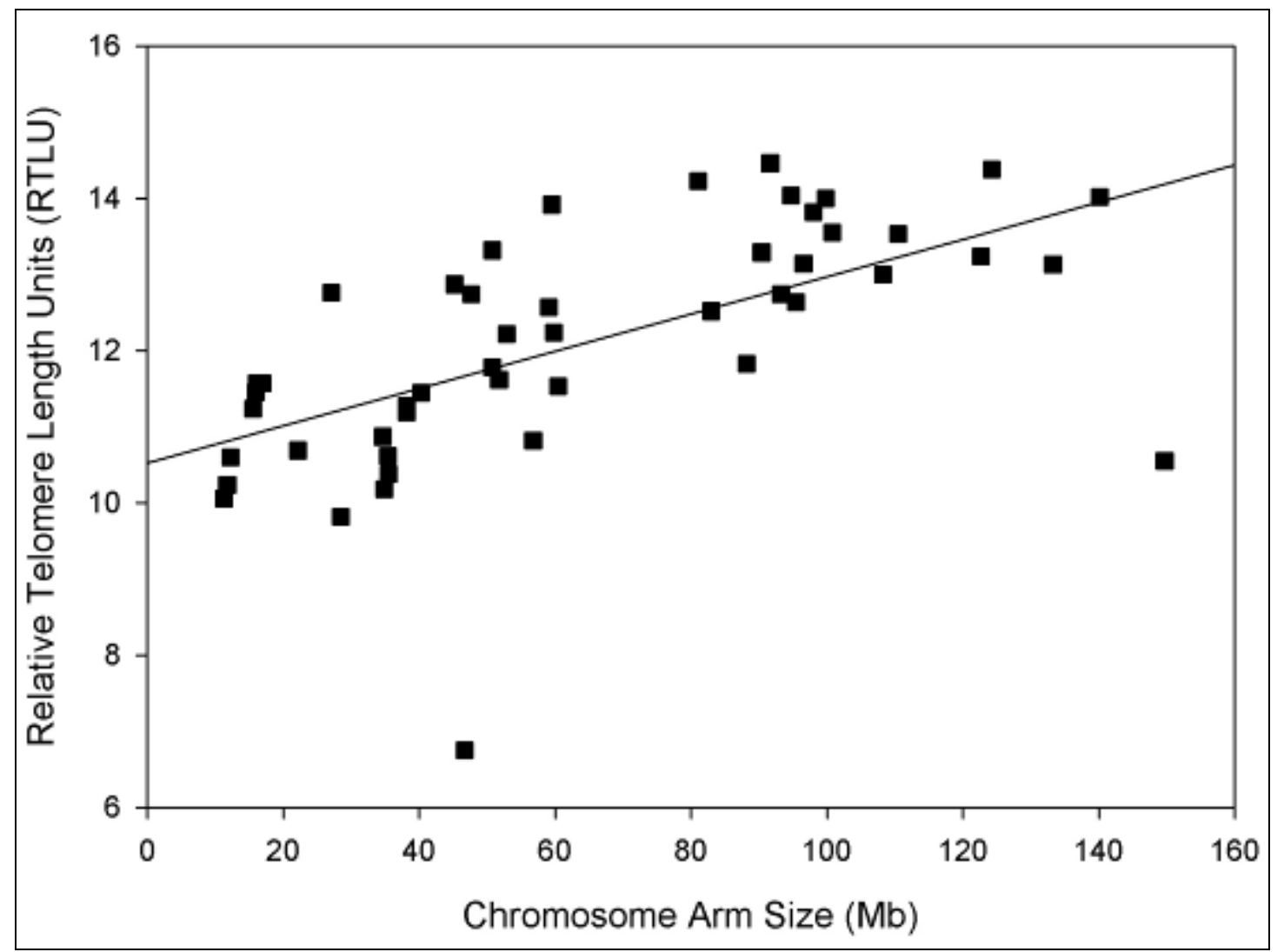

Figure 26. Chromosome arm values, measured in Mb pairs, are plotted against relative telomere length in RTLU from Table 7. The linear regression line corresponds to a correlation coefficient of 0.6 and $p<0.0001$ 


\section{DISCUSSION}

\section{CORRECTING FOR CHROMOSOME VARIABILITY}

This study relied heavily on the accurate measurement of telomere length and physical chromosome arm length. Standardized chromosome arm measurements were taken from the NCBI map viewer website to correct for the variability that occurs when measuring chromosomes by photographic means and the variation in chromosome condensation. This approach has not been documented elsewhere.

\section{TELOMERE LENGTH AND AgE}

The erosion of telomere length with increasing age has been well documented (Chiu and Harley, 1997; Filatov et al., 1998; von Zglinicki et al., 2000; Aragona et al., 2000; Goyns and Lavery, 2000; Martens et al., 2000; Shay and Wright, 2001; Yang et al., 2001). In this study, telomere length showed a trend to shorten with increased age of subject. However, the insensitivity of this assay and the young average age of the individuals studied did not yield statistically significant correlations, since there was not enough age difference to obtain the necessary sensitivity.

In general, studies of telomere length have used individuals who are the oldest and the youngest 5\% of the population (Harley et al., 1990; Bischoff et al., 2005a; 2005b; Graakjaer et al., 2006a). The difference in age of the oldest and youngest individual in this study was only 43 years of age. It is difficult to obtain enough sensitivity with PNA FISH or any other assay (Hultdin et al., 1998; Uhlmann et al., 2000; Slijepcevic, 2001; Baerlocher et al., 2002; Bekaert et al., 2002; Perner et al., 2003; de Pauw et al., 2005) to detect a statistically significant difference 
in overall telomere length without a greater range of ages in the sample. However, a strong but not statistically significant $(\mathrm{f}=0.18)$ negative correlation $(\mathrm{r}=-0.48)$ was observed.

\section{TELOMERE LENGTH AND CHROMOSOME ARM SIZE}

In this study, the telomere length for each chromosome arm was measured to help clarify the relationship of telomere length to the size of chromosome arm, since few studies have examined this relationship in detail. The data showed that telomere length directly correlates to the length of the chromosome arm.

Only two research groups have examined the telomere length profile in humans with regard to chromosome arm size. Martens and colleagues (Martens et al., 1998) found a weak positive correlation between human chromosome arm size and corresponding telomere length; however, they did not show their data and only briefly commented on the findings between human chromosome arm size and corresponding telomere length. Overall, the data of this study using $\mathrm{Mb}$ had a correlation coefficient of 0.60 , similar to results of 0.51 and 0.79 reported using physical measurement of chromosome arms (Graakjaer et al., 2003; 2004; 2006a)

Several studies have found statistically significant correlations of $\mathrm{p}$ and $\mathrm{q}$ telomere length to the total size of each chromosome (summation of $\mathrm{p}$ and $\mathrm{q}$ arms) (Martens et al., 1998; Graakjaer et al., 2003; 2004; 2006a; 2006b). Comparison of data in this study for whole chromosomes (summation of $\mathrm{p}$ arm and $\mathrm{q}$ arm size in $\mathrm{Mb}$ pairs and correlation to average individual telomere length for those arms from Table 7) showed a similar statistically significant correlation $(\mathrm{p}<0.0001)$.

The correlations of telomere length with chromosome arm size and total chromosome size would be expected since the summation of $\mathrm{p}$ and $\mathrm{q}$ chromosome arm size and the summation 
of $\mathrm{p}$ and $\mathrm{q}$ telomere length would show the same proportional relationships as single arm and single telomere measurements. Because of this property, the correlation with the arm rather than the entire chromosome suggests that individual telomere length to chromosome arm size is the functional relationship, but does not exclude the possibility of a combination of effects from both relationships. It is also important to keep in mind that correlation does not necessarily indicate causation.

In 2002, Sridevi et al. examined the telomeres of three species of Fountain grass (Pennisetum). One species had a longer average chromosome length than the other two species, while the other speciens had chromosomes that were all close to the same size. The species that had longer chromosomes had longer telomeres when compared to the species with shorter chromosomes. In the species where the chromosomes were all about the same size, individual telomere lengths were all about the same. This suggests that the trend of larger chromosomes having longer telomeres may be present across species even as evolutionarily distant as Fountain grass from human. Non-human studies using mouse models (Zijlmans et al., 1997), Chinese hamster models (Slijepcevic et al., 1998), and plant Pennisetum glaucum (pear millet) (Sridevi et al., 2002) have demonstrated correlation between telomere length and chromosome arm size. These findings are important because, along with human studies, they demonstrate that chromosome arm size and telomere length relationships have been conserved by evolution. Evolutionary conservation may suggest a greater functional relationship rather than structural stability. To further understand telomere-chromosome relationships it may be beneficial to examine telomere length in diverse taxonomic classes as well as examining other factors such as chromosome numbers and genomic organization. 


\section{CONCLUSIONS}

In conclusion, the linear relationship between telomere length and physical chromosome arm size is consistent from individual to individual regardless of sex or age. Variations based on age and gender occurs but the general trend of increasing telomere length with increasing chromosome arm size remains. These data show that the distribution of telomere length correlates with length of chromosome arm, suggesting that the common telomere pattern in humans may be more dependent on chromosome arm size rather than the physical size of the entire chromosome. This study also has used standardized $\mathrm{Mb}$ measurement rather than photographic measurements of chromosome arm size, which eliminates the error caused by variable condensation of chromosomes in the metaphase spread. 


\section{FUTURE STUDY AND LIMITATIONS}

In general, studies of telomere length have used individuals who are the oldest and the youngest $5 \%$ of the population. The difference in age of the oldest and youngest individual in this study was only 43 years of age. Having a greater range of ages in this study would have provided greater difference in telomere length which would have been more easily detected with the resolution of Q-FISH.

An interesting study would be to examine the telomere lengths of individuals who have large heterochromatic regions on chromosomes $1,9,16$ or Y, which are polymorphisms. The heterochromatin would increase the length of the chromosome arm and should therefore increase telomere length. This type of study could also be applied to those with balanced visible chromosome rearrangements to see if the telomere length is affected by change in chromosome arm size.

As with most studies, it would have been beneficial to have a greater number of individuals in the study and a greater number of cells per individual. Additionally, wising individuals in the study who were related, estimates of single chromosome arm attrition rates and inheritance patterns could be attempted. 


\section{REFERENCES}

Abruzzo MA, Mayer M, Jacobs PA. 1985. Aging and aneuploidy: evidence for the preferential involvement of the inactive X chromosome. Cytogenet Cell Genet 39(4):275-8.

Adeyinka A, Adams SA, Lorentz CP, Van Dyke DL, Jalal SM. 2005. Subtelomere deletions and translocations are frequently familial. Am J Med Genet A 135(1):28-35.

Allsopp RC, Vaziri H, Patterson C, Goldstein S, Younglai EV, Futcher AB, Greider CW, Harley CB. 1992. Telomere length predicts replicative capacity of human fibroblasts. Proc Natl Acad Sci U S A 89(21):10114-8.

Altherr MR, Bengtsson U, Elder FF, Ledbetter DH, Wasmuth JJ, McDonald ME, Gusella JF, Greenberg F. 1991. Molecular confirmation of Wolf-Hirschhorn syndrome with a subtle translocation of chromosome 4. Am J Hum Genet 49(6):1235-42.

Anderlid BM, Schoumans J, Anneren G, Sahlen S, Kyllerman M, Vujic M, Hagberg B, Blennow E, Nordenskjold M. 2002. Subtelomeric rearrangements detected in patients with idiopathic mental retardation. Am J Med Genet 107(4):275-84.

Aragona M, Maisano R, Panetta S, Giudice A, Morelli M, La Torre I, La Torre F. 2000. Telomere length maintenance in aging and carcinogenesis. Int J Oncol 17(5):981-9.

Aubert G, Lansdorp PM. 2008. Telomeres and aging. Physiol Rev 88(2):557-79.

Baerlocher GM, Mak J, Tien T, Lansdorp PM. 2002. Telomere length measurement by fluorescence in situ hybridization and flow cytometry: tips and pitfalls. Cytometry 47(2):89-99.

Bailey SM, Goodwin EH. 2004. DNA and telomeres: beginnings and endings. Cytogenet Genome Res 104(1-4):109-15.

Bailey SM, Meyne J, Chen DJ, Kurimasa A, Li GC, Lehnert BE, Goodwin EH. 1999. DNA double-strand break repair proteins are required to cap the ends of mammalian chromosomes. Proc Natl Acad Sci U S A 96(26):14899-904.

Baker E, Hinton L, Callen DF, Altree M, Dobbie A, Eyre HJ, Sutherland GR, Thompson E, Thompson P, Woollatt E and others. 2002. Study of 250 children with idiopathic mental retardation reveals nine cryptic and diverse subtelomeric chromosome anomalies. Am J Med Genet 107(4):285-93.

Ballif BC, Rorem EA, Sundin K, Lincicum M, Gaskin S, Coppinger J, Kashork CD, Shaffer LG, Bejjani BA. 2006. Detection of low-level mosaicism by array CGH in routine diagnostic specimens. Am J Med Genet Part A 140A:2757-2767.

Ballif BC, Sulpizio SG, Lloyd RM, Minier SL, Theisen A, Bejjani BA, Shaffer LG. 2007. The clinical utility of enhanced subtelomeric coverage in array CGH. Am J Med Genet A 143(16):1850-7. 
Bar-Shira A, Rosner G, Rosner S, Goldstein M, Orr-Urtreger A. 2006. Array-based comparative genome hybridization in clinical genetics. Pediatr Res 60(3):353-8.

Bauters M, Van Esch H, Marynen P, Froyen G. 2005. X chromosome array-CGH for the identification of novel X-linked mental retardation genes. Eur J Med Genet 48(3):263-75.

Bekaert S, De Meyer T, Rietzschel ER, De Buyzere ML, De Bacquer D, Langlois M, Segers P, Cooman L, Van Damme P, Cassiman P and others. 2007. Telomere length and cardiovascular risk factors in a middle-aged population free of overt cardiovascular disease. Aging Cell 6(5):639-47.

Bekaert S, Koll S, Thas O, Van Oostveldt P. 2002. Comparing telomere length of sister chromatids in human lymphocytes using three-dimensional confocal microscopy. Cytometry 48(1):34-44.

Benetos A, Gardner JP, Zureik M, Labat C, Xiaobin L, Adamopoulos C, Temmar M, Bean KE, Thomas F, Aviv A. 2004. Short telomeres are associated with increased carotid atherosclerosis in hypertensive subjects. Hypertension 43(2):182-5.

Bischoff C, Graakjaer J, Petersen HC, Hjelmborg JB, Vaupel JW, Bohr V, Koelvraa S, Christensen K. 2005a. The heritability of telomere length among the elderly and oldestold. Twin Res Hum Genet 8(5):433-9.

Bischoff C, Graakjaer J, Petersen HC, Jeune B, Bohr VA, Koelvraa S, Christensen K. 2005b. Telomere length among the elderly and oldest-old. Twin Res Hum Genet 8(5):425-32.

Bischoff C, Petersen HC, Graakjaer J, Andersen-Ranberg K, Vaupel JW, Bohr VA, Kolvraa S, Christensen K. 2006. No association between telomere length and survival among the elderly and oldest old. Epidemiology 17(2):190-4.

Blackburn EH, Challoner PB. 1984. Identification of a telomeric DNA sequence in Trypanosoma brucei. Cell 36(2):447-57.

Blackburn EH. 1984. The molecular structure of centromeres and telomeres. Annu Rev Biochem 53:163-94.

Blackburn EH. 1991. Structure and function of telomeres. Nature 350(6319):569-73.

Bocian E, Helias-Rodzewicz Z, Suchenek K, Obersztyn E, Kutkowska-Kazmierczak A, Stankiewicz P, Kostyk E, Mazurczak T. 2004. Subtelomeric rearrangements: results from FISH studies in 84 families with idiopathic mental retardation. Med Sci Monit 10(4):CR143-51.

Brouilette S, Singh RK, Thompson JR, Goodall AH, Samani NJ. 2003. White cell telomere length and risk of premature myocardial infarction. Arterioscler Thromb Vasc Biol 23(5):842-6.

Brouilette SW, Moore JS, McMahon AD, Thompson JR, Ford I, Shepherd J, Packard CJ, Samani NJ. 2007. Telomere length, risk of coronary heart disease, and statin treatment in the 
West of Scotland Primary Prevention Study: a nested case-control study. Lancet 369(9556):107-14.

Brown RA, MacKinnon PJ, Villasanté A, Spurr N, Buckle VJ, Dobson MJ. 1990. Structure and polymorphism of human telomere-associated DNA. Cell 63, 119-132.

Catalan J, Surralles J, Falck GC, Autio K, Norppa H. 2000. Segregation of sex chromosomes in human lymphocytes. Mutagenesis 15: 251-255.

Cherkas LF, Hunkin JL, Kato BS, Richards JB, Gardner JP, Surdulescu GL, Kimura M, Lu X, Spector TD, Aviv A. 2008. The association between physical activity in leisure time and leukocyte telomere length. Arch Intern Med 168(2):154-8.

Chiu CP, Harley CB. 1997. Replicative senescence and cell immortality: the role of telomeres and telomerase. Proc Soc Exp Biol Med 214(2):99-106.

Cooke HJ, Smith BA. 1986. Variability at the telomeres of the human X/Y pseudoautosomal region. Cold Spring Harb Symp Quant Biol 51 Pt 1:213-9.

Cross S, Lindsey J, Fantes J, McKay S, McGill N, and Cooke H, 1990. The structure of a subterminal repeated sequence present on many human chromosomes. Nucleic Acids Res. 18, 6649-6657.

Dalton KL and Abbott M-A. A mother and son with an isolated 6q subtelomere deletion and comparison to other reported cases. 2008. Poster at Am College of Med Genet annual meeting, March 13-16, 2008, Phoenix, Az

de Lange T, Shiue L, Myers RM, Cox DR, Naylor SL, Killery AM, Varmus HE. 1990. Structure and variability of human chromosome ends. Mol. Cell. Biol. 10, 518-527.

de Lange T. 2002. Protection of mammalian telomeres. Oncogene 21(4):532-40.

de Lange T. 2005. Shelterin: the protein complex that shapes and safeguards human telomeres. Genes Dev 19(18):2100-10.

de Pauw ES, Roelofs H, Zwinderman A, van Houwelingen JC, Fibbe WE, de Knijff P, Pearson PL, Tanke HJ. 2005. Studying the biological and technical sources of variation in telomere length of individual chromosomes. Cytometry A 65(1):35-9.

de Vries BB, White SM, Knight SJ, Regan R, Homfray T, Young ID, Super M, McKeown C, Splitt M, Quarrell OW and others. 2001. Clinical studies on submicroscopic subtelomeric rearrangements: a checklist. J Med Genet 38(3):145-50.

de Vries BB, Winter R, Schinzel A, van Ravenswaaij-Arts C. 2003. Telomeres: a diagnosis at the end of the chromosomes. J Med Genet 40(6):385-98.

de Vries BB, Pfundt R, Leisink M, Koolen DA, Vissers LE, Janssen IM, Reijmersdal S, Nillesen WM, Huys EH, Leeuw $\mathrm{N}$ and others. 2005. Diagnostic genome profiling in mental retardation. Am J Hum Genet 77(4):606-16. 
Demissie S, Levy D, Benjamin EJ, Cupples LA, Gardner JP, Herbert A, Kimura M, Larson MG, Meigs JB, Keaney JF and others. 2006. Insulin resistance, oxidative stress, hypertension, and leukocyte telomere length in men from the Framingham Heart Study. Aging Cell 5(4):325-30.

Dhaene K, Hubner R, Kumar-Singh S, Weyn B, Van Marck E. 1998. Telomerase activity in human pleural mesothelioma. Thorax 53(11):915-8.

Dhaene K, Van Marck E, Parwaresch R. 2000. Telomeres, telomerase and cancer: an up-date. Virchows Arch 437(1):1-16.

Epel ES, Blackburn EH, Lin J, Dhabhar FS, Adler NE, Morrow JD, Cawthon RM. 2004. Accelerated telomere shortening in response to life stress. Proc Natl Acad Sci U S A 101(49):17312-5.

Estop AM, Cieply KM, Aston CE (1997) The meiotic segregation pattern of a reciprocal translocation $\mathrm{t}(10 ; 12)(\mathrm{q} 26.1 ; \mathrm{p} 13.3)$ by fluorescence in situ hybridization sperm analysis. Eur J Hum Genet 5: 78-82.

Fang JS, Lee KF, Huang CT, Syu CL, Yang KJ, Wang LH, Liao DL, Chen CH. 2008. Cytogenetic and molecular characterization of a three-generation family with chromosome 5p terminal deletion. Clinical Genetics 73:585-90.

Filatov L, Golubovskaya V, Hurt JC, Byrd LL, Phillips JM, Kaufmann WK. 1998. Chromosomal instability is correlated with telomere erosion and inactivation of G2 checkpoint function in human fibroblasts expressing human papillomavirus type 16 E6 oncoprotein. Oncogene 16(14):1825-38.

Fitzgerald PH. 1975. A mechanism of X chromosome aneuploidy in lymphocytes of aging women. Humangenetik 28(2):153-8.

Fitzpatrick AL, Kronmal RA, Gardner JP, Psaty BM, Jenny NS, Tracy RP, Walston J, Kimura M, Aviv A. 2007. Leukocyte telomere length and cardiovascular disease in the cardiovascular health study. Am J Epidemiol 165(1):14-21.

Flint J, Wilkie AO, Buckle VJ, Winter RM, Holland AJ, McDermid HE. 1995. The detection of subtelomeric chromosomal rearrangements in idiopathic mental retardation. Nat Genet 9(2):132-40.

Flint J, Wilkie AO. 1996. The genetics of mental retardation. Br Med Bull 52(3):453-64.

Ford CE, Jones KW, Polani PE, De Almeida JC, Briggs JH. 1959. A sex-chromosome anomaly in a case of gonadal dysgenesis (Turner's syndrome). Lancet 1(7075):711-3.

Ford JH, Russell JA (1985) Differences in the error mechanisms affecting sex and autosomal chromosomes in women of different ages within the reproductive age group. Am J Hum Genet 37: 973-983.

Frenck RW, Jr., Blackburn EH, Shannon KM. 1998. The rate of telomere sequence loss in human leukocytes varies with age. Proc Natl Acad Sci U S A 95(10):5607-10. 
Friedman JM, Baross A, Delaney AD, Ally A, Arbour L, Armstrong L, Asano J, Bailey DK, Barber S, Birch P and others. 2006. Oligonucleotide microarray analysis of genomic imbalance in children with mental retardation. Am J Hum Genet 79(3):500-13.

Fuster JJ, Andres V. 2006. Telomere biology and cardiovascular disease. Circ Res 99(11):116780.

Gartler SM. 2006. The chromosome number in humans: a brief history. Nat Rev Genet 7(8):65560.

Goyns MH, Lavery WL. 2000. Telomerase and mammalian ageing: a critical appraisal. Mech Ageing Dev 114(2):69-77.

Graakjaer J, Bischoff C, Korsholm L, Holstebroe S, Vach W, Bohr VA, Christensen K, Kolvraa S. 2003. The pattern of chromosome-specific variations in telomere length in humans is determined by inherited, telomere-near factors and is maintained throughout life. Mech Ageing Dev 124(5):629-40.

Graakjaer J, Der-Sarkissian H, Schmitz A, Bayer J, Thomas G, Kolvraa S, Londono-Vallejo JA. 2006a. Allele-specific relative telomere lengths are inherited. Hum Genet 119(3):344-50.

Graakjaer J, Londono-Vallejo JA, Christensen K, Kolvraa S. 2006b. The pattern of chromosomespecific variations in telomere length in humans shows signs of heritability and is maintained through life. Ann N Y Acad Sci 1067:311-6.

Graakjaer J, Pascoe L, Der-Sarkissian H, Thomas G, Kolvraa S, Christensen K, Londono-Vallejo JA. 2004. The relative lengths of individual telomeres are defined in the zygote and strictly maintained during life. Aging Cell 3(3):97-102.

Guttenbach M, Koschorz B, Bernthaler U, Grimm T, Schmid M (1995) Sex chromosome loss and aging: in situ hybridization studies on human interphase nuclei. Am J Hum Genet 57: 1143-1150.

Harada N, Hatchwell E, Okamoto N, Tsukahara M, Kurosawa K, Kawame H, Kondoh T, Ohashi H, Tsukino R, Kondoh Y and others. 2004. Subtelomere specific microarray based comparative genomic hybridisation: a rapid detection system for cryptic rearrangements in idiopathic mental retardation. J Med Genet 41(2):130-6.

Harley CB, Futcher AB, Greider CW. 1990. Telomeres shorten during ageing of human fibroblasts. Nature 345(6274):458-60.

Harris SE, Deary IJ, MacIntyre A, Lamb KJ, Radhakrishnan K, Starr JM, Whalley LJ, Shiels PG. 2006. The association between telomere length, physical health, cognitive ageing, and mortality in non-demented older people. Neurosci Lett 406(3):260-4.

Hayflick L, Moorhead PS. 1961. The serial cultivation of human diploid cell strains. Exp Cell Res 25:585-621.

Helias-Rodzewicz Z, Bocian E, Stankiewicz P, Obersztyn E, Kostyk E, Jakubow-Durska K, Kutkowska-Kazmierczak A, Mazurczak T. 2002. Subtelomeric rearrangements detected 
by FISH in three of 33 families with idiopathic mental retardation and minor physical anomalies. J Med Genet 39(9):e53.

Hemann MT, Strong MA, Hao LY, Greider CW. 2001. The shortest telomere, not average telomere length, is critical for cell viability and chromosome stability. Cell 107(1):67-77.

Hoehn H, Engel W. 1969. Screening for minute deletions in patients with suspected cri-du-chat syndrome and apparently normal karyotype. Humangenetik 8(2):105-10.

Hook E, Hamerton J. 1977. The frequency of chromosome abnormalities detected in consecutive newborn studies - differences between studies - results by sex and by severity of phenotypic involvement; Hook E, Porter I, editors: Academic Press, Inc. 63-79 p.

Hultdin M, Gronlund E, Norrback K, Eriksson-Lindstrom E, Just T, Roos G. 1998. Telomere analysis by fluorescence in situ hybridization and flow cytometry. Nucleic Acids Res 26(16):3651-6.

Ijdo JW, Lindsay EA, Wells RA, Baldini A. 1992. Multiple variants in subtelomeric regions of normal karyotypes. Genomics 14(4):1019-25.

International Standing Committee on Human Cytogenetic Nomenclature., Shaffer LG, Slovak ML, Campbell LS. 2009. ISCN 2009 : An international system for human cytogenetic nomenclature (2009) : recommendations of the International Standing Committee on Human Cytogenetic Nomenclature. Basel ; Karger. 138 pp.

Iqbal MA, Ramadan S, Ali FA, Kurdi W. 2005. Complex de novo cryptic subtelomeric rearrangements in a fetus with multiple ultrasonographic abnormalities and a normal karyotype at amniocentesis. Prenat Diagn 25(12):1142-9.

Jacobs PA, Baikie AG, Brown WM, Macgregor TN, Maclean N, Harnden DG. 1959. Evidence for the existence of the human "super female". Lancet 2(7100):423-5.

Jacobs PA, Court Brown WM, Doll R. 1961. Distribution of human chromosome counts in relation to age. Nature 191:1178-80.

Jacobs PA, Strong JA. 1959. A case of human intersexuality having a possible XXY sexdetermining mechanism. Nature 183(4657):302-3.

Kaiser-Rogers KA, Rao KW, Michaelis RC, Lese CM, Powell CM. 2000. Usefulness and limitations of FISH to characterize partially cryptic complex chromosome rearrangements. Am J Med Genet 95(1):28-35.

Kim NW, Piatyszek MA, Prowse KR, Harley CB, West MD, Ho PL, Coviello GM, Wright WE, Weinrich SL, Shay JW. 1994. Specific association of human telomerase activity with immortal cells and cancer. Science 266(5193):2011-5.

Kirchhoff M, Pedersen S, Kjeldsen E, Rose H, Duno M, Kolvraa S, Lundsteen C. 2004. Prospective study comparing HR-CGH and subtelomeric FISH for investigation of individuals with mental retardation and dysmorphic features and an update of a study using only HR-CGH. Am J Med Genet A 127(2):111-7. 
Kitsiou-Tzeli S, Sismani C, Ioannides M, Bashiardes S, Ketoni A, Touliatou V, Kolialexi A, Mavrou A, Kanavakis E, Patsalis PC. 2007. Array-CGH analysis and clinical description of 2q37.3 de novo subtelomeric deletion. Eur J Med Genet 50(1):73-8.

Knight SJ, Horsley SW, Regan R, Lawrie NM, Maher EJ, Cardy DL, Flint J, Kearney L. 1997. Development and clinical application of an innovative fluorescence in situ hybridization technique which detects submicroscopic rearrangements involving telomeres. Eur J Hum Genet 5(1):1-8.

Knight SJ, Regan R, Nicod A, Horsley SW, Kearney L, Homfray T, Winter RM, Bolton P, Flint J. 1999. Subtle chromosomal rearrangements in children with unexplained mental retardation. Lancet 354(9191):1676-81.

Krepischi-Santos AC, Vianna-Morgante AM, Jehee FS, Passos-Bueno MR, Knijnenburg J, Szuhai K, Sloos W, Mazzeu JF, Kok F, Cheroki C and others. 2006. Whole-genome array-CGH screening in undiagnosed syndromic patients: old syndromes revisited and new alterations. Cytogenet Genome Res 115(3-4):254-61.

Kurz DJ, Kloeckener-Gruissem B, Akhmedov A, Eberli FR, Buhler I, Berger W, Bertel O, Luscher TF. 2006. Degenerative aortic valve stenosis, but not coronary disease, is associated with shorter telomere length in the elderly. Arterioscler Thromb Vasc Biol 26(6):e114-7.

Lansdorp PM, Verwoerd NP, van de Rijke FM, Dragowska V, Little MT, Dirks RW, Raap AK, Tanke HJ. 1996. Heterogeneity in telomere length of human chromosomes. Hum Mol Genet 5(5):685-91.

Lansdorp PM. 2006. Stress, social rank and leukocyte telomere length. Aging Cell 5(6):583-4.

Lauzon W, Sanchez Dardon J, Cameron DW, Badley AD. 2000. Flow cytometric measurement of telomere length. Cytometry 42(3):159-64.

Le Caignec C, De Mas P, Vincent MC, Boceno M, Bourrouillou G, Rival JM, David A. 2005. Subtelomeric 6p deletion: clinical, FISH, and array CGH characterization of two cases. Am J Med Genet A 132(2):175-80.

Ledbetter DH. 1992. Minireview: cryptic translocations and telomere integrity. Am J Hum Genet 51(3):451-6.

Lejeune J, Turpin R, Gautier M. 1959. [Mongolism; a chromosomal disease (trisomy).]. Bull Acad Natl Med 143(11-12):256-65.

Li R, Zhao ZY. 2004. Two subtelomeric chromosomal deletions in forty-six children with idiopathic mental retardation. Chin Med J (Engl) 117(9):1414-7.

Lugtenberg D, de Brouwer AP, Kleefstra T, Oudakker AR, Frints SG, Schrander-Stumpel CT, Fryns JP, Jensen LR, Chelly J, Moraine C and others. 2006. Chromosomal copy number changes in patients with non-syndromic $\mathrm{X}$ linked mental retardation detected by array CGH. J Med Genet 43(4):362-70. 
Macina RA, Negorev DG, Spais C, Ruthig LA, Hu XL, Riethman HC. 1994. Sequence organization of the human chromosome 2q telomere. Hum Mol Genet 3:1847-1853

Manning M \& L Hudgins 2007. Use of array-based technology in the practice of medical genetics. Genetics in Medicine 9:650-3

Martens UM, Chavez EA, Poon SS, Schmoor C, Lansdorp PM. 2000. Accumulation of short telomeres in human fibroblasts prior to replicative senescence. Exp Cell Res 256(1):2919.

Martens UM, Zijlmans JM, Poon SS, Dragowska W, Yui J, Chavez EA, Ward RK, Lansdorp PM. 1998. Short telomeres on human chromosome 17p. Nat Genet 18(1):76-80.

Martin-Ruiz C, Dickinson HO, Keys B, Rowan E, Kenny RA, Von Zglinicki T. 2006. Telomere length predicts poststroke mortality, dementia, and cognitive decline. Ann Neurol 60(2):174-80.

McClintock B. 1938. The fusion of broken ends of sister half-chromatids following chromatid breakage at meitoic anaphase. Res Bull -Mo, Agric Exp Stn 290:1-38.

McClintock B. 1939. The behavior of successive nuclear divisons of a chromosome broken at meiosis. Proc Natl Acad Sci U S A 25:405-416.

McClintock B. 1941. The stability of broken ends of chromosomes in Zea mays Genetics 26:234-82.

McEachern MJ, Iyer S, Fulton TB, Blackburn EH. 2000. Telomere fusions caused by mutating the terminal region of telomeric DNA. Proc Natl Acad Sci U S A 97(21):11409-14.

McGavin DD, Cant JS, Ferguson-Smith MA, Ellis PM. 1967. The cri-du-chat syndrome with an apparently normal karyotype. Lancet 2(7511):326-30.

Morla M, Busquets X, Pons J, Sauleda J, MacNee W, Agusti AG. 2006. Telomere shortening in smokers with and without COPD. Eur Respir J 27(3):525-8.

Mukherjee AB, Alejandro J, Payne S, Thomas S. 1996. Age-related aneuploidy analysis of human blood cells in vivo by fluorescence in situ hybridization (FISH). Mech Ageing Dev 90(2):145-56.

Muller HJ. 1938. The remaking of chromosomes Collect Net 8:182-95.

Obana N, Takagi S, Kinouchi Y, Tokita Y, Sekikawa A, Takahashi S, Hiwatashi N, Oikawa S, Shimosegawa T. 2003. Telomere shortening of peripheral blood mononuclear cells in coronary disease patients with metabolic disorders. Intern Med 42(2):150-3.

Olovnikov AM. 1971. [Principle of marginotomy in template synthesis of polynucleotides]. Dokl Akad Nauk SSSR 201(6):1496-9. 
Olovnikov AM. 1973. A theory of marginotomy. The incomplete copying of template margin in enzymic synthesis of polynucleotides and biological significance of the phenomenon. $\mathbf{J}$ Theor Biol 41(1):181-90.

Overhauser J, Bengtsson U, McMahon J, Ulm J, Butler MG, Santiago L, Wasmuth JJ. 1989. Prenatal diagnosis and carrier detection of a cryptic translocation by using DNA markers from the short arm of chromosome 5. Am J Hum Genet 45(2):296-303.

Painter TS. 1921. The Y-Chromosome in Mammals. Science 53(1378):503-504.

Palomares M, Delicado A, Lapunzina P, Arjona D, Aminoso C, Arcas J, Martinez Bermejo A, Fernandez L, Lopez Pajares I. 2006. MLPA vs multiprobe FISH: comparison of two methods for the screening of subtelomeric rearrangements in 50 patients with idiopathic mental retardation. Clin Genet 69(3):228-33.

Perner S, Bruderlein S, Hasel C, Waibel I, Holdenried A, Ciloglu N, Chopurian H, Nielsen KV, Plesch A, Hogel J and others. 2003. Quantifying telomere lengths of human individual chromosome arms by centromere-calibrated fluorescence in situ hybridization and digital imaging. Am J Pathol 163(5):1751-6.

Pinkel D, Gray JW, Trask B, van den Engh G, Fuscoe J, van Dekken H. 1986. Cytogenetic analysis by in situ hybridization with fluorescently labeled nucleic acid probes. Cold Spring Harb Symp Quant Biol 51 Pt 1:151-7.

Polk DE, Weyant RJ, Crout RJ, McNeil DW, Tarter RE, et al. 2008. Study protocol of the Center for Oral Health Research in Appalachia (COHRA) etiology study. BMC Oral Health 8: 18.

Ravnan JB, Tepperberg JH, Papenhausen P, Lamb AN, Hedrick J, Eash D, Ledbetter DH, Martin CL. 2006. Subtelomere FISH analysis of 11688 cases: an evaluation of the frequency and pattern of subtelomere rearrangements in individuals with developmental disabilities. J Med Genet 43(6):478-89.

Riethman H. Ambrosini A. Paul S. 2005. Human subtelomere structure and variation. Chromosome Research. 13(5):505-15.

Rickman L, Fiegler H, Shaw-Smith C, Nash R, Cirigliano V, Voglino G, Ng BL, Scott C, Whittaker J, Adinolfi M and others. 2006. Prenatal detection of unbalanced chromosomal rearrangements by array CGH. J Med Genet 43(4):353-61.

Rosenberg C, Knijnenburg J, Bakker E, Vianna-Morgante AM, Sloos W, Otto PA, Kriek M, Hansson K, Krepischi-Santos AC, Fiegler H and others. 2006. Array-CGH detection of micro rearrangements in mentally retarded individuals: clinical significance of imbalances present both in affected children and normal parents. J Med Genet 43(2):1806.

Rufer N, Brummendorf TH, Kolvraa S, Bischoff C, Christensen K, Wadsworth L, Schulzer M, Lansdorp PM. 1999. Telomere fluorescence measurements in granulocytes and T 
lymphocyte subsets point to a high turnover of hematopoietic stem cells and memory $\mathrm{T}$ cells in early childhood. J Exp Med 190(2):157-67.

Russell LM, Strike P, Browne CE, Jacobs PA. 2007. X chromosome loss and ageing. Cytogenet Genome Res 116: 181-185.

Saldanha SN, Andrews LG, Tollefsbol TO. 2003. Assessment of telomere length and factors that contribute to its stability. Eur J Biochem 270(3):389-403.

Samani NJ, Boultby R, Butler R, Thompson JR, Goodall AH. 2001. Telomere shortening in atherosclerosis. Lancet 358(9280):472-3.

Samanich JM, Carter SM, Delgado S, Pope KO, Shanaham M, Suri V, Dar P, Gross SJ. 2008. Ascertainment of terminal deletion of chromosome 5p in a mother, son and fetus; cytogenetic and clinical findings. American College of Medical Genetics. Phoenix, Arizona.

Sampson MJ, Winterbone MS, Hughes JC, Dozio N, Hughes DA. 2006. Monocyte telomere shortening and oxidative DNA damage in type 2 diabetes. Diabetes Care 29(2):283-9.

Sandberg AA, Koepf GF, Ishihara T, Hauschka TS. 1961. An XYY human male. Lancet 2(7200):488-9.

Satoh H, Hiyama K, Takeda M, Awaya Y, Watanabe K, Ihara Y, Maeda H, Ishioka S, Yamakido M. 1996. Telomere shortening in peripheral blood cells was related with aging but not with white blood cell count. Jpn J Hum Genet 41(4):413-7.

Schoumans J, Ruivenkamp C, Holmberg E, Kyllerman M, Anderlid BM, Nordenskjold M. 2005. Detection of chromosomal imbalances in children with idiopathic mental retardation by array based comparative genomic hybridisation (array-CGH). J Med Genet 42(9):699705.

Shaffer LG. 2005. American College of Medical Genetics guideline on the cytogenetic evaluation of the individual developlmental delay or mental retardation. Genetics In Medicine 7(9):650-654.

Shaw-Smith C, Redon R, Rickman L, Rio M, Willatt L, Fiegler H, Firth H, Sanlaville D, Winter R, Colleaux L and others. 2004. Microarray based comparative genomic hybridisation (array-CGH) detects submicroscopic chromosomal deletions and duplications in patients with learning disability/mental retardation and dysmorphic features. J Med Genet 41(4):241-8.

Shay JW, Wright WE. 2001. Telomeres and telomerase: implications for cancer and aging. Radiat Res 155(1 Pt 2):188-193.

Shay J, Wright W. 2007. Hallmarks of telomeres in ageing research. J Pathol 211(2):114-23. 
Simon NM, Smoller JW, McNamara KL, Maser RS, Zalta AK, Pollack MH, Nierenberg AA, Fava M, Wong KK. 2006. Telomere shortening and mood disorders: preliminary support for a chronic stress model of accelerated aging. Biol Psychiatry 60(5):432-5.

Slagboom PE, Droog S, Boomsma DI. 1994. Genetic determination of telomere size in humans: a twin study of three age groups. Am J Hum Genet 55(5):876-82.

Slijepcevic P. 2001. Telomere length measurement by Q-FISH. Methods Cell Sci 23(1-3):17-22.

Sridevi V DKU, Sivaramakrishnan S, Isola N R 2002. Telomere Length as Related to Chromosome Length in the Genus Pennisetum. Cytologia 67(2):185-190.

Steele MW, Breg WR, Jr. 1966. Chromosome analysis of human amniotic-fluid cells. Lancet 1(7434):383-5.

Szilard RK, Durocher D. 2006. Telomere protection: an act of God. Curr Biol 16(14):R544-6.

Tijo JH, Levan A. 1956. The Chromosome Number of Man. Hereditas 42:1-6.

Tyson C, Harvard C, Locker R, Friedman JM, Langlois S, Lewis ME, Van Allen M, Somerville M, Arbour L, Clarke L and others. 2005. Submicroscopic deletions and duplications in individuals with intellectual disability detected by array-CGH. Am J Med Genet A 139(3):173-85.

Tyson C, McGillivray B, Chijiwa C, Rajcan-Separovic E. 2004. Elucidation of a cryptic interstitial 7q31.3 deletion in a patient with a language disorder and mild mental retardation by array-CGH. Am J Med Genet A 129(3):254-60.

Uhlmann V, Prasad M, Silva I, Luettich K, Grande L, Alonso L, Thisted M, Pluzek KJ, Gorst J, Ring $\mathrm{M}$ and others. 2000. Improved in situ detection method for telomeric tandem repeats in metaphase spreads and interphase nuclei. Mol Pathol 53(1):48-50.

Valdes AM, Andrew T, Gardner JP, Kimura M, Oelsner E, Cherkas LF, Aviv A, Spector TD. 2005. Obesity, cigarette smoking, and telomere length in women. Lancet 366(9486):6624.

Van Karnebeek CD, Koevoets C, Sluijter S, Bijlsma EK, Smeets DF, Redeker EJ, Hennekam RC, Hoovers JM. 2002. Prospective screening for subtelomeric rearrangements in children with mental retardation of unknown aetiology: the Amsterdam experience. J Med Genet 39(8):546-53.

Van Overbeek M, de Lange T. 2006. Apollo, an Artemis-related nuclease, interacts with TRF2 and protects human telomeres in S phase. Curr Biol 16(13):1295-302.

Veltman JA, Schoenmakers EF, Eussen BH, Janssen I, Merkx G, van Cleef B, van Ravenswaaij CM, Brunner HG, Smeets D, van Kessel AG. 2002. High-throughput analysis of subtelomeric chromosome rearrangements by use of array-based comparative genomic hybridization. Am J Hum Genet 70(5):1269-76. 
Von Zglinicki T, Pilger R, Sitte N. 2000. Accumulation of single-strand breaks is the major cause of telomere shortening in human fibroblasts. Free Radic Biol Med 28(1):64-74.

Walter S, Sandig K, Hinkel GK, Mitulla B, Ounap K, Sims G, Sitska M, Utermann B, Viertel P, Kalscheuer V and others. 2004. Subtelomere FISH in 50 children with mental retardation and minor anomalies, identified by a checklist, detects 10 rearrangements including a de novo balanced translocation of chromosomes 17p13.3 and 20q13.33. Am J Med Genet A 128(4):364-73.

Wang TS. 1991. Eukaryotic DNA polymerases. Annu Rev Biochem 60:513-52.

Watson JD. 1972. Origin of concatemeric T7 DNA. Nat New Biol 239(94):197-201.

Wenger SL, Golden WL, Dennis SP, Steele MW (1984) Are the occasional aneuploid cells in peripheral blood cultures significant? Am J Med Genet 19: 715-719.

Wilkie AO, Higgs DR, Rack KA, Buckle VJ, Spurr NK, Fischel-Ghodsian N, Ceccherini I, Brown WR, Harris PC. 1991. Stable length polymorphism of up to $260 \mathrm{~kb}$ at the tip of the short arm of human chromosome 16. Cell 64(3):595-606.

Wong A, Lese Martin C, Heretis K, Ruffalo T, Wilber K, King W, Ledbetter DH. 2005. Detection and calibration of microdeletions and microduplications by array-based comparative genomic hybridization and its applicability to clinical genetic testing. Genet Med 7(4):264-71.

Yang L, Suwa T, Wright WE, Shay JW, Hornsby PJ. 2001. Telomere shortening and decline in replicative potential as a function of donor age in human adrenocortical cells. Mech Ageing Dev 122(15):1685-94.

Zannolli R, Mohn A, Buoni S, Pietrobelli A, Messina M, Chiarelli F, Miracco C. 2008. Telomere length and obesity. Acta Paediatr 97(7):952-4.

Zijlmans JM, Martens UM, Poon SS, Raap AK, Tanke HJ. 1997. Telomeres in the mouse have large inter-chromosomal variations in the number of T2AG3 repeats. Proc Natl Acad Sci USA 94: 7423-7428. 


\section{APPENDIX A}

X/Y Probe Abbott Molecular

Available from http://www.abbottmolecular.com catalogue number 30-161050.

ToTelVysion Probe

Available from www.abbottmolecular.com catalogue number 33-270000

PNA Telomere Probe

Available from www.dako.com catalogue number K5325

PNA Centromere Probe

Available by special request from www.dako.com

Tris Buffered Saline (TBS)

$1 \mathrm{X}$ concentration provided with DAKO PNA FISH probes.

Phosphate Buffered Saline (PBS)

$1 \mathrm{X}$ concentration prepared from 10X stock solution. Available from Sigma Aldrich Cat. \#P5493

\section{Blood culture media}

In a sterile hood mix, 500ml RPMI, 100ml FBS, 6.5ml PHA, 6.5 Pen strep, 6.5 L-

Glutamine. Aliquot 9.0ml/tube Makes 71 tubes

\section{Colcemid}

Available from GIBCO cat\# 890-3014

cDenhyb Solution

Available from http://www.insitus.com/DenHyb.html. Cat\#D002

Carnoy's Fixative

Mix a 3 to 1 ratio of cold methanol to room temperature glacial acetic acid to quantity needed. Chill to $4^{\circ} \mathrm{C}$ if desired.

$1 \%$ Formaldehyde solution

In a coplin jar add $49 \mathrm{ml}$ of $1 \mathrm{X}$ PBS, $1.25 \mathrm{ml}$ of $37 \%$ formaldehyde, and $2.5 \mathrm{ml}$ of $1 \mathrm{M}$ $\mathrm{MgCl}$. Store in the refrigerator at $4{ }^{\circ} \mathrm{C}$ for up to 1 week.

\section{Protease/Pepsin Solution}

In a glass coplin jar add $50 \mathrm{ml}$ of distilled water, $0.025 \mathrm{gm}$ of pepsin and $500 \mu \mathrm{l}$ of $1 \mathrm{~N}$ $\mathrm{HCl}$. Place jar in $37^{\circ} \mathrm{C}$ water bath. Prepare fresh daily. 
$2 X$ Saline Sodium Citrate (SSC)

Place $50 \mathrm{ml}$ 20X SSC (Gibco BRL \#15557-044\#) into $500 \mathrm{ml}$ volumetric flask.

Bring to $500 \mathrm{ml}$ with distilled water and $\mathrm{pH}$ to 7.0 .

$2 X$ Saline Sodium Citrate 1\% NP-40

Place $40 \mathrm{ml} 2 \mathrm{X}$ SSC into a glass coplin jar. Add $40 \mu \mathrm{l}$ of NP- 40

0.04X Saline Sodium Citrate 0.5\% NP-40

Place $40 \mathrm{ml}$ of $0.4 \mathrm{X}$ SSC into a glass coplin jar and add $120 \mu \mathrm{l}$ of NP-40

PNA Telomere Probe Pretreament Solution

Supplied in DAKO FITC PNA telomere probe kit

PNA Telomere Probe Wash Solution

Supplied in DAKO FITC PNA Telomere probe kit 


\section{APPENDIX B}

Table 8. Locus and Clone ID for each FISH probe used in the ToTelVysion Kit.

\begin{tabular}{|c|c|l|}
\hline Probe & Probe Size & \multicolumn{1}{|c|}{ Locus/Clone ID } \\
\hline $1 \mathrm{p}$ & $90 \mathrm{~kb}$ & CEB108/T7 \\
$1 \mathrm{q}$ & $100 \mathrm{~kb}$ & VIJ1 yRM21233, 1QTEL10 (D1S3738), 1QTEL193 (D1S3739) \\
$2 \mathrm{p}$ & $175 \mathrm{~kb}$ & VIJ1 yRM1051 (GenBank U31389) \\
$2 \mathrm{q}$ & $60 \mathrm{~kb}$ & VIJ1 yRM2112 (D2S447), 2QTEL47 \\
$3 \mathrm{p}$ & $80 \mathrm{~kb}$ & 3PTEL25 (D3S4559) \\
$3 \mathrm{q}$ & $95 \mathrm{~kb}$ & 3QTEL05 (D3S4560) \\
$4 \mathrm{p}$ & $145 \mathrm{~kb}$ & GS10K2/T7 4p \\
$4 \mathrm{q}$ & $130 \mathrm{~kb}$ & AFM A224XH1 (D4S2930) \\
$5 \mathrm{p}$ & $191 \mathrm{~kb}$ & C84C11/T3 \\
$5 \mathrm{q}$ & $105 \mathrm{~kb}$ & GS3508/T7, 5QTEL703 \\
$6 \mathrm{p}$ & $80 \mathrm{~kb}$ & 6PTEL48 \\
$6 \mathrm{q}$ & $100 \mathrm{~kb}$ & VIJ1 yRM2158, 6QTEL543 \\
$7 \mathrm{p}$ & $60 \mathrm{~kb}$ & VIJ1 yRM1185 (GenBank G31341) \\
$7 \mathrm{q}$ & $95 \mathrm{~kb}$ & VYJ1 yRM2000 (STS 2000H), 7QTEL203 \\
$8 \mathrm{p}$ & $135 \mathrm{~kb}$ & AFM 197XG5 (D8S504) \\
$8 \mathrm{q}$ & $100 \mathrm{~kb}$ & VIJ1 yRM2053 \\
$9 \mathrm{p}$ & $115 \mathrm{~kb}$ & 305J7-T7 \\
$9 \mathrm{q}$ & $95 \mathrm{~kb}$ & VIJ1 yRM2241 (D9S325) \\
$10 \mathrm{p}$ & $80 \mathrm{~kb}$ & 10PTEL006 (GenBank:Z96139) \\
$10 \mathrm{q}$ & $75 \mathrm{~kb}$ & 10QTEL24 (D10S2490) \\
$11 \mathrm{p}$ & $110 \mathrm{~kb}$ & D11S2071 (GenBank U12896), 11PTEL033, VIJ1 yRM22093 \\
$11 \mathrm{q}$ & $160 \mathrm{~kb}$ & VIJ1 yRM2072 \\
$12 \mathrm{p}$ & $100 \mathrm{~kb}$ & 8M16/SP6 \\
$12 \mathrm{q}$ & $165 \mathrm{~kb}$ & VIJ1 yRM2196 (Genbank 011838) \\
$13 \mathrm{q}$ & $75 \mathrm{~kb}$ & VIJ1 yRM2002 (D13S327) \\
$14 \mathrm{q}$ & $160 \mathrm{~kb}$ & sts-X583992; SHGC-361562; sts-AA0344922, \\
$15 \mathrm{q}$ & $100 \mathrm{~kb}$ & WI-5214 (D15S936) \\
$16 \mathrm{p}$ & $110 \mathrm{~kb}$ & SHGC-153362, 16PTEL032 (D16S3399) \\
$16 \mathrm{q}$ & $110 \mathrm{~kb}$ & 16QTEL013 (GenBank Z96319) \\
$17 \mathrm{p}$ & $70 \mathrm{~kb}$ & 282M15/SP6 \\
$17 \mathrm{q}$ & $160 \mathrm{~kb}$ & AFMZ17yD10 (D17S928, GenBank Z23646) \\
$18 \mathrm{p}$ & $160 \mathrm{~kb}$ & VIJ1 yRM2102 (D18S552) \\
$18 \mathrm{q}$ & $170 \mathrm{~kb}$ & VIJ1 yRM2050, 18QTEL112 (D18S1390) \\
$19 \mathrm{p}$ & $80 \mathrm{~kb}$ & 129F16/SP6 \\
$19 \mathrm{q}$ & $160 \mathrm{~kb}$ & D19S238E \\
$20 \mathrm{p}$ & $160 \mathrm{~kb}$ & 20PTEL18 (D20S1157) \\
$20 \mathrm{q}$ & $140 \mathrm{~kb}$ & 20QTEL14 \\
$21 \mathrm{q}$ & $170 \mathrm{~kb}$ & VIJ1 yRM2029, S100B32, 21QTEL082, D21S15752 (21QTEL07) \\
$22 \mathrm{q}$ & $80 \mathrm{~kb}$ & MS607 (GenBank X58044), ACR, 22QTEL312 (D22S1726) \\
$\mathrm{Xp} / \mathrm{Yp}$ & $175 \mathrm{~kb}$ & DXYS129 \\
Xq/Yq & $170 \mathrm{~kb}$ & EST Cdy 16c07 (Genbank Z43206) \\
\hline
\end{tabular}




\title{
CURRICULUM VITAE
}

\author{
JASEN LEE WISE
}

\section{EDUCATION}

Doctor of Philosophy in Genetics and Developmental Biology, 2004-2009

West Virginia University, Morgantown, WV

Dissertation: "Cryptic Balanced Subtelomeric Rearrangements and Studies of Telomere Length"

Master of Science in Genetics and Developmental Biology, 2002-2004

West Virginia University, Morgantown, WV

Thesis: "Screening Urine Cytology: The Addition of Fluorescence In Situ Hybridization for Detecting Genetic Abnormalities Associated with Urothelial Neoplasia"

Bachelor of Science in Biology, 1998-2002

West Liberty State College, West Liberty, WV

High School Diploma, 1998

Cameron High School, Cameron, WV

\section{PEER REVIEWED PUbliCATIONS}

Wise JL, Crout RJ, McNeil DW, Weyant RJ, Marazita ML, et al. (2009) Human Telomere Length Correlates to the Size of the Associated Chromosome Arm. PLoS ONE 4(6): e6013. doi:10.1371/journal.pone. 0006013

Wise JL, Crout RJ, McNeil DW, Weyant RJ, Marazita ML, Wenger SL. (2009) Cryptic Subtelomeric Rearrangements and X Chromosome Mosaicism: A Study of 565 Apparently Normal Individuals with Fluorescent In Situ Hybridization. PLoS ONE 4(6): e5855. doi:10.1371/journal.pone.0005855

Wise JL, Hummel M, Wenger SL. 2008. Subtelomeric Deletions: The Importance of Ruling Out Polymorphic Variants or Inherited Deletion. The Journal of the Association of Genetic Technologists 34(3):89-90.

Doelling JH, Phillips AR, Soyler-Ogretim G, Wise JL, Chandler J, Callis J, Otegui MS, Vierstra RD. 2007. The ubiquitin-specific protease subfamily UBP3/UBP4 is essential for pollen development and transmission in Arabidopsis. Plant Physiol 145(3):801-13. 


\section{ABSTRACTS AND POSTERS}

Wenger SL, Wise JL, Crout RJ, McNeil DW, Weyant RJ, Marazita ML. Analysis of 514 unrelated individuals for incidence of cryptic subtelomeric rearrangements. Poster to: Annual meeting of the American College of Medical Genetics March 21-25, 2007, Nashville.

Doelling J, Gulsum S, Wise J, Vierstra R, Genetics Analysis of the ubiquitin-specific proteases and ubiquitin conjugating enzymes in Arabidopsis thaliana. Poster to: 2005 University of Wisconsin Arabidopsis Conference.

Wenger SL, Wise JL, Crout RJ, McNeil DW, Wyant RJ, Marazita ML. Utilization of a large dental genetic study for cryptic chromosomal rearrangments. Poster to: International Assn for Dental Res, Baltimore, March 9-1, 2005.

Wise JL, Wenger SL, Ducatman B, Coad JE. Focusing UroVysion on Screening Urine Cytology. Modern Pathology 2005;18:80A. Poster selected for student award session to USCAP annual meeting, San Antonio, Feburary 26 - March 4, 2005.

Hernandez SJ, Wise JL, Wenger SL, Ducatman BS, Barboza O, Coad JE. FISHing for neoplasia in screening urine cytology. Poster to the Mexican Academy of Cytopathology, Monterrey, 2005

Singh AJ, Archer SA, Wise JL, Jackman SM. An automated approach to comet assay analysis. Annual Environmental Mutagen Society Meeting, Pittsburgh, PA, October 2-6, 2004.Mexico, December 5-9, 2004.

Wise JL, Wenger SL, Ducatman B, Coad JE. FISHing for answers in screening urine cytology specimens: a pilot study. Modern Pathology 2004; 17:85A. Poster selected for student award session to: USCAP annual meeting, Vancouver, March 6-12, 2004. 